Transformations of Mercury in the Marine Water Column

By

Kathleen M. Munson

B. A., Vassar College, 2006

Submitted in partial fulfillment of the requirements for the degree of

Doctor of Philosophy

at the

MASSACHUSETTS INSTITUTE OF TECHNOLOGY

and the

WOODS HOLE OCEANOGRAPHIC INSTITUTION

February 2014

(C) 2014 Kathleen M. Munson

All rights reserved.

The author hereby grants MIT and WHOI permission to reproduce and to distribute publicly paper and electronic copies of this thesis document in whole or in part in any medium now known or hereafter created.

Signature of Author

Joint Program in Oceanography Massachusetts Institute of Technology and Woods Hole Oceanographic Institution

10 December 2013

Certified by

Dr. Carl H. Lamborg Thesis Supervisor

Accepted by

Dr. Elizabeth Kujawinski Chair, Joint Committee for Chemical Oceanography Woods Hole Oceanographic Institution 


\begin{abstract}
Methylation of mercury $(\mathrm{Hg})$ in the marine water column has been hypothesized to serve as the primary source of the bioaccumulating chemical species monomethylmercury $(\mathrm{MMHg})$ to marine food webs. Despite decades of research describing mercury methylation in anoxic sediments by anaerobic bacteria, mechanistic studies of water column methylation are severely limited. These essential studies have faced analytical challenges associated with quantifying femtomolar concentrations of the methylated $\mathrm{Hg}$ species dimethylmercury (DMHg) and $\mathrm{MMHg}$ in marine systems. In addition, the complex biogeochemical cycling of $\mathrm{Hg}$ in natural systems require consideration of gaseous, dissolved, and particulate species of $\mathrm{Hg}$ in order to probe potential controls on its ultimate transfer into marine food webs.

The presented work provides a comprehensive study of $\mathrm{Hg}$ chemical speciation and transformations in Tropical Pacific waters. We developed an analytical method for MMHg determination from seawater that has the potential to ease measurements of MMHg distributions, as well as mechanistic studies of $\mathrm{Hg}$ species transformations.

We used this method, in addition to previously established methods, to measure dissolved and particulate $\mathrm{Hg}$ species distributions and fluxes along a transect of the Pacific Ocean. Over significant gradients in oxygen utilization and primary productivity, we observed a region of methylated $\mathrm{Hg}$ species focused in the Equatorial Pacific that appeared spatially separated from higher concentrations in North Pacific Intermediate Waters. From the first full water column depth profiles of this region, we also observed the intrusion of elevated $\mathrm{Hg}$ into deep waters of the Equatorial and South Pacific Ocean.

In addition we observed substantial potential rates of mercury methylation in subsurface and low oxygen waters along the Pacific transect as well as the Sargasso Sea using $\mathrm{Hg}$ isotope tracers. We observed dynamic production and decomposition of methylated $\mathrm{Hg}$ in low productivity waters, despite low ambient methylated $\mathrm{Hg}$ concentrations. From the addition of bulk organic matter as well as individual compounds important for methylation in anaerobic bacteria, we observe no simple limitation of $\mathrm{Hg}$ methylation in marine waters but highly dynamic conversion of $\mathrm{Hg}$ between methylated and inorganic species.
\end{abstract}

Thesis Supervisor: Carl H. Lamborg

Title: Assistant Scientist, Marine Chemistry and Geochemistry, Woods Hole Oceanographic Institution 


\section{Dedication}

For

Prof. Roger Merritt

Prof. Carolyn Wetzel

Prof. Zachary Donhauser

Dr. Randy Peterson

and

Dr. Carl Lamborg 


\section{Table of Contents}

Title Page 1

$\begin{array}{lll}\text { Abstract } & 3\end{array}$

Dedication 5

$\begin{array}{ll}\text { Table of Contents } & 7\end{array}$

List of Figures $\quad 9$

List of Tables $\quad 13$

$\begin{array}{ll}\text { Chapter 1: Introduction } & 15\end{array}$

Chapter 2: Determination of monomethylmercury from seawater with ascorbic acid- 29 assisted direct ethylation

Chapter 3: Methylation and demethylation of mercury in the Sargasso Sea 49

Chapter 4: Mercury species concentrations and fluxes in the Central Tropical Pacific 71

Ocean

Chapter 5: Controls on mercury methylation in the Central Pacific Ocean 109

$\begin{array}{ll}\text { Chapter 6: Conclusions } & 143\end{array}$

Appendix I: Methylation and demethylation rate measurements 149 


\section{List of Figures}

Chapter 2: Determination of monomethylmercury from seawater with ascorbic acidassisted direct ethylation

Figure 1: Monomethylmercury from consecutive bubbling of samples

Figure 2: Acetate- and citrate-buffered standard curves

Figure 3: Recovery of monomethylmercury standard from filtered seawater

Figure 4: Citrate-buffered monomethylmercury standard curve

Figure 5: Monomethylmercury standard recovery from de-ionized water versus filtered seawater

Chapter 3: Methylation and demethylation of mercury in the Sargasso Sea

Figure 1: Quantification of $\mathrm{Hg}(\mathrm{II})$ standard

Figure 2: Methylated mercury production from the BATS site during the April spring bloom

Figure 3: Methylated mercury produced during 24-hour time course in the fall

Figure 4: Methylmercury degradation during 24-hour time course incubation in the fall

Chapter 4: Mercury species concentrations and fluxes in the Central Tropical Pacific Ocean

Figure 1: Map of Metzyme cruise stations

Figure 2: Hydrographic characteristics of the North to South transect of the Metzyme cruise

Figure 3: Oxygen and apparent oxygen utilization along the North to South transect of the Metzyme cruise

Figure 4: Full water column profiles of total mercury and elemental mercury at all stations of the Metzyme cruise track

Figure 5: Upper $1500 \mathrm{~m}$ water column depth profiles of total mercury and elemental mercury at all stations of the Metzyme cruise track

Figure 6: Full water column depth profiles of monomethylmercury and dimethylmercury at all stations along the Metzyme cruise track 
Figure 7: Upper water column depth profiles of monomethylmercury and dimethylmercury at all stations along the Metzyme cruise track

Figure 8: Ocean Data View gridded sections of mercury species concentrations along North to South transect of the Metzyme cruise

Figure 9: Percent saturation of $\operatorname{Hg}(0)$ in the water column of the Tropical Pacific Ocean

Figure 10: Mercury reduction by denitrification at the southern base of the North Pacific Subtropical Gyre

Figure 11: Suspended particulate total mercury and monomethylmercury collected from five stations using in situ pumps

Figure 12: Ratios of monomethylmercury to total mercury in dissolved and 100 suspended particulate pools

Figure 13: Sinking particulate total mercury fluxes from three stations in the 101 Tropical Pacific Ocean

Figure 14: Total methylated mercury concentrations versus apparent oxygen 102 utilization for all stations along the Metzyme cruise track

Figure 15: Ratios of monomethylmercury to dimethylmercury versus depth for four stations along the Metzyme cruise track

Figure 16: Depth profiles in the upper $1000 \mathrm{~m}$ of the Equatorial Pacific water column measured in 1990 by Mason and Fitzgerald and 2011 during the Metzyme cruise

Figure 17: Total dissolved mercury concentrations measured in the water column at three sites in the North Pacific over a nine-year span

Figure 18: Total dissolved methylated mercury and total mercury concentrations 106 from the CLIVAR P16N section in the North Pacific and the Metzyme cruise in the Tropical Pacific

Chapter 5: Control on mercury methylation in the Tropical Pacific Ocean

Figure 1: Map of stations where mercury methylation incubations were performed 126 in the Pacific Ocean along the Metzyme cruise track

Figure 2: Reduction of mercury in incubations of marine waters amended with methylcobalamin 
Figure 3: Concentrations of dissolved oxygen and calculated values of apparent oxygen utilization at incubation stations

Figure 4: Concentrations of dissolved total and methylated mercury at incubation stations

Figure 5: Initial and total methylation of $\mathrm{Hg}(\mathrm{II})$ in Tropical Pacific waters

Figure 6: Methylated mercury production over a 36-hour time course in South Pacific waters

Figure 7: Demethylation of monomethylmercury over a 36-hour time course incubation in South Pacific waters

Figure 8: Methylation of mercury in treatment-amended incubations of water from chlorophyll maximum waters in the Tropical Pacific

Figure 9: Methylation of mercury in treatment-amended incubations of water from 136 oxygen minimum waters in the Tropical Pacific

Figure 10: Relationship between methylation and measured $\mathrm{MeHg}$ and $\mathrm{THg}$ concentrations in Tropical Pacific waters

Figure 11: Calculated dissolved $\mathrm{Hg}(\mathrm{II})$ in the Tropical Pacific

Chapter 6: Conclusions

Figure 1: Methylated mercury concentrations in marine intermediate waters (100$1000 \mathrm{~m}$ ) versus organic carbon remineralization rates

Figure 2: Schematic representation of marine mercury transformations in surface and intermediate waters 


\section{List of Tables}

Chapter 1: Introduction

Table 1: Mercury stable isotopes and their natural abundances

Chapter 2: Determination of monomethylmercury from seawater with ascorbic acidassisted direct ethylation

Table 1: Reagent addition for $30-\mathrm{mL}$ and $180-\mathrm{mL}$ sample volumes

Chapter 3: Methylation and demethylation of mercury in the Sargasso Sea

Table 1: Experimental details for measurements of mercury methylation and demethylation potential in waters from the BATS site

Table 2: Potential demethylation rates from water collected from the BATS site

Table 3: Potential methylation rates for water collected from the BATS site

Chapter 4: Mercury species concentrations and fluxes in the Central Tropical Pacific Ocean

Table 1: Station coordinates and speciation samples collected at each stations of the Metzyme cruise

Chapter 5: Controls on mercury methylation in the Tropical Pacific Ocean

Table 1: Water column characteristics for Pacific Ocean waters from which potential mercury methylation rates were measured

Table 2: Amendments tested for enhancement of mercury methylation

Table 3: Potential methylation rates from Tropical Pacific waters 


\section{Chapter 1 \\ Introduction}

Monomethylmercury (MMHg, chemically: $\mathrm{CH}_{3} \mathrm{Hg}^{+}$) bioaccumulates in marine food webs and has deleterious effects on upper trophic levels of marine life by reducing fertility and offspring survival [Scheuhammer et al, 2007]. In humans, MMHg acts a neurotoxin, capable of crossing both the blood-brain and placental barriers and thereby poses a specific threat to fetuses and children [Clarkson and Magos, 2006]. Due to its toxicity, the Environmental Protection Agency among other health organizations have recommended maximum consumption levels of fish with high MMHg concentrations for children and expectant mothers [US FDA-EPA, 2009]. Despite these guidelines, it is estimated that $0.6-11 \%$ of US women ages $16-49$ have blood mercury $(\mathrm{Hg})$ levels above the recommended limit for safe exposure [Mahaffey et al, 2004]. Estimates of fish sources suggest that up to $90 \%$ of fish consumed in the US are from marine and estuarine environments [Sunderland, 2007]. As a result, understanding the factors that control MMHg sources and transfer in marine environments is crucial for minimizing potential health threats to humans and marine life.

\section{Mercury from Marine Waters to Biota}

The need to quantify MMHg sources in natural waters is related to its uptake and transfer through marine trophic levels. Concentrations of dissolved MMHg in the open-ocean water column are typically <0.5 pM [Mason and Fitzgerald, 1990, 1993; Mason et al 1995, 1998; Sunderland et al, 2009; Cossa et al, 2011; Hammerschmidt and Bowman, 2012] but concentrations in fish tissue are in the range from 0.01 to $>1000 \mu \mathrm{g} / \mathrm{kg}$ [Senn et al, 2010; Choy et al, 2009; Kraepiel et al, 2003]. Thus, $\mathrm{Hg}$ is bioaccumulated to a large degree through marine trophic levels. The most important step in the marine bioaccumulation of MMHg is related to the preferential retention of $\mathrm{MMHg}$ by phytoplankton [Mason et al, 1996]. In the example of $\mathrm{Hg}$ transfer between diatoms and the copepod grazers, $\mathrm{Hg}(\mathrm{II})$ was bound to the membrane of diatoms and is excreted rather than retained during feeding [Mason et al, 1996]. In copepods, the increased hydrophobicity of $\mathrm{MMHg}$ relative to $\mathrm{Hg}$ (II) that occurs upon the addition of the methyl group resulted in its preferential retention [Mason et al, 1996]. Bioaccumulation factors (BAF) measured in marine phytoplankton suggest that this initial step of trophic transfer is the most substantial, with BAF values of $10^{4}-10^{7}$ [Baeyens, et al, 2003; Hammerschmidt and Fitzgerald, 2006; Szczebak et al, 2011; Hammerschmidt et al, 2013]. The large magnitude of transfer 
between MMHg dissolved in the water column and the base of the marine food chain illustrates the importance of the initial production and partitioning of $\mathrm{MMHg}$ between dissolved and particulate pools.

\section{Sources and Sinks of Marine Mercury}

Marine cycling of $\mathrm{Hg}$ is linked to its behavior in the atmosphere. Mercury is highly volatile and also is found dissolved in water in its gaseous elemental form $\left(\mathrm{Hg}^{\circ}\right)$. Emissions from coal burning, concrete production, gold amalgamation, and volcano outgassing are the primary sources of $\mathrm{Hg}^{\circ}$ to the atmosphere [Streets et al, 2011]. Anthropogenic sources dominate the net release of $\mathrm{Hg}^{\circ}$ by a factor of 3 since the beginning of the Industrial Revolution [Lamborg et al, 2002]. $\mathrm{Hg}^{\circ}$ can enter marine systems directly via gas exchange, but is primarily delivered by wet and dry deposition after $\mathrm{Hg}^{\circ}$ is oxidized to $\mathrm{Hg}$ (II) in the atmosphere, resulting in significant changes to its sorption properties. Once deposited in the surface ocean, large proportions of $\mathrm{Hg}$ are re-emitted to the atmosphere due to reduction of $\mathrm{Hg}(\mathrm{II})$ to reform $\mathrm{Hg}^{\circ}$, extending the residence time of $\mathrm{Hg}$ in the atmosphere [Mason et al 1994; Sørensen et al, 2010].

Other potential sources of $\mathrm{Hg}$ to the oceans are limited in magnitude. Modeling studies have proposed that riverine contributions of $\mathrm{Hg}$ to global oceans are low due to coastal deposition of riverine sediment [Sunderland and Mason, 2007] although warming Arctic rivers are thought to release large amounts of $\mathrm{Hg}$ on a basin scale [Fisher et al, 2012]. Submarine groundwater discharge has been identified as a possible source of $\mathrm{Hg}$ but is also limited in its spatial scale [Bone et al, 2007]. Hydrothermal sources of $\mathrm{Hg}$ are also small compared to atmospheric sources [Lamborg et al, 2006].

The primary sink for $\mathrm{Hg}$ from the ocean is evasion to the atmosphere in the surface ocean, which can remove up to $80 \%$ of deposited $\mathrm{Hg}$ (II) as a result of photooxidation in the surface ocean via gas exchange [Mason et al, 1994; Sorensen et al, 2010]. For $\mathrm{Hg}$ that is not evaded from the surface ocean, sorption, removal on sinking particles, and eventual burial in sediments are the primary sinks.

Mercury that remains in the water column serves as the pool for methylation reactions to produce MMHg. However, the sorption of $\mathrm{Hg}$, either as $\mathrm{Hg}(\mathrm{II})$ or $\mathrm{MMHg}$, onto particles decreases the dissolved pool and potentially impacts the production of $\mathrm{MMHg}$, either by removing $\mathrm{Hg}$ (II) substrate or by providing a surface for methylation. Once buried, porewater diffusion of $\mathrm{Hg}$ is a small flux, into deep waters [Hammerschmidt and Fitzgerald, 2006], although 
the measurements of fluxes differ greatly between those measured by benthic flux chambers and those calculated from porewaters [Hammerschmidt and Fitzgerald, 2008] and have not been measured in sediments from the deep ocean.

\section{Marine Mercury Distributions}

Distributions of total $\mathrm{Hg}$ ( $\mathrm{THg}$ ) reveal the importance of atmospheric deposition as well as particle scavenging of $\mathrm{Hg}$ in the water column. Concentrations of $\mathrm{THg}$ are measurable in the surface ocean, generally $<1$ pM in the Pacific [Laurier et al, 2004; Sunderland et al, 2009; Cossa et al, 2011; Hammerschmidt and Bowman, 2012], although substantially higher concentrations have been measured in the Atlantic [Mason et al, 1995; Mason and Sullivan, 1999].

Concentrations of THg generally increase with depth due to particle scavenging and release upon remineralization [Hammerschmidt and Bowman, 2012]. Deep waters, below $2000 \mathrm{~m}$, often show substantial concentrations of $\mathrm{THg}$ that have been attributed to transport of $\mathrm{THg}$ via thermohaline circulation [Hammerschmidt and Bowman 2012].

Methylated Hg species, MMHg and DMHg, were first measured in the open ocean in 1990 [Mason and Fitzgerald, 1990, 1993]. However, high limits of detection ( 50 fM) prevented MMHg determination in $\sim 70 \%$ of water samples analyzed in this early study [Mason and Fitzgerald, 1993]. Similar high detection limits hindered full $\mathrm{Hg}$ speciation determination in early measurements in the Mediterranean and North Atlantic [Cossa et al, 1997; Mason et al, 1998].

Despite the analytical challenges associated with MMHg determination, marine distributions of MMHg, either as a distinct species or in combination with DMHg, are found to be low in marine surface waters and elevated at depths of low dissolved oxygen concentrations in the water column [Mason and Fitzgerald 1990, 1993; Mason and Sullivan, 1999; Cossa et al, 2009; Sunderland et al, 2009; Cossa et al, 2011; Hammerschmidt and Bowman, 2012]. These concentrations have been compared to rates of apparent oxygen utilization (AOU) in the water column, resulting in varied relationships between the two parameters [Mason and Sullivan, 1999; Sunderland et al, 2009; Cossa et al, 2011]. From these relationships a relatively simple model of $\mathrm{Hg}$ methylation has emerged. $\mathrm{Hg}$ methylation is thought to occur within the marine water column after the release of $\mathrm{Hg}$ (II) substrate from remineralized organic matter. This has been illustrated most clearly by the linear correlation between methylated Hg concentrations and organic carbon remineralization rate [Sunderand et al, 2009]. However, the mechanistic pathways of in situ methylation in marine environments have not been well characterized. 
From a combination of limited DMHg and MMHg distribution data and supporting laboratory experiments, Mason et al, proposed that marine MMHg is produced from the breakdown of DMHg [Mason and Fitzgerald, 1993]. More recently, direct production of MMHg from $\mathrm{Hg}(\mathrm{II})$ has been proposed as a significant source of MMHg in Arctic waters [Lehnherr et al, 2011]. However, because many studies have not distinguished between the two organomercuric species, it is difficult to determine potential controls on the interconversion between DMHg and MMHg that results in MMHg availability for uptake through marine trophic webs.

The need for lower detection limits has been recognized as a significant hindrance to understanding MMHg production and breakdown in marine waters [Fitzgerald et al, 2007]. The recent development of a direct ethylation method for MMHg determination at sea [Bowman and Hammerschmidt, 2011] has improved the detection limit to $\sim 5 \mathrm{fM}$ but is not adaptable for preserving samples for shore-based analysis. Although methods with low femtomolar detection limits exist, including isotope dilution inductively coupled plasma mass spectrometry (IDICPMS) and cold vapor atomic fluorescence spectrometry (CVAFS), they have relied on tedious separation techniques such as organic extraction [Bloom, 1989; Horvat et al, 1993] or distillation [Horvat et al, 1993] to isolate MMHg from the seawater matrix, hindering MMHg species distribution data. In addition, the preservation of samples with acid for shore-based laboratory analysis result in the breakdown of DMHg to MMHg, yields combined methylated $\mathrm{Hg}$ ([DMHg] $+[\mathrm{MMHg}])$ concentrations [Parker and Bloom, 2007] that hinder the mechanistic understanding of $\mathrm{MMHg}$ production.

\section{Marine Mercury Methylation}

Despite the importance of marine $\mathrm{Hg}$ cycling to resulting MMHg concentrations in marine fish and implications for human health, our mechanistic understanding of the biological and abiotic factors that might contribute to $\mathrm{MMHg}$ production are based on substantial work in coastal and freshwater systems. Theses studies have identified several potential targets for studies of marine $\mathrm{MMHg}$ production, but few established connections between anaerobic bacterial methylation and in situ methylation in marine waters.

Sulfate-reducing bacteria (SRB) were identified as $\mathrm{Hg}$ methylators in sediments in the 1980s [Choi et al, 1984a,b]. Subsequent work based on cultured organisms of SRB and ironreducing bacteria, especially Desulfovibrio and Geobacter species have provided much of the current knowledge of $\mathrm{Hg}$ methylation. Long suspected of involving a reaction by 
methylcobalamin (vitamin b12) in the acetyl-CoA pathway [Choi et al,1984b; Ekstrom and Morel, 2008], methylation in a variety of delta-proteobacteria, methanogens, and firmicutes has recently been attributed to the presence of two genes, $h g c A$ and $h g c B$ encoding a cobalaminutilizing methyltransferase upstream of a ferrodoxin protein [Parks et al, 2013, Gilmour et al, 2013].

In addition, culture-based experiments have provided insight into mechanisms of cellular uptake of $\mathrm{Hg}$ (II) substrate for methylation by anaerobes, including the role of low molecular weight thiol ligands such as the amino acid cysteine and glutathione [Schaefer and Morel, 2009; Schaefer et al, 2011]. These experiments have revealed a role of active $\mathrm{Hg}$ (II) uptake by methylating bacteria, possibly via low-specificity metal uptake pathways [Schaefer et al, 2011].

MMHg production is also possible through abiotic mechanisms. Methylcobalamin, methyltin, and methyliodide are known to methylate $\mathrm{Hg}$ (II) in the absence of cells by the donation of their methyl groups [Maynard, 1932; Filippeli and Baldi, 1993]. Although laboratorybased and theoretical studies have suggested abiotic methyaltion pathways may be significant sources of MMHg in marine waters [Celo et al, 2006; Jimenez-Moreno et al, 2013], no fieldbased experiments have quantified their relative importance.

\section{Isotope Tracers of Mercury Transformations}

The seven stable isotopes of $\mathrm{Hg}$ (Table 1) provide a means of tracing $\mathrm{Hg}$ chemical species transformations in natural systems. Such experiments fall into two broad categories:

1. Measurements of mass dependent and mass independent $\mathrm{Hg}$ fractionation attributed to specific $\mathrm{Hg}$ species transformation, such as reduction, methylation, or ligand binding that are first characterized in controlled experiments and are then used to identify transformations from environmental samples [reviewed by Kritee et al, 2013].

2. Tracer addition experiments in which one or more well-characterized isotopically enriched $\mathrm{Hg}$ species are added to incubations of water or sediment and transformation reactions are quantified from changes in the isotopic ratio of a species of interest [Hintelmann et al, 1995; Hintelmann and Evans, 1997; Hintelmann and Ogrinc, 2003] 
Stable $\mathrm{Hg}$ isotope signatures have been used to trace mechanisms of $\mathrm{Hg}$ transformations as a result of fractionation, both mass dependent fractionation and mass independent fractionation, that occur as a result of small differences in mass among Hg isotopes. Laboratory studies have been performed to measure fractionation during many abiotic and biotic $\mathrm{Hg}$ transformations, including photoreduction, photodemethylation, methylation by SRB, abiotic methylation and microbial reduction [Kritee et al, 2013]. However, these studies rely on wellcharacterized mechanisms that can be controlled in laboratory conditions to measure changes less than 5 per mil between isotopes.

Thus far, mass independent fractionation has been found to occur only during photodemethylation and photoreduction [Bergquist and Blum, 2007], which results in unique isotopic signatures of the odd isotopes, ${ }^{199} \mathrm{Hg}$ and ${ }^{201} \mathrm{Hg}$. Mass dependent fractionation has been measured in microbial mediated methylation, demethylation, and reduction reactions [Kritee et al, 2007, 2008, 2009; Rodriguez-Gonzalez, 2009]. Fractionation has also been measured in abiotic transformations of $\mathrm{Hg}$, including methylation by methylcobalamin at low $\mathrm{pH}$ [Jimenez-Martinez et al, 2013] and binding to ligands [Weiderhold, et al, 2010].

Blum et al, 2013 recently measured the isotopic composition of fish $\mathrm{Hg}$ from fish thought to feed at different depths in the water column. Measured $\delta^{202} \mathrm{Hg}$ and $\Delta^{201} \mathrm{Hg}$ values increased with feeding depth in nine fish tested [Blum et al, 2013]. The decreasing values of $\Delta^{201} \mathrm{Hg}$ were interpreted to represent the uptake of less photochemically processed $\mathrm{MMHg}$ with increasing feeding depth in the ocean. The decreasing values of $\delta^{202} \mathrm{Hg}$ were interpreted to represent a largely microbial process for methylation. Combined, these isotope signatures align with enhanced methylation of $\mathrm{Hg}$ by microbes at depth of net organic matter remineralization [Mason and Fitzgerald, 1993; Sunderland et al, 2009]. The use of isotope signatures to trace sources of $\mathrm{Hg}$ within food webs is intriguing. However, as Blum et al, 2013 note, the experimental values used to interpret the measured isotopic compositions have not been determined from marine systems. Furthermore, recent work has measured a similar extend of fractionation in abiotic $\mathrm{Hg}$ methylation by methylcobalamin as is seen in methylation by SRB [Jiminez-Martinez et al, 2013]. Therefore, measured stable isotope signatures of $\mathrm{Hg}$ from marine systems, either $\mathrm{Hg}$ species in the water column or in marine biota, cannot be fully interpreted until the fractionation factor associated with different marine mechanisms can be measured individually.

Isotope tracer studies allow quantification of $\mathrm{Hg}$ species transformations without the prior identification of the mechanisms involved. However, because they rely on the addition of 
isotopically enriched spikes of $\mathrm{Hg}$ species, isotope tracer studies can only be used to quantify the potential for a transformation to take place in the tested system, typically seawater or sediment. These experiments rely on the assumption that additions of $\mathrm{Hg}$ species produce responses that mimic those that occur in situ, but this assumption is subject to scrutiny. For example, in the potential methylation rate measurements presented in this work, we investigated whether delivery of $\mathrm{Hg}(\mathrm{II})$ by organic matter remineralization is the primary limitation of $\mathrm{Hg}$ methylation. Since additions of isotoptically enriched $\mathrm{Hg}$ (II) are necessary to measure methylation rates in these dual tracer experiments, relief of $\mathrm{Hg}$ (II) limitation is implicit in all our presented measurements.

Tracer experiments quantify $\mathrm{Hg}$ species conversions by monitoring the isotopic changes of a single $\mathrm{Hg}$ species over the course of an incubation period. Such quantification hinges on the ability to accurately distinguish between $\mathrm{Hg}$ species. Mass balance of $\mathrm{Hg}$ species is not typically measured during these experiments and yields of $\mathrm{MMHg}$ are determined relative to internal standard recovery [Hintelmann and Evans, 1997]. The use of isotope tracer experiments therefore depends on the selection of appropriate experimental conditions to probe mechanisms of $\mathrm{Hg}$ transformations.

The work presented in the following chapters aimed to fill a variety of gaps in our knowledge of mercury biogeochemistry in marine systems. Our approach was to improve $\mathrm{MMHg}$ measurement techniques in order to allow for better coverage of $\mathrm{Hg}$ distributions in marine systems, use these techniques to analyze spatial and temporal variations in $\mathrm{Hg}$ species distributions, and determine which environmental factors control MMHg production in the open ocean water column by dual isotope tracer experiments testing potential limitations of methylation in marine waters. Together, our results provide important progress in determining both spatial variations in $\mathrm{MMHg}$ distributions as well as potential controls on their distributions.

Chapter 2 details a method for measurement of MMHg from small volumes of seawater. This method is adaptable to shipboard measurements as well shore-based determination of $\mathrm{MMHg}$ from preserved samples. When combined with purging of samples to remove DMHg from the sample volume, this method allows for easy distinction between these two $\mathrm{Hg}$ chemical species in open ocean environments. The method is also adaptable to hyphenated analysis, such as CVAFS-ICPMS methods for isotope tracer experiments presented in Chapters 3 and 5.

Chapter 3 presents potential methylation and demethylation rate measurements from the water colum of the Bermuda Atlantic Time Series (BATS) site in the Sargasso Sea. During two 
cruises, we measured methylation and demethylation potential in oligotrophic waters from chlorophyll maximum and oxygen minimum depths. In our evaluation of measurements of transformations of isotopically enriched $\mathrm{Hg}$ species over the course of incubations, we discuss the relative importance of methylation and demethylation and the implied role of bacteria in water column methylation at this site.

Chapter 4 presents distributions of dissolved and particulate $\mathrm{Hg}$ between $17^{\circ} \mathrm{N}$ and $15^{\circ} \mathrm{S}$ in the Central Pacific Ocean along a transect of strong gradients in oxygen concentrations and utilization. In addition to providing information on potential sources and sinks of MMHg in these waters, the distribution data provide insight into the relative importance of spatial and temporal trends when viewed relative to the body open ocean $\mathrm{Hg}$ data currently available.

Chapter 5 presents $\mathrm{Hg}$ methylation potentials measured in waters collected from a subset of stations occupied for the speciation measurements shown in Chapter 4. In addition to methylation potentials in unamended waters, we also measured changes in methylation promoted by addition of organic matter. In measurements of methylation in both filtered and unfiltered water, we observe dynamic transformations between $\mathrm{Hg}$ (II) substrate and methylated $\mathrm{Hg}$. The experiments described in this chapter are modeled after limitation measurements and are the first attempts to determine the controls on mercury methylation in the marine water column.

Appendix I provides explicit details of the analytical set up, data analysis, and example calculations for the linear matrix approach used in dual tracer CVAFS-ICPMS measurements of MMHg presented in Chapters 3 and 5.

\section{References}

Baeyens, W., M. Leermakers, T. Papina, A. Saprykin, N. Brion, J. Noyen, M. De Gieter, M. Elskens, and L. Goeyens (2003) Bioconcentraion and biomagnifications of mercury and methylmercury in North Sea and Scheldt Estuary fish. Arch. Environ. Contam. Toxicol. 45, 498508.

Bergquist, B. A., and J. D. Blum (2007) Mass-dependent and mass-independent fractionation of $\mathrm{Hg}$ isotopes by photo-reduction in aquatic systems. Science, 318, 417-420.

Bloom, N. 1989 Determination of picogram levels of methylmercury by aqueous phase ethylation, followed by cryogenic gas chromatography with cold vapour atomic fluorescence detection. Can. J. Fish. Aquat. Sci., 46, 1131-1140.

Blum, J. D., B. N. Popp, J. C. Drazen, C. A. Choy, and M. W. Johnson (2013) Methylmercury production below the mixed layer in the North Pacific Ocean. Nat. Geosci., 6, 879-884. 
Bone, S. E., M. A. Charette, C. H. Lamborg, and M. E. Gonneea (2007) Has submarine groundwater discharge been overlooked as a source of mercury to coastal waters? Environ. Sci. Technol., 41, 3090-3095.

Bowman, K. L., and C. R. Hammerschmidt (2011) Extraction of monomethylmercury from seawater for low-femtomolar determination. Limnol. Oceanogr. Methods 9:121-128.

Celo, V., D. R. S. Lean, S. L. Scott (2006) Abiotic methylation of mercury in the aquatic environment. Sci Tot. Environ., 328, 126-137.

Choi, S.-C., T. Chase Jr., R. Bartha (1994) Enzymatic catalysis of mercury methylation by Desulfovibrio desulfuricans LS, Appl. Environ. Microbiol. 60, 1432-1436.

Choi, S.-C., T. Chase Jr., R. Bartha (1994) Metabolic pathways leading to mercury methylation in Desulfovibrio desulfuricans LS Appl. Environ. Microbiol. 60, 4072-4077.

Choy, C. A., B. N. Bopp, J. J. Kenko, J. C. Drazen (2009) THe influence of depth on mercury levels in pelagic fishes and their prey. Proc. Natl. Acad. Sci. USA 106, 13865-13869.

Clarkson, T. W., and J. Magos (2006) The toxicology of mercury and its chemical compounds. Crit. Rev. Toxicol. 36, 609-662.

Cossa, D., B. Averty, N. Pirrone (2009) The origin of methylmercury in open Mediterranean waters. Limnol. Oceanogr. 54, 837-844.

Cossa, D., J.-M. Martin, K. Takayanagi, J. Sanjuan (1997) The distribution and cycling of mercury species in the western Mediterranean. Deep-Sea Res. II 44, 721-740.

Cossa, D., L. E. Heimburger, D. Lannuzel, R. S. Rintoul, E. C. V. Bulter, A. R. Bowie, B. Averty, R. J. Watson, and T. Remenyi (2011) Mercury in the Southern Ocean. Geochim. Cosmochim. Acta 75, 4037-4052.

Ekstrom, E. B., and F. M. M. Morel (2008) Cobalt limitation of growth and mercury methylation in sulfate-reducing bacteria. Environ. Sci. Technol. 42, 93-99.

Fisher, J. A., D. J. Jacob, A. L. Soerensen, A. L. Amos, A. Steffen, and E. M. Sunderland (2012) Riverine sources of Arctic Ocean mercury inferred from atmospheric observations. Nat. Geosci., $5,499-504$.

Fitzgerald, W. F., C. H. Lamborg, C. R. Hammerschmidt (2007) Marine biogeochemical cycling of mercury, Chem. Rev., 107, 641-662.

Filippelli, M., and F. Baldi (1993) Alkylation of ionic mercury to methylmercury and dimethylmercury by methylcobalamin: simultaneous determination by purge-and-trap GC in line with FTIR. Appl Organomet. Chem. 7, 487-493.

Hammerschmidt, C. R., and K. L. Bowman (2012) Vertical methylmercury distribution in the subtropical North Pacific Ocean. Mar. Chem., 132-133, 77-82. 
Hammerschmidt, C. R., M. B. Finiguerra, R. L. Weller, and W. F. Fitzgerald (2013)

Methylmercury accumulation in plankton on the continental margin of the Northwest Atlantic

Ocean, Environ. Sci. Technol., 47, 3671-3677.

Hammerschmidt, C. R., and W. F. Fitzgerald (2006) Bioaccumulation and trophic transfer of methylmercury in Long Island Sound. Arch. Environ. Contam. Toxicol. 51, 416-424.

Hammerschmidt, C. R., and W. F. Fitzgerald (2006b) Methylmercury cyling in sediments on the continental shelf of southern New England. Geochim. Cosmochim. Acta 70, 918-930.

Hammerschmidt, C. R., and W. F. Fitzgerald (2008) Sediment-water exchange of methylmercury determined from shipboard benthic flux chambers. Mar. Chem. 109, 86-97.

Hintelmann, H., R. D. Evans, and J. Y. Villeneuve (1995) Measurement of mercury methylation in sediments by using enriched stable mercury isotopes combined with methylmercury determineaiton by gas chromatography-inductively coupled plasma mass spectrometry, J. Anal. Atom. Spectrom., 10, 619-624.

Hintelmann, H., and R. D. Evans (1997) Application of stable isotopes in environmental tracer studies - measurement of monomethylmercury $\left(\mathrm{CH}_{3} \mathrm{Hg}^{+}\right)$by isotope dilution ICP-MS and detection of species transformation, Fresenius J. Anal. Chem., 358, 378-385.

Hintelmann, H., and N. Ogrinc (2003) Determination of stable mercury isotopes by ICP/MS and their application in environmental studies, in Biogeochemistry of environmentally important trace elements, Eds: Cai, Y., and C. O. Braids, ACS Symp Ser Vol. 835, Washington, DC, p. 321-338.

Horvat, M., L. Liang, and N. S. Bloom (1993) Comparison of distillation with other current isolation methods for the determination of methyl mercury compounds in low level environmental samples Part II. Water. Anal. Chimica Acta 282, 153-168.

Jiménez-Moreno, M., V. Perrot, V. N. Epov, M. Monperrus, and D. Amouroux (2013) Chemical kinetic isotope fractionation of mercury during abiotic methylation of $\mathrm{Hg}(\mathrm{II})$ by methylcobalamin in aqueous chloride media. Chem. Geol. 336, 26-36.

Kraepiel, A. M. L., K. Keller, H. B. Chin, E. G. Malcolm, F. M. M. Morel (2003) Sources and variations of mercury in tuna. Environ. Sci. Technol., 37, 5551-5558.

Kritee, K., J. D. Blum, J. R. Reinfelder, T. Barkay (2013) Microbial stable isotope fractionation of mercury: a synthesis of present understanding and future directions. Chem. Geol., 336, 13-25.

Lamborg, C. H., W. F. Fitzgerald, J. O’Donnell, T. Torgersen (2002) An examination of globalscale mercury biogeochemistry using a non-steady state compartment model which features interhemispheric gradients in the atmosphere as constraints. Geochim. Cosmochim. Acta 66, 1105-1118. 
Lamborg, C. H., K. L. Von Damm, W. F. Fitzgerald, C. R. Hammerschmidt, and R. Zierenberg (2006) Mercury and monomethylmercury in fluids from Sea Cliff submarine hydrothermal field, Gorda Ridge. Geophys. Res. Lett., 33, L17606.

Laurier, F. J. G., R. P. Mason, G. A. Gill, and L. Whalin (2004) Mercury distributions in the North Pacific Ocean-20 years of observations. Mar. Chem., 90, 3-19.

Lehnherr, I., V. L. St Louis, H. Hintelmann, and J. L. Kirk (2011) Methylation of inorganic mercury in polar marine waters. Nat. Geosci. 4, 298-302.

Mahaffey, K. R., R. P. Clickner, C. C. Bodurow (2004) Blood organic mercury and dietary mercury intake: National Health and Nutrition Examination Survey, 1999 and 2000. Environ. Health Perspec. 112, 562-570.

Mason, R. P., and W. F. Fitzgerald (1990) Alkylmercury species in the equatorial Pacific. Nature $347,457-459$.

Mason, R. P., and W. F. Fitzgerald (1993) The distribution and cycling of mercury in the equatorial Pacific Ocean. Deep Sea Res. Part I 40, 1897-1924.

Mason, R. P., J. R. Reinfelder, F. M. M. Morel (1996) Uptake, toxicity, and trophic transfer of mercury in a coastal diatom. Environ. Sci. Technol., 30, 1835-1845.

Mason, R. P., W. F. Fitzgerald, F. M. M. Morel (1994) The biogeochemical cycling of elemental mercury_anthropogenic influences. Geochim. Cosmochim. Acta 58, 3191-3198.

Mason, R. P., K. R. Rolfhus, W. F. Fitzgerald (1995) Methylated and elemental mercury cycling in surface and deep ocean waters of the North Atlantic. Water Air Soil Pollut. 80, 665-677.

Mason, R. P., K. R. Rolfhus, W. F. Fitzgerald (1998) Mercury in the North Atlantic. Mar. Chem. $61,37-53$.

Mason, R. P., K. A. Sullivan (1999) The distribution and speciation of mercury in the south and equatorial Atlantic. Deep Sea Res II, 46, 937-956.

Maynard, J. L. (1932) The action of mercury on organic iodides I: the formation of methylmercury iodide and benzylmercuric iodide. J. Am. Chem. Soc., 54: 2108-2112.

Monperrus, M., E. Tessier, D. Amouroux, A. Laynaert, P. Huonnic, O. F. X. Donard (2007) Mercury methylation, demethylation and reduction rates in coastal and marine surface waters of the Mediterranean Sea. Mar. Chem. 107, 49-63.

Parker, J. L., and N. S. Bloom (2007) Preservation and storage techniques for low-level aqueous mercury speciation. Sci. Tot. Environ., 337, 253-263.

Rodriguez-Gonzalez, P., V. N. Epov, R. Bridou, E. Tessier, R. Guyoneaud, M. Monperrus, and D. Amouroux (2009) Species-specific stable isotope fractionation of mercury during $\mathrm{Hg}(\mathrm{II})$ 
methylation by an anaerobic bacteria (Desulfobulbus propionicus) under dark conditions. Environ. Sci. Technol., 43, 9183-9188.

Schaefer, J. K., and F. M. M. Morel (2009) High methylation rates of mercury bound to cysteine by Geobacter sulfurrducens Nat. Geosci. 2, 123-126.

Schaefer, J. K., S. S. Rocks, W. Zheng, L. Liang, B. Gu, and F. M. M. Morel (2011) Active transport, substrate specificity, and methylation of $\mathrm{Hg}(\mathrm{II})$ in anaerobic bacteria. Proc. Natl. Acad. Sci., 108, 8714-8719.

Scheuhammer, A. M., M. W. Meyer, M. B. Sandheinrich, M. W. Murray (2007) Effects of environmental methylmercury on the health of wild birds, mammals and fish. Amibo. 36, 12-18.

Senn, D. B., E. J. Chesney, J. D. Blum, M. S. Bank, A. Maage, J. P. Shine (2010) Stable isotope $(\mathrm{N}, \mathrm{C}, \mathrm{Hg}$ ) study of methylmercury sources and trophic transfer in the northern Gulf of Mexico. Environ. Sci. Technol., 44, 1630-1637.

Sørensen, A. L., D. J. Jacob, D. G. Streets, M. L. I. Witt, R. Ebinghaus, R. P. Mason, M. Andersson, and E. M. Sunderland (2012) Multi-decadal decline of mercury in the North Atlantic atmosphere explained by changing subsurface seawater concentrations. Geophys. Res. Letts. 39, L21810.

Sørensen, A. L., E. M. Sunderland, C. D. Holmes, D. J. Jacob, R. M. Yantosca, H. Skov, J. H. Christensen, S. A. Strode, and R. P. Mason (2010) An improved global model for air-sea exchange of mercury: high concentrations over the North Atlantic. Environ. Sci. Technol. 44, $8574-8580$.

Streets, D. G., M. K. Devane, Z. Lu, T. C. Bond, E. M. Sunderland, and D. J. Jacob (2011) Alltime releases of mercury to the atmosphere from human activities. Environ. Sci. Technol. 54, 10485-10491.

Sunderland, E. M. (2007) Mercury exposure from domestic and imported estuarine and marine fish in the US seafood market. Environ. Health Perspec. 115, 235-242.

Sunderland, E. M., and R. P. Mason (2007) Human impacts on open ocean mercury concentrations, Global Biogeochem. Cy., 4, GB4002.

Sunderland, E. M., D. P. Krabbenhoft, J. W. Moreau, S. A. Strode, and W. M. Landing (2009) Mercury sources, distribution, and bioavailability in the North Pacific Ocean: insights from data and models. Gobal Biogeochem. Cy., 23, GB2010.

Szczebak, J. T., and D. L. Taylor (2011) Ontogenic patters in bluefish (Pomatomus sultatrix) feeding ecology and the effect on mercury biomagnifications. Environ. Toxicol. Chem., 30, 14471458 .

United States Food and Drug Administration and Environmental Protection Agency (2009) What you need to know about mercury in fish and shellfish: advice for woman who might become pregnant, women who are pregnant, nursing mothers, young children. [Brochure]. 
Weiderhold, J. G., C. J. Cramer, K. Daniel, I. Ifante, B. Bourdon, and R. Kretzchmar (2010)

Equilibrium mercury isotope fractionation between dissolved $\mathrm{Hg}(\mathrm{II})$ species and thiol-bound $\mathrm{Hg}$.

Environ. Sci. Technol., 44, 4191-4197. 
Tables and Table Legends

Table 1: Mercury stable isotopes and their natural abundances

\begin{tabular}{|l|l|}
\hline Isotope & Abundance (\%) \\
\hline${ }^{196} \mathrm{Hg}$ & $\mathbf{0 . 1 5}$ \\
\hline${ }^{198} \mathrm{Hg}$ & 9.97 \\
\hline${ }^{199} \mathrm{Hg}$ & 16.87 \\
\hline${ }^{200} \mathrm{Hg}$ & 23.10 \\
\hline${ }^{201} \mathrm{Hg}$ & 13.18 \\
\hline${ }^{202} \mathrm{Hg}$ & 29.86 \\
\hline${ }^{204} \mathrm{Hg}$ & 6.87 \\
\hline
\end{tabular}




\title{
Chapter 2 \\ Determination of monomethylmercury from seawater with ascorbic acid-assisted direct ethylation
}

\author{
Kathleen M. Munson ${ }^{1}$, Diana Babi ${ }^{2}$, and Carl H. Lamborg ${ }^{1}$ \\ ${ }^{1}$ Marine Chemistry and Geochemistry Department, Woods Hole Oceanographic Institution, \\ Woods Hole, Massachusetts, 02543. \\ ${ }^{2}$ Tekran Instruments Corporation, 330 Nantucket Boulevard, Toronto, Ontario, M1P 2P4, Canada. \\ In revision for publication in Limnology and Oceanography: Methods
}

\begin{abstract}
We developed a technique to measure monomethylmercury (MMHg) concentrations from small volumes $(180-\mathrm{mL})$ of seawater at low femtomolar concentrations using direct ethylation derivitization, decreasing the required volume by $90 \%$ from current methods while maintaining a $<20 \mathrm{fM}$ detection limit. In this method, addition of ascorbic acid prior to the derivitization of $\mathrm{MMHg}$ allows for full recovery of $\mathrm{MMHg}$ from the seawater matrix without the need for sample distillation or extraction. The small sample size and relative ease of detection is ideal both for shipboard as well as shore-based measurements of preserved MMHg samples. Combined with shipboard determination of dimethylmercury (DMHg) and elemental mercury $(\operatorname{Hg}(0))$, this method can be used to determine full mercury speciation.
\end{abstract}




\section{Introduction}

Mercury $(\mathrm{Hg})$ is a toxic metal with an organic monomethylmercury ( $\mathrm{MMHg}$ ) chemical form that bioaccumulates in aquatic food webs. At sufficiently high concentrations, $\mathrm{MMHg}$ toxicity can cause decreased fertility and offspring survival in the upper trophic levels of terrestrial and marine systems [Scheuhammer et al, 2007]. In humans, MMHg acts as a neurotoxin and can cause developmental defects to fetuses and small children [Clarkson and Magos, 2006]. Due to the importance of marine protein sources in human diets, efforts to improve our understanding of the production and distribution of $\mathrm{MMHg}$ in open-ocean systems have increased in recent decades. However, until recently, descriptions of $\mathrm{Hg}$ cycling in marine systems have relied heavily on studies of coastal and sedimentary systems, in which higher $\mathrm{MMHg}$ concentrations are more easily measured.

Determination of monomethylmercury concentrations is analytically challenging due to its femtamolar concentrations in much of the open ocean [Cossa et al, 2011; Hammerschmidt and Bowman, 2012; Mason and Fitzgerald, 1993; Sunderland et al, 2009]. Analytical methods, based on ethylation, to quantify MMHg, including the US EPA Standard Method 1630, require separation of MMHg from its environmental matrix. Either solvent extraction \{Bloom 1989; Horvat et al, 1993] or distillation [Horvat et al, 1993] methods are commonly used to isolate MMHg for analysis. Following separation, MMHg is volatilized through derivitizaton, most commonly by addition of the ethylating agent sodium tetraethylborate (NaTEB) to form gaseous methylethylHg. Preconcentration of gaseous methylethylHg is achieved through trapping onto a Carbotrap [Bloom, 1989] or Tenax [Bowman and Hammerschmidt, 2011] column before analysis by GC separation of the methylethylHg and gaseous diethylmercury produced from $\mathrm{Hg}(\mathrm{II})$ substrate in solution. Once preconcentrated, sub-pM concentrations of MMHg can be quantified by atomic fluorescence spectrometry (AFS) or isotope dilution inductively-coupled plasma mass spectrometry (ID-ICPMS).

Initial attempts to avoid either MMHg distillation or extraction steps by direct ethylation of MMHg with NaTEB were inefficient, recovering 5-60\% of added MMHg [Horvat et al 1993]. However, a method has recently been developed to detect $\mathrm{MMHg}$ from direct ethylation of 2-L volumes of seawater [Bowman and Hammerschmidt, 2011]. This method is advantageous for two reasons. First, it requires a minimal amount of sample processing compared to $\mathrm{MMHg}$ distillation or extraction, which makes the technique amenable for ship-based analyses. Second, the method allows for quantification of both dissolved $\mathrm{MMHg}$ and the gaseous dimethylmercury (DMHg) 
organomercuric chemical species in seawater. The 2-L sample bottles can be purged with nitrogen $\left(\mathrm{N}_{2}\right)$ gas to measure DMHg concentrations in seawater prior to acidification and ethylation to volatilize MMHg. However, the 2-L sample volume can hinder shore-based analysis due to difficulties in sample transport and storage for high-resolution depth profiles. In addition, the efficiency of direct ethylation from seawater is variable, requiring careful consideration of appropriate standards for MMHg quantification [Bowman and Hammerschmidt, 2011].

Prior to the development of the direct ethylation method, preservation of samples with acid for shore-based MMHg determination using distillation or extraction methods prevented separate determination of $\mathrm{DMHg}$ and $\mathrm{MMHg}$ since $\mathrm{DMHg}$ decomposes to $\mathrm{MMHg}$ within a matter of hours in acidic conditions [Parker and Bloom, 2007]. As a result, profiles of acidpreserved samples cannot distinguish between the $\mathrm{DMHg}$ and $\mathrm{MMHg}$ organomercuric forms in their analyses and instead represent a combined ([DMHg + MMHg]) concentration [e.g., Sunderland et al, 2009].

Direct volatilization is also possible via hydride generation of mercury hydrides via the addition of sodium tetrahydridoborate (sodium borohydride) followed by collection on a cold-trap before analysis using AFS [Cossa et al, 2009]. Like other methods, hydride generation requires application at sea to distinguish between DMHg and MMHg. Otherwise, quantification of acidpreserved samples yields combined $([\mathrm{DMHg}]+[\mathrm{MMHg}])$ concentrations. However, liquid $\mathrm{N}_{2}$ is required to analyze the volatile mercury hydride compound. In addition, like the 2-L direct ethylation method, the mercury hydride method cannot be easily automated or adapted to in-line analysis for isotopic studies.

In order to address the limitations of current methods, we developed a method that improves the recently described direct ethylation method while simultaneously allowing for sample preservation. Ascorbic acid addition has been found to improve MMHg detection from distilled samples using US EPA Method 1630 [Tekran Instruments Corporation, 2011]. We therefore adapted the use of ascorbic acid to improve the low ethylation efficiency of $\mathrm{MMHg}$ from seawater samples observed using the direct ethylation method [Bowman and Hammerschmidt, 2011]. The method can be coupled with acidification and purging prior to $\mathrm{MMHg}$ derivatization to collect and quantify volatile DMHg as a distinct species [Lamborg et al., 2012]. 


\section{Materials and Procedures}

\section{Plastic and Glassware}

All plastic and glass bottles, tubing, and filter holders for water collection, reagents, and sample preparation were acid-washed in a class 100 clean room according to described protocols [Hammerschmidt et al., 2011]. Pre-filters for water filtration were combusted prior to use. Capsule filters were filled with $10 \% \mathrm{HCl}$, soaked for 24 hours, and rinsed with de-ionized water (>18 M $\Omega$-cm; "MQ") until the rinse water $\mathrm{pH}$ was $>6$.

Either 42-mL amber glass vials (I-CHEM ${ }^{\mathrm{TM}}$, Fisher) or 250-mL amber glass bottles (I$\mathrm{CHEM}^{\mathrm{TM}}$, Fisher) were used for MMHg analysis from $30-\mathrm{mL}$ or $180-\mathrm{mL}$ sample volumes, respectively. The sample volumes were chosen to maximize the MMHg signal detected from the purged sample while maintaining adequate headspace for appropriate positioning of the instrument's dual sample purge and analyte inlet needle (see below) above the height of the liquid. New Teflon backed septa $\left(\right.$ SunChem $\left.^{\mathrm{TM}}\right)$ were soaked in Citranox ${ }^{\mathrm{TM}}(1 \%)$ overnight and $10 \% \mathrm{HCl}$ for $>24$ hours, then rinsed with MQ prior to use. Previously pierced septa were reused after soaking in Citranox ${ }^{\mathrm{TM}}(1 \%)$ overnight and up to 6 days in $10 \% \mathrm{HCl}$ and rinsed with MQ prior to use.

\section{Seawater}

Seawater used for method development was collected from the Equatorial Pacific Ocean in October 2011 on board the R/V Kilo Moana and from Vineyard Sound in Woods Hole, MA intermittently between November 2011 and March 2012. Open-ocean seawater was collected in acid-rinsed X-Niskin bottles on a dedicated trace-metal clean rosette deployed on Amsteel line. Seawater was filtered $(47 \mathrm{~mm}$, Supor polycarbonate membrane, $0.2-\mu \mathrm{m}$ pore size, Pall Corporation) from X-Niskin bottles that were pressurized with ultra high purity $\mathrm{N}_{2}$ in a positive pressure, HEPA-filtered bubble constructed onboard the ship. Water was decanted into acid-clean 10-L polyethylene carboys and stored at room temperature until use. Vineyard Sound coastal seawater was collected in acid cleaned 2-L Teflon bottles mounted on a pole sampler from the shore at the Quissett Campus of the Woods Hole Oceanographic Institution. Water was filtered with a GF/A pre-filter (42-mm Whatman) and a $0.2-\mu \mathrm{m}$ Sterivex-GVTM (Millipore) filter. 


\section{Monomethylmercury Determination}

MMHg was determined by CVAFS gas chromatography with a Tekran 2700 Automated Methyl Mercury Analysis System (Tekran, Ontario, Canada). The system is designed to determine MMHg from 30-mL samples of freshwater. Samples are analyzed using an autosampler that features a septa-piercing needle equipped with a purge gas outlet and a sample inlet. After piercing the septum, Ar flow through the tip of the needle purges the sample and allows the loading of gaseous methylethylHg through the sample inlet until the needle withdraws from the sample vial. The dual purging and loading allows for in-line loading of the Tenax column (Supelco) and separation of derivitized $\mathrm{Hg}$ species through a GC column.

In the manufacturer set-up of the instrument, an event table file (ETF) is used to automate sample purging followed by loading and heating of the Tenax trap and GC column via a sequence of valve activation and deactivation. Gaseous species of $\mathrm{Hg}$ are purged from the sample at controlled flow rates $(82,120$ or $152 \mathrm{~mL} / \mathrm{min})$ and loaded onto a Tenax trap at $31^{\circ} \mathrm{C}$ while bypassing the GC column, which has a separate continuous flow of Ar. During the desorption state, the valve between the Tenax trap and the GC column is opened, the Tenax trap is heated to $180^{\circ} \mathrm{C}$, and the desorbed $\mathrm{Hg}$ derivatives are carried from the Tenax trap to the GC column $\left(85^{\circ} \mathrm{C}\right)$. The chromatographically separated mercury species are fully combusted in a quartz pyrolysis column $\left(720^{\circ} \mathrm{C}\right)$, combined with an Ar make up gas, and quantified by AFS. The Tenax trap and GC column are heated between sample loadings to avoid carryover between samples.

The resulting chromatograph displays separate peaks of $\mathrm{Hg}(0)$, methylethyl $\mathrm{Hg}$, and diethyl $\mathrm{Hg}$, of which the methylethylHg peak can be quantitatively integrated to determine $\mathrm{MMHg}$ concentration.

Modifications of factory-installed software and hardware are necessary in order to detect MMHg from 180-mL of seawater using the Tekran 2700. The autosampler comes equipped with 3 trays that each hold $2142-\mathrm{mL}$ sample vials that correspond to pre-set autosampler positions. Although the autosampler has alternative settings for smaller sample vial sizes, there is no preinstalled set up for sufficiently large volume samples for seawater detection. Therefore, a custom foam and cardboard tray that accommodates $250-\mathrm{mL}$ volume bottles was designed for bottle positions that correspond to vial positions that are pre-set for the autosampler configuration for 3 trays of 40 sample vials. In order to accommodate the differences in height between the $42-\mathrm{mL}$ and $250-\mathrm{mL}$ sample bottles, the z-axis height setting of the dual purge/inlet needle was adjusted 
from $14700 \mathrm{~mm}$ to $13400 \mathrm{~mm}$ to keep the sampling inlet in the headspace during sample loading. In addition, the vial stopper was adjusted to allow clearance over the height of the bottles.

In order to maximize the signal, the flow rate of Ar gas for sample purging and the sample purging time were increased. The Ar gas flow was modified from manufacturer's installation by replacing the original $82-\mathrm{mL} / \mathrm{min}$ flow restrictor with a $152-\mathrm{mL} / \mathrm{min}$ flow restrictor. In addition, a new ETF was created that extended the sample purge time from 4 min to $8 \mathrm{~min}$. As with the recommended configuration for analysis of $30-\mathrm{mL}$ samples of freshwater, the gas stripping of MMHg from the 180-mL samples is not complete despite the extended purge time, but approaches $80 \%$ after $8 \mathrm{~min}$. This extended purge time was chosen as a balance between maintaining the shortest possible analysis time, minimizing the amount of moisture that is forced onto the Tenax column, and maximizing the MMHg signal.

\section{Standard and Sample Preparation}

Acetate and citrate buffers, $\mathrm{KOH}$, and sulfuric acid, were stored in acid-cleaned Teflon bottles. Solutions were remade as needed and to address any contaminants detected from reagent blanks.

For standard curve preparation, secondary stocks of $50 \mathrm{pM}$ were prepared from dilution of concentrated MMHg primary stock (Alfa Aesar, 1000 ppm methylmercury chloride in water) in MQ and acidified to $0.25 \% \mathrm{HCl}$ (concentrated, SEASTAR ${ }^{\text {TM }}$ Chemical) to prevent loss of analyte to sides of the glass bottle. Standard curves ranging from $10 \mathrm{fM}$ to $1000 \mathrm{fM}$ were prepared daily from the secondary stock in MQ, filtered Equatorial Pacific seawater, and filtered Vineyard Sound seawater. MMHg was equilibrated with ambient ligands for at least 24 hours prior to further processing.

After equilibration, all samples and standards were acidified to a final concentration of $0.5 \%$ with concentrated sulfuric acid (Fisher, TM Grade) to extract MMHg from the seawater matrix and allowed to react for 24 hours prior to ethylation (Bowman and Hammerschmidt, 2011). Ascorbic acid (2.5\% wt:vol in MQ, Fisher) was added to each sample prior to ethylation. Sample $\mathrm{pH}$ was then adjusted to 5 with $\mathrm{KOH}$ (45\% wt:vol in MQ, Fisher). Sample pH was determined by testing $20 \mu \mathrm{L}$ volumes of sample on $\mathrm{pH}$ strips (MColorpHast range 4.0-7.0, EMD Millipore). Neutralized samples were buffered with either acetate buffer (2M sodium acetate, Fisher; adjusted to $\mathrm{pH} 5$ with $\mathrm{H}_{2} \mathrm{SO}_{4}$, conc. Fisher) or citrate buffer (1M sodium citrate Fisher; adjusted to $\mathrm{pH} 5$ with $\mathrm{H}_{2} \mathrm{SO}_{4}$, conc. Fisher) according to sample size (Table 1). Sodium 
tetraethylborate (NaTEB, Strem Chemical) was dissolved (1\% final wt:vol) in pre-chilled 2\% $\mathrm{KOH}$ in MQ and quickly aliquoted into 10-mL Teflon vials and kept frozen until use. For sample ethylation, an aliquot of NaTEB was thawed just until it formed a slush and was added to the buffered sample. Samples were then capped with Teflon-backed septa and inverted 10 times. The ethylation reaction was allowed to proceed for at least 20 minutes prior to initiating analysis.

Samples bottles were loaded into either the $42-\mathrm{mL}$ vial tray provided by the manufacturer or the custom 250-mL bottle foam tray. Samples were analyzed after standards showed a linear relationship and peak area values for standards could be distinguished from those of reagent blanks ( $3 \mathrm{x}$ the standard deviation of triplicate regent blanks). Since the custom tray accommodates a maximum of 11 sample bottles, sets of 8-11 samples were typically prepared and all were analyzed within 4 hours of ethylation.

\section{Assessment}

The development of the presented method was focused on achieving two goals. First, we attempted to lower the detection limit of the automated method to adequately measure the low femtomolar concentrations of MMHg in open-ocean water. We did this by increasing the total sample volume from $30-\mathrm{mL}$ to $180-\mathrm{mL}$ as well as increasing total purge flow for larger sample volume by lengthening the purge time as well as increasing the Ar purge rate.

Second, we sought to improve the efficiency of MMHg extraction from the saltwater matrix. This was accomplished by the addition of ascorbic acid, which allowed for full extraction of added MMHg from seawater. We also replaced the acetate buffer commonly used in $\mathrm{MMHg}$ determination methods with citrate buffer in order to reduce signal inconsistencies that we observed after making alterations to the instrument method.

\section{Sample Volume Adjustment}

Using the instrument as designed with $30-\mathrm{mL}$ sample volumes of seawater, the detection limit of $100 \mathrm{fM}$, as calculated from 3x the standard deviation of the blanks, was insufficient for low open-ocean MMHg concentrations, typically $<100 \mathrm{fM}$ in the upper water column [Cossa et al, 2011; Hammerschmidt and Bowman, 2012; Mason and Fitzgerald, 1993; Sunderland et al, 2009]. The modification of the instrument to accommodate an increase in sample volume to $180-\mathrm{mL}$ resulted in a daily detection limit of $\sim 5 \mathrm{fM}$, from triplicate reagent blanks, which was sufficient for most depths within the open-ocean water column. This detection limit is on the same order of 
magnitude as that of the recently described 2-L direct ethylation method [Bowman and Hammerschmidt, 2011] while decreasing the required volume by $90 \%$ and allowing the process to be automated.

\section{Ar Purge Rate and Purge Volume}

Unlike alternative analytical methods, the Tekran automated instrument used in this study does not completely purge MMHg from the sample. Instead, a purge time of up to $4 \mathrm{~min}$ is recommended for $\mathrm{MMHg}$ determination from freshwater samples for adequate mercury species separation. However, we observed a methylation artifact when using a 4 min purge time with $180-\mathrm{mL}$ sample volumes. This artifact appeared after repeated analyses of individual acetate buffered samples and produced MMHg signals ranging between $73-477 \%(n=5)$ of the initial MMHg signal (Figure 1, A). The artifact was most pronounced in samples and standards with MMHg concentrations near $15 \mathrm{fM}$ (Figure 1, B). We increased the purge time to $8 \mathrm{~min}$ in order to extract a higher proportion of the MMHg present in samples. The increased purge time resulted in a predictable decrease in measured $\mathrm{MMHg}$ from the first purge to the second but not in subsequent purges of an individual standard buffered with acetate (Figure 1, C). It is important to note that this artifact was not the result of $\mathrm{MMHg}$ carry over from previously analyzed samples.

$\mathrm{MMHg}$ concentrations measured from blanks run between repeated purging of individual samples or standards were not elevated $(<\mathrm{DL})$. Because acetate buffers are known to produce $\mathrm{MMHg}$ when exposed to light (e.g., Falter, 1999), we sought to avoid the apparent MMHg production in acetate buffered samples by using citrate buffer (see below).

Although we increased both the Ar purge rate and the Ar purging time, it is important to note that increasing the Ar purge rate from $80-\mathrm{mL} / \mathrm{min}$ to $120-\mathrm{mL} / \mathrm{min}$ produced only a modest increase in the MMHg sample signal of $\sim 5 \%(\mathrm{n}=5)$ from 30-60 mL sample volumes. However, the increase in total purge time from $1 \mathrm{~min} 45 \mathrm{sec}$ to 4 min increased the MMHg sample signal by $25 \%(n=5)$. The difference between the effectiveness of changing the purge rate versus the total purge time may be attributed to the increase in gas pressure in the headspace above the aqueous sample and therefore a decrease in the volatilization of methylethylHg. While the MMHg signal was less sensitive to increases in the Ar purge rate than to increases in the sample volume, the increased purge rate combined with the increased length of the purge allowed for samples to be processed in a relatively high throughput manner while still retaining low femtamolar detection limits. 


\section{Determination of Reagent Blanks}

Due to low MMHg concentrations present in open-ocean seawater, it is important to quantify the $\mathrm{Hg}$ species content of reagent blanks and take steps to minimize contamination. MQ in our laboratory often has measurable $\mathrm{MMHg}$ and $\mathrm{Hg}$ (II) concentrations that would hinder analysis of low seawater concentrations. As a result, we used two methods to quantify MMHg in the reagent blanks. First, MQ was exposed to ambient outdoor UV in 2-L Teflon bottles for 7-10 days until the concentration of MMHg in the water was negligible $(<3 \mathrm{fM})$ and this water was then used to prepare reagent blanks. Alternatively, in order to check the MMHg contribution of the reagents to the total signal from blanks, the reagents prepared in lab MQ were added in increasing amounts (e.g., 1x, 2x and 3x above those values in Table 1) and were determined as the MMHg signal above the MQ water background (Figure 2).

The precision of the standard curves was determined daily to have an average relative standard deviation from 4 replicate standards of 6\% (range: 4-9\%) during method development. Generally, the slope of the standard curve was also consistent from day to day. Over a 14-day period, the average slope of daily standard curves of MMHg peak area versus the amount of MMHg added (fM) averaged 2.61 ( \pm 0.31$)$ area units per $\mathrm{fM} \mathrm{Hg}$ for 180 -mL volume standards. Differences in the slopes between standard curves prepared with MQ and those prepared with filtered seawater were similar, varying between $-12 \%$ to $+16 \%(n=3$; Figure 5$)$ for $180-m L$ volumes without the need to adjust for reduced ethylation efficiency due to the seawater matrix. As a result, standard curves prepared in MQ can be used for quantification of $\mathrm{MMHg}$ concentrations.

\section{Ascorbic Acid Addition}

The addition of ascorbic acid dramatically improved the extraction of MMHg from the seawater matrix. Extraction of MMHg standard from MQ averaged 34\% (range: 2.7-81\%, n=10) and improved to $97 \%$ (range: $86-109 \% \mathrm{n}=7$ ) when ascorbic acid was added (Figure 3). Although the mechanism by which MMHg recovery was improved is unknown, the function of ascorbic acid to overcome seawater matrix effects is affected by neither the order of reagent addition nor the length of time that ascorbic acid is allowed to react with the seawater sample. The increased extraction efficiency rendered by ascorbic acid yielded 98\% recovery of equilibrated $\mathrm{MMHg}$ standard spikes from 30-mL volumes of filtered seawater within the 20-min reaction time allowed for the ethylation reaction (range: $81-128 \%, \mathrm{n}=15$ ). Exposing the sample to additional 
manipulation by first adding ascorbic acid, resealing the sample bottle, incubating for $12 \mathrm{hrs,} \mathrm{and}$ then adding the remaining reagents yielded an average of $130 \%$ recovery (range: $104-155 \%, n=8$ ) of added MMHg standard. In addition, recovery of MMHg from previously purged filtered seawater to which no ascorbic acid was added was enhanced, from $34 \%$ to $70 \%$ (range: $61-71 \%$, $\mathrm{n}=2$ ) compared to unpurged filtered seawater (Figure 3). This suggests that a volatile, oxidizing component of seawater may be the source of interference that inhibits extraction of MMHg from the seawater matrix.

Addition of ascorbic acid to samples prior to ethylation also greatly improved the effective lifespan of NaTEB. Previous studies have found that NaTEB quickly loses its ethylation ability in a matter of days, even when kept frozen in individual aliquots until use [USEPA, 2001; DeWild et al, 2002; Lamborg et al, 2012]. The addition of ascorbic acid extended the ethylation capacity of NaTEB. Individual aliquots of NaTEB were stable through several freeze and thaw cycles over weeks of analyses without noticeable changes in the ability to ethylate MMHg standards. Dissolved NaTEB stored frozen $\left(-20^{\circ} \mathrm{C}\right)$ for $>2$ months maintained its ability to ethylate MMHg equilibrated in filtered seawater ( $\sim 88 \%$ recovery of added $\mathrm{MMHg}$; $n=2$; Figure 4). This suggests that the perceived instability of NaTEB is not due to chemical breakdown from oxidation during storage, but is instead a result of interferences with the ethylation reaction by some component of either the seawater matrix or a breakdown product of NaTEB itself.

\section{Citrate Buffering}

Contamination from reagents can be minimized through the use of trace metal grade acids and bases. However, the organic acid buffers can contribute a significant amount of MMHg contamination to sample signals. In initial attempts to reduce this contamination, NaTEB was added to the acetate buffer, allowed to react at room temperature for $20 \mathrm{~min}$, and purged with $\mathrm{Hg}$ free $\mathrm{N}_{2}$ at $0.5-\mathrm{L} / \mathrm{min}$ for $30 \mathrm{~min}$ to remove $\mathrm{MMHg}$ and inorganic $\mathrm{Hg}$ species. However, upon analysis, it was discovered that this daily addition of NaTEB and purging of the acetate buffer contributed to an in-growth of MMHg observed with subsequent purges of individual samples/standards (Figure 1). As a result, we replaced the acetate buffer with citrate buffer to avoid similar production of MMHg during analysis. Although the citrate buffer has a higher concentration of MMHg contamination, ranging between 5 and $73 \mathrm{fM}(\mathrm{n}=15)$ compared to less than $5 \mathrm{fM}$ in acetate buffer, the contamination from the citrate buffer did not appear to increase with time or exposure to light. Repeated purging of citrate buffered samples for 8 minutes also 
resulted in a predictable decrease in the MMHg peak area averaging $77 \%$ of its previous value (range: $74-82 \%, \mathrm{n}=6$ ) without the MMHg in-growth observed with acetate buffered $\mathrm{MMHg}$ concentrations $<15 \mathrm{fM}$.

In addition to the greater MMHg contamination found with citrate buffer, its use decreased the sensitivity of the MMHg detection, calculated from the slope of the MMHg peak area versus concentration of added MMHg standard, to $45 \%$ that of acetate buffered standards at a flow rate of $82-\mathrm{mL} / \mathrm{min}$. However, at the higher $152-\mathrm{mL} / \mathrm{min}$ flow rate, the slope of the citrate buffered standards is $77 \%$ that of acetate buffered standards (Figure 2).

\section{Discussion}

Direct ethylation of MMHg has provided a means to vastly improve the understanding of $\mathrm{Hg}$ speciation in marine systems, especially the organomercuric species $\mathrm{DMHg}$ and $\mathrm{MMHg}$, which are present in low femtomolar concentrations in the open-ocean water column [Cossa et al, 2011; Hammerschmidt and Bowman, 2012; Mason and Fitzgerald, 1993; Sunderland et al, 2009]. Because sample preservation with acid leads to the demethylation of DMHg to $\mathrm{MMHg}$ [Parker and Bloom, 2005], a method capable of distinguishing between these two organomercuric species is essential to understand the partitioning of $\mathrm{Hg}$ species. Although the direct ethylation method provides a promising alternative to sample distillation, the seawater matrix presents interferences that can lower ethylation efficiency.

Although the addition of ascorbic acid does not lower the detection limit ( $\sim 5 \mathrm{fM})$ compared to the current method of direct ethylation of MMHg from sweater (Bowman and Hammerschmidt 2011), complete recovery of MMHg from the seawater matrix is advantageous for two reasons. First, the ethylation enhancement observed using ascorbic acid, presumably due to its function as a mild reductant, may occur to unknown degrees in seawater samples, depending on their concentrations of naturally occurring reductants. As a result, without complete $\mathrm{MMHg}$ extraction, relative concentrations between seawater samples may reflect differences in ethylation efficiency due to the composition of the seawater matrices rather than differences in $\mathrm{MMHg}$ concentrations. Second, the increased ethylation efficiency observed in pre-purged seawater (Figure 3) can potentially overestimate the assumed ethylation efficiency when $\mathrm{MMHg}$ standard curves are prepared in purged samples [Bowman and Hammerschmidt, 2011].

Preservation of open-ocean seawater samples can be essential for mechanistic studies of mercury species cycling in ocean environments. Thus, the presented ascorbic acid-assisted direct 
ethylation method has been developed to allow for both ship-based and lab-based MMHg measurement. In combination with ship-based measurement of DMHg from untreated seawater prior to preservation with $\mathrm{H}_{2} \mathrm{SO}_{4}$, this method overcomes major restrictions faced while using many of the current methods used for MMHg analysis. In addition, our semi-automated method can improve throughput for linked anaylsis, such as CVAFS-ICPMS for mechanistic studies using additions of stable $\mathrm{Hg}$ isotopes [Monperrus et al, 2007; Lehnherr et al, 2011].

\section{Comments and Recommendations}

We developed the described method specifically to reduce the required volume needed to measure $\mathrm{MMHg}$ from seawater while maintaining a minimal amount of sample manipulation. The addition of ascorbic acid enables complete extraction of low open-ocean concentrations of $\mathrm{MMHg}$ from seawater matrices. Complete extraction is important for avoiding potential biases in $\mathrm{MMHg}$ determination that may result from changes in ethylation efficiency caused by differences in seawater matrix composition between samples.

Direct methylation from $\mathrm{Hg}(\mathrm{II})$ has recently been revealed as a potentially significant source of MMHg in the marine water column [Lehnherr et al, 2011; Sunderland et al, 2009]. However, MMHg may also be produced from the abiotic degradation of highly photolabile DMHg [Mason et al, 1995]. Since we developed this method to measure MMHg from acidpreserved samples that were stripped of DMHg before preservation, we have not run standard curves to quantify the DMHg detected by the Tekran 2700. Thus, we recommend that the described method be used in conjunction with ship-based measurements of DMHg for full dissolved Hg speciation analysis [Bowman and Hammerschmidt 2011; Lamborg et al, 2012].

Although our method was developed using one of two commonly used commercially available MMHg auto analyzers, the addition of ascorbic acid can be adapted to existing manual methods in order to minimize matrix effects during analysis.

\section{Acknowledgements}

This research was supported by the National Science Foundation (OCE-1031271). K. M. M. was supported by a Graduate Research Fellowship from the National Science Foundation. 


\section{References}

Bloom, N. 1989 Determination of picogram levels of methylmercury by aqueous phase ethylation, followed by cryogenic gas chromatography with cold vapour atomic fluorescence detection. Can. J. Fish. Aquat. Sci., 46, 1131-1140.

Bowman, K. L., and C. R. Hammerschmidt (2011) Extraction of monomethylmercury from seawater for low-femtomolar determination. Limnol. Oceanogr. Methods 9, 121-128.

Clarkson, T.W. and L. Magos (2006) The toxicology of mercury and its chemical compounds.

Crit. Rev. Toxicol. 36, 609-662.

Cossa, D., B. Averty, and N. Pirrone (2009) The origin of methylmercury in open Mediterranean waters. Limnol. Oceanogr. 54, 837-844.

Cossa, D., L. E. Heimburger, D. Lannuzel, S. R. Rintoul, E. C. V. Bulter, A. R. Bowie, B. Averty, R. J. Watson, and T. Remenyi (2011) Mercury in the Southern Ocean. Geochim. Cosmochim. Acta 75, 4037-4052.

DeWild, J., M. Olson, and S. Olund (2002) Determination of methylmercury by aqueous phase ethylation, followed by gas chromatographic separation with cold vapor atomic fluorescence detection. U. S. Geol Surv. Open File Rep 01-445, 19 pp.

Falter, R. (1999) Experimental study on the unintentional abiotic methylation of inorganic mercury during analysis: Part 2: Controlled laboratory experiments to elucidate the mechanism and critical discussion of the species specific isotope addition correction method. Chemosphere 39, 1075-1091.

Hammerschmidt, C. R., and K. L. Bowman (2012) Vertical methylmercury distribution in the subtropical North Pacific Ocean. Mar. Chem. 132-133, 77-82.

Hammerschmidt, C.R., Bowman, K.L., Tabatchnick, M.D., and C. H. Lamborg (2011) Storage bottle material and cleaning for determination of total mercury in seawater. Limnology and Oceanography-Methods, 9, 426-431.

Horvat, M., L. Liang, and N. S. Bloom (1993) Comparison of distillation with other current isolation methods for the determination of methyl mercury compounds in low level environmental samples Part II. Water. Anal Chimica Acta 282, 153-168.

Lamborg, C.H., Hammerschmidt, C.R., Gill, G.A., Mason, R.P. and S. Gichuki (2012) An Intercomparison of Procedures for the Determination of Total Mercury in Seawater and Recommendations Regarding Mercury Speciation during GEOTRACES Cruises. Limnology and Oceanography-Methods, 10, 90-100.

Lehnherr, I., V. L. St. Louis, H. Hintelmann, and J. L. Kirk. (2011) Methylation of inorganic mercury in polar marine waters. Nat. Geo. 4, 298-302. 
Mason, R. P. and W. F. Fitzgerald (1993) The distribution and biogeochemical cycling of mercury in the equatorial Pacific Ocean. Deep-Sea Res. I 40, 1897-1924.

Mason, R. P., K. P. Rolfhus., and W. F. Fitzgerald (1995) Methylated and elemental mercury cycling in surface and deep ocean waters of the North Atlantic. Water, Air, Soil, Pollut. 80, 665677.

Monperrus, M., E. Tessier, D. Amouroux, A. Leynaert, P. Huonnic, and O. F. X. Donard (2007) Mercury methylation, demethylation and reduction rates in coastal and marine surface waters of the Mediterranean Sea. Mar. Chem. 107, 49-63.

Parker, J. L. and N. S. Bloom (2005) Preservation and storage techniques for low-level aqueous mercury speciation. Sci. Total. Environ. 337, 253-363.

Sunderland, E. M., D. P. Krabbenhoft, J. W. Moreau, S. A. Strode, and W. M. Landing (2009) Mercury sources, distribution, and bioavailability in the North Pacific Ocean: Insights from data and models. Global Biogeochem. Cy. 23, GB2010.

Tekran Instruments Corporation (2011) Series 2700 Methyl Mercury Analysis System: Analytical Guides. Rev: 1.10 .

US EPA (USEPA) (2001) Method 1630: methyl mercury in water by distillation, aqueous ethylation, purge and trap, and cold vapor atomic spectrometry. Washington, DC. 


\section{Figures and Figure Legends}

Figure 1: Increases in measured $\mathrm{MMHg}$, relative to the initial MMHg measured, was observed during repeated analysis of individual seawater samples buffered with acetate buffer (180-mL) (A). Similar variability was observed in acetate-buffered standards of $25 \mathrm{fM} \mathrm{MMHg}$ added to filtered seawater using a 4-minute Ar purge in the analytical method (B). Extending the Ar purge time of acetate-buffered standard to 8 minutes failed to alleviate this variability (C). Quantitative stripping of $\mathrm{MMHg}$ was observed from citrate-buffered standards using an 8-minute Ar purge (D).

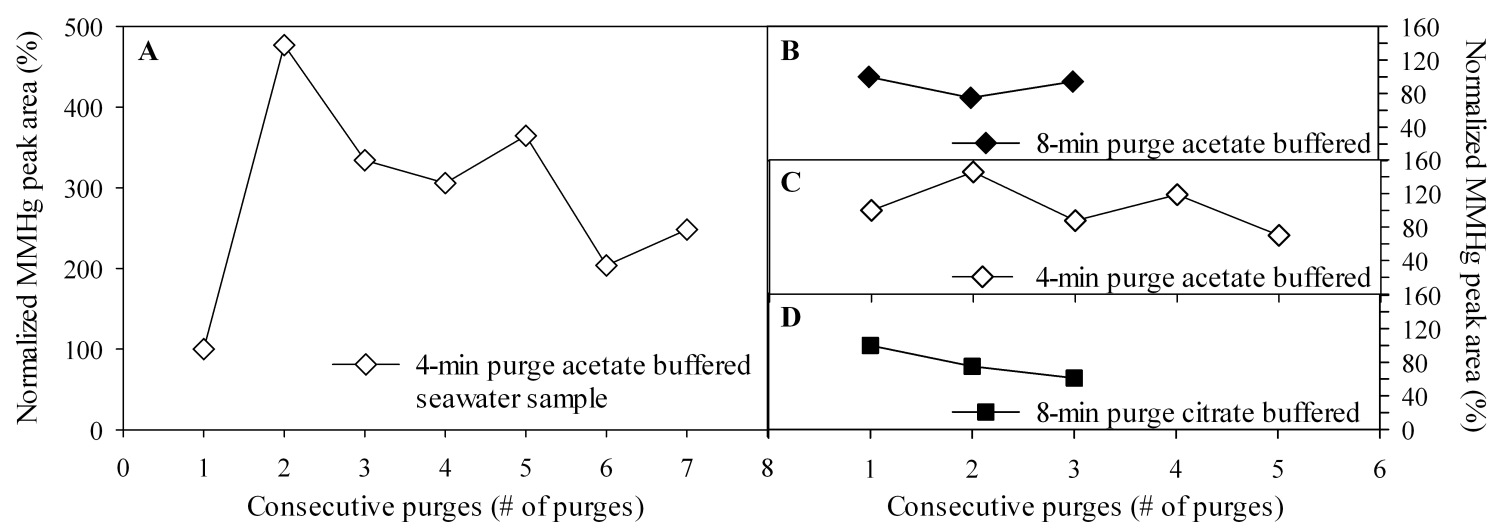


Figure 2: Comparison of standard curves of instrument $\mathrm{MMHg}$ peak area versus added $\mathrm{MMHg}$ standard (5-100 fM) prepared with acetate buffer and citrate buffer. Citrate buffered standards yield less sensitivity as observed from the lower slope of the standard curve. By increasing the rate of the Ar purging during sample analysis by replacing the $82-\mathrm{mL} / \mathrm{min}$ flow restrictor with a $152-\mathrm{mL} / \mathrm{min}$ flow restrictor, the sensitivity of the citrate-buffered standard curve approaches that of the acetate-buffered standard curve.

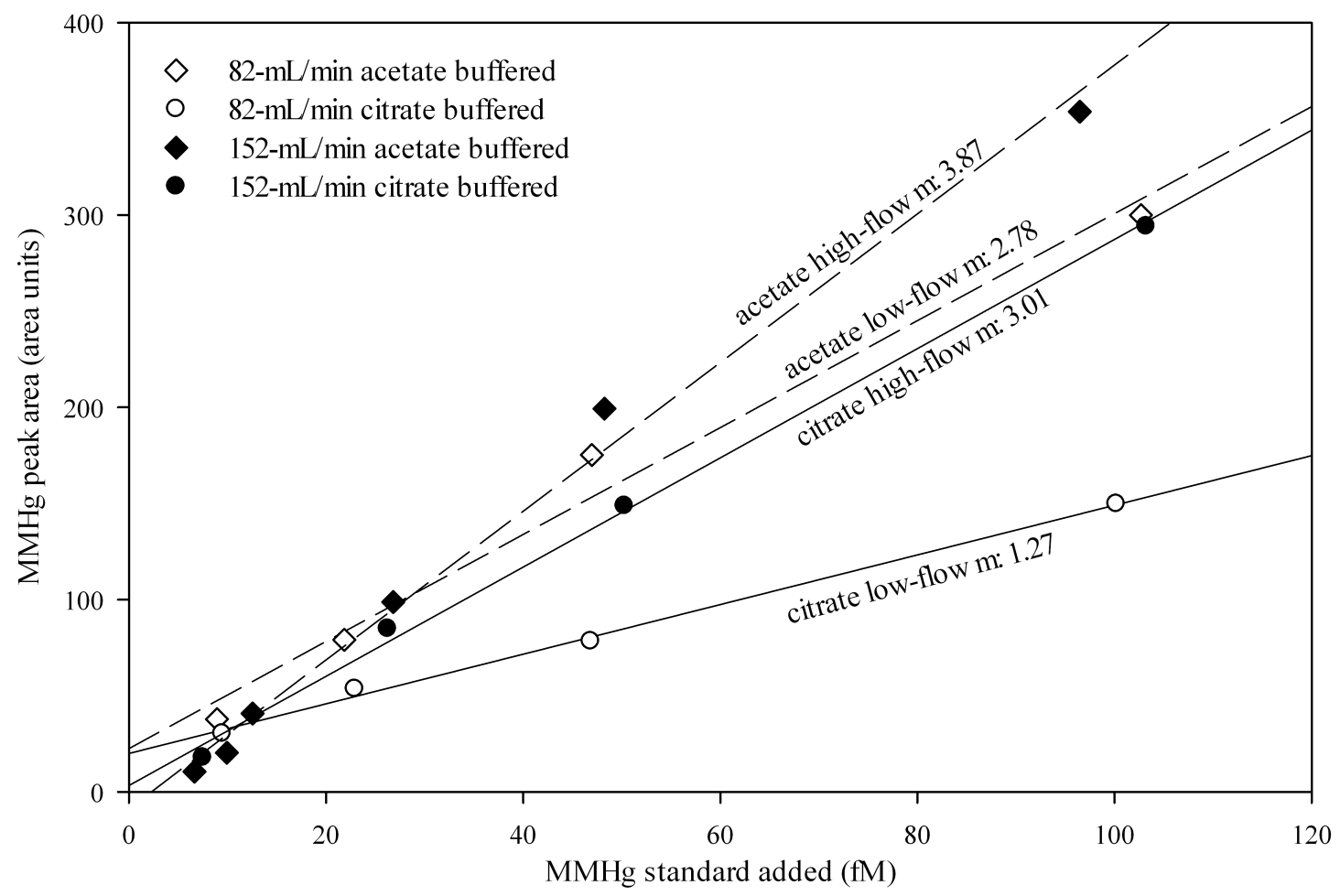


Figure 3: Percent recovery of added MMHg standard (0.02-1ppt) equilibrated for 24 hours in filtered Vineyard Sound seawater measured by direct ethylation. In the absence of ascorbic acid (left) the recovery of MMHg is generally less than $40 \%$. Purging of filtered seawater prior to MMHg standard addition (center) may increase the recovery. The addition of ascorbic acid (right) yields significantly greater recovery from seawater not purged before standard addition $(\mathrm{p}<$ $0.005)$.

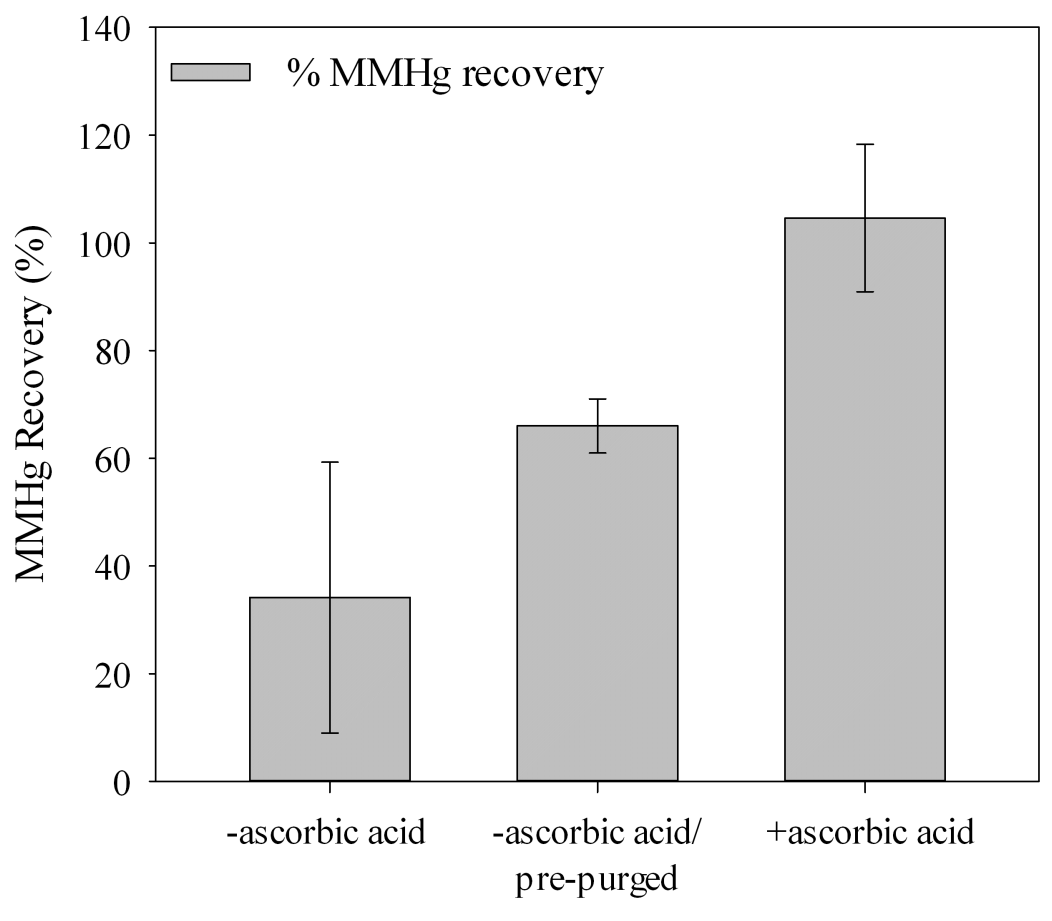


Figure 4: Representative standard curve of instrument $\mathrm{MMHg}$ peak area versus added $\mathrm{MMHg}$ standard (15-250 fM) from 180-mLvolumes used to quantify seawater samples. Four replicates of $25 \mathrm{fM}$ are shown and are used to calculate standard variability. Inset: MMHg blank in reagents is calculated from the slope of the linear fit obtained from the instrument MMHg peak area versus stepwise increases in reagent concentrations




Figure 5: Recovery of added MMHg standard from de-ionized water (MQ) and filtered Vineyard Sound seawater (FSW) using ascorbic acid assisted direct ethylation. Instrument MMHg peak areas are corrected for reagent blanks measuring from each of the corresponding sample matrices. The addition of ascorbic acid to the FSW prevents the need for correcting for low ethylation efficiency from direct ethylation of seawater. Although open-ocean concentrations of $\mathrm{MMHg}$ are generally well below $1000 \mathrm{fM}$, standards show similar recovery from FSW and MQ beyond the range required for determining ocean $\mathrm{MMHg}$ concentrations.

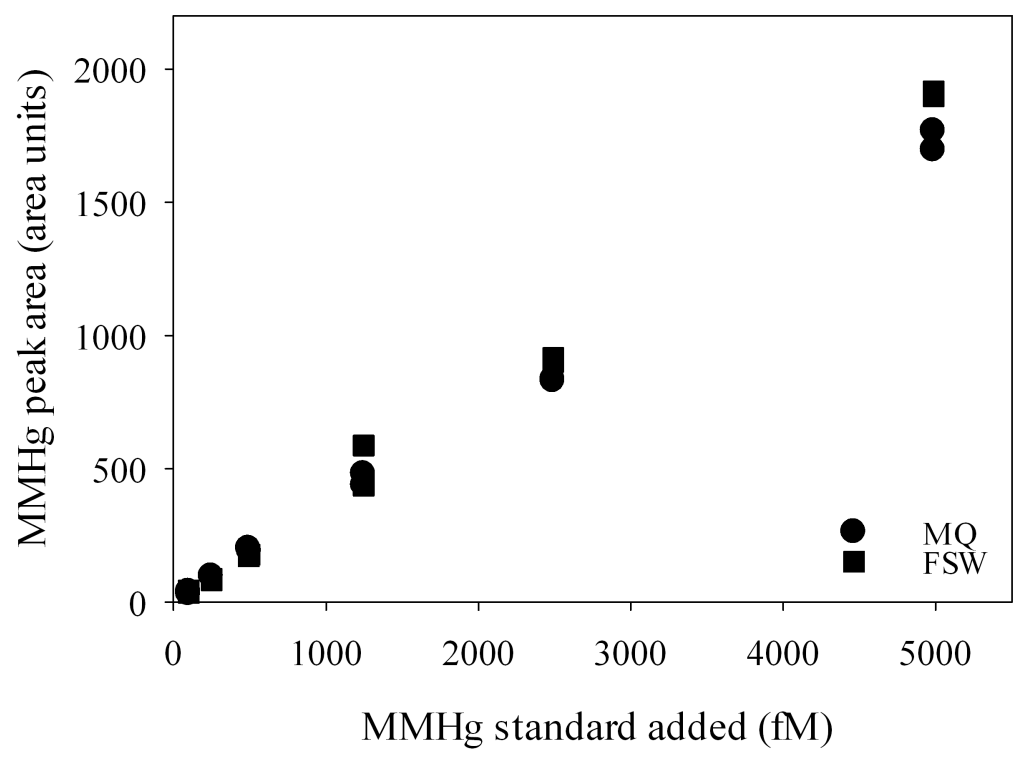




\section{Tables and Table Legends}

Table 1: Reagents optimized for $30-\mathrm{mL}$ and $180-\mathrm{mL}$ sample volumes. Acetate buffer (2M) was used initially as outlined in USEPA Standard Method 1630. However, citrate buffer (1M) replaced acetate buffer for low concentration seawater samples to eliminate ingrowth of $\mathrm{MMHg}$ in samples upon repeated analytical runs of the same samples.

\begin{tabular}{|l|l|l|l|l|l|}
\hline $\begin{array}{l}\text { Final Sample } \\
\text { Volume }(\mathrm{mL})\end{array}$ & $\begin{array}{l}\text { Detection } \\
\text { Limit }(\mathrm{fM})\end{array}$ & $\begin{array}{l}\text { Ascorbic Acid } \\
(\mu \mathrm{L})\end{array}$ & $\begin{array}{l}\text { 2M Acetate } \\
\text { Buffer }(\mathrm{mL})\end{array}$ & $\begin{array}{l}\text { 1M Citrate } \\
\text { Buffer }(\mathrm{mL})\end{array}$ & NaTEB $(\mu \mathrm{L})$ \\
\hline 30 & 100 & 50 & 0.225 & 0.55 & 30 \\
\hline 180 & 5 & 300 & 1.0 & 2.0 & 85 \\
\hline
\end{tabular}




\title{
Chapter 3 \\ Methylation and Demethylation of Mercury in the Sargasso Sea
}

\begin{abstract}
We measured potential rates of mercury methylation and demethylation at the Bermuda Atlantic Time-series Study (BATS) site during the spring bloom and fall within a single calendar year. Bottle incubations of filtered and unfiltered seawater reveal active methylation and demethylation within the chlorophyll maximum and the oxygen minimum zone at the BATS site, resulting in specific methylation rate constant $\left(\mathrm{k}_{\mathrm{m}}\right)$ values between 4.58-5.17 $\left(\% \mathrm{~d}^{-1}\right)$ in April and $0.22-0.61\left(\% \mathrm{~d}^{-1}\right)$ in October. We observed no clear enhancement of methylation in unfiltered waters during 24-hour incubations in April compared to filtered controls. Higher resolution measurements over the 24-hour incubation period in October revealed highly dynamic methylation and demethylation despite small net changes over the total incubation period. In waters from the chlorophyll maximum depth, concentrations of methylated mercury $(\mathrm{MeHg})$ produced from inorganic mercury $(\mathrm{Hg}(\mathrm{II}))$ spike additions reached a maximum within 4 hours and decreased throughout the remainder of the incubation period. The transition from net methylation to net demethylation was enhanced by the presence of particles. In contrast, unfiltered waters from the oxygen minimum depth showed continual methylation over the course of 24-hour incubations.

Demethylation measured during April show enhanced demethylation in unfiltered water compared to filtered water. Overall rates were comparable to those measured in marine Arctic and Mediterranean waters. Demethylation rates were enhanced within the oxygen minimum region. However, we could not make quantitative comparisons of demethylation rates between April and October because of rapid demethylation of the monomethylmercury (MMHg) spike that occurred at the beginning of the October incubation.

These results show that methylation does take place in oligotrophic marine waters despite low standing concentrations of methylated mercury species. In addition, methylated mercury concentrations in marine waters may be largely controlled by rates of demethylation, rather than methylation in the open-ocean water column.
\end{abstract}




\section{Introduction}

Despite the importance of marine fish for human consumption [Sunderland, 2007] and the potential health risks posed by exposure to high concentrations of mercury ( $\mathrm{Hg})$ [Clarkson and Magos, 2006], little is known about the potential for $\mathrm{Hg}$ methylation in the marine water column. This is important to explore as monomethlymercury (MMHg) is the chemical species of $\mathrm{Hg}$ that bioaccumulates in marine food webs. Measurements of methylation within the marine water column have been performed in a limited number of marine sites, largely limited to coastal and semi-coastal locations within the Canadian Arctic Archipelago [Lehnherr et al, 2011] and the Mediterranean Sea [Monperrus et al, 2007]. Experiments at these sites have found significant production of MMHg in seawater and have suggested that observed methylation may be driven by microbial processes [Monperrus et al, 2007].

The impact of changing anthropogenic emissions of $\mathrm{Hg}$ on ocean $\mathrm{Hg}$ distributions and resulting bioaccumulation is the central question for potential mitigation strategies [Krabbenhoft and Sunderland, 2013]. A decreasing trend in total Hg (THg) concentrations has been suggested for North Atlantic water due to decreases in European and North American Hg emissions [Mason et al, 2012]. Recent compilations of atmospheric and surface ocean $\mathrm{Hg}$ measurements and model results have proposed the net evasion of anthropogenic mercury from the North Atlantic surface ocean [Sørensen, et al 2010, Sørensen et al, 2012], which might enhance surface water depletion

of $\mathrm{THg}$. However, few water column measurements of $\mathrm{Hg}$ species concentrations have been made repeatedly at open ocean sites in the North Atlantic over the past 3 decades. In addition early measurements of $\mathrm{Hg}$ may be subject to contamination [e. g. Gill and Mason (2005) as shown in Mason et al, 2012] and recent intercalibration for total $\mathrm{Hg}$ ( $\mathrm{THg}$ ) determination show that modern analyses have low consistency, $40 \%$, among participating laboratories [Lamborg et al, 2012]. Despite the difficulty in determining temporal trends in $\mathrm{THg}$ distributions, concentrations of the bioaccumulating $\mathrm{MMHg}$ in the North Atlantic depend on the dynamic cycling of $\mathrm{Hg}$ species within the water column. At any depth, measured MMHg concentrations can potentially result from $\mathrm{Hg}(\mathrm{II})$ substrate delivery via sinking particulate matter to zones of net remineralization, advective transport from sedimentary sources, in situ production within the water column, and loss processes such as demethylation and particle scavenging [reviewed by Mason et al, 2012]. In North Atlantic waters, $\mathrm{MMHg}$ composes a small percentage, generally $<10 \%$, of $\mathrm{THg}$ and is often decoupled from THg concentrations [Bowman et al, 2013]. As a result, in order to determine whether North Atlantic MMHg concentrations are decreasing with lowered regional emissions, 
and, as a result, whether MMHg available for bioaccumulation in marine food webs is changing over time, it is important to determine the controls on methylation in these marine waters.

Early studies of $\mathrm{MMHg}$ distributions and stability in marine waters proposed that $\mathrm{MMHg}$ is produced from the breakdown dimethylmercury $(\mathrm{DMHg})$ that is directly formed from microbial methylation of $\mathrm{Hg}(\mathrm{II})$ [Mason and Fitzgerald, 1993]. Subsequent measurements of dissolved $\mathrm{Hg}$ species in surface and intermediate waters have observed correlations between concentrations of methylated $\mathrm{Hg}$ species (DMHg and/or MMHg) and rates of oxygen utilization [Sunderland, et al, 2009; Cossa et al, 2011]. As a result of these observations, methylation rates are thought to be limited by the rate of $\mathrm{Hg}(\mathrm{II})$ substrate delivery from remineralization of sinking organic matter [Sunderland et al, 2009]. Potential $\mathrm{Hg}$ methylation and demethylation rates from the sites in the Mediterranean and the Canadian Arctic Archipelago have demonstrated the complexity of $\mathrm{MMHg}$ and $\mathrm{DMHg}$ formation and degradation in marine waters. Methylation rates appear significant not only in waters of net remineralization, but also in euphotic waters where methylated Hg concentrations are typically lower [Monperrus et al, 2007; Lehnherr et al, 2011]. In these upper water column depths, methylated $\mathrm{Hg}$ species may be controlled by demethylation processes that are absent deeper in the water column, such as photodemethylation [Whalin et al, 2007; Monperrus et al, 2007; Lehnherr et al, 2011].

However, methylation rates in surface waters may also be influenced by primary productivity. Coastal waters of the Mediterranean Sea yield both higher rates of methylation than more open-ocean waters as well as larger seasonal signals, with enhanced methylation during the spring bloom and lower methylation in the late fall [Monperrus et al, 2007]. Demethylation rates measured at the same locations are more consistent between coastal and more open-ocean sites but show a contrasting seasonal signal, with enhancement of demethylation during late fall months only in more open-ocean waters [Monperrus et al, 2007]. Methylated $\mathrm{Hg}$ concentrations result from the net balance between methylation and demethylation. Thus, seasonal differences between these two processes may result in seasonal variations in dissolved concentrations of $\mathrm{MMHg}$ and its availability for uptake and eventual transfer to marine fish.

We measured potential methylation and demethylation rates at the Bermuda Atlantic Time-series Study (BATS) site during the spring bloom and in the fall in order to assess seasonal changes in methylation and demethylation potential within oligotrophic marine waters. We compared potential methylation and demethylation rates at the base of the euphotic zone, where phytoplankton abundance is highest but methylated $\mathrm{Hg}$ concentrations are generally low, to those 
at the depth of highest net organic matter remineralization, where marine methylated $\mathrm{Hg}$ concentrations are typically greatest. By comparing unfiltered waters to $0.2 \mu \mathrm{m}$ filtered controls, we aimed to determine the potential for methylation and demethylation driven by heterotrophic bacteria from dark incubations.

\section{Materials and Methods}

Incubations were performed on board the $R / V$ Atlantic Explorer with water collected from the BATS site $\left(31^{\circ} 40^{\prime} \mathrm{N}, 64^{\circ} 10^{\prime} \mathrm{W}\right)$ between 25-27 April 2012 and 7-13 October 2012. During the April 2012 cruise two sets of incubations were performed. Water for one set was collected from acid-cleaned GO-Flo bottles deployed on Kevlar line and triggered with Teflon messengers. For the second set of incubations water was collected from Niskin bottles deployed on the ship's rosette. In order to avoid contamination due to sampling water through which the rosette and line had previously travelled, water collection was triggered during the downcast. Concentrations of MMHg of water collected from Niskins and GO-Flo bottles were within 5\% of each other, suggesting little contamination from the Niskin bottles. As a result, water for October incubations was collected from the rosette Niskin bottles.

Water was decanted from all bottles within a "bubble" constructed from plastic sheeting and filled with HEPA-filtered air under positive pressure provided by an AirClean 3000 flow bench. Water from GO-Flo bottles or Niskin bottles was decanted into acid-cleaned 9-L polycarbonate carboys (Nalgene). Bottles for filtered incubations were filled with water pumped through a $0.2 \mu \mathrm{m}$ capsule filter ( $47 \mathrm{~mm}$, Supor polycarbonate membrane, Pall Corporation) through acid-washed Teflon tubing linked by a short piece of silicon tubing (Masterflex 25) by a peristaltic pump (Masterflex). Bottles for unfiltered incubations were filled by pumping water though the tubing without the capsule filter in line.

Isotopically enriched ${ }^{198} \mathrm{MMHg}$ and ${ }^{202} \mathrm{Hg}(\mathrm{II})$ spikes were pre-equilibrated at $4{ }^{\circ} \mathrm{C}$ with natural ligands in $0.2 \mu \mathrm{m}$ filtered seawater for 24 hours prior to addition to incubation bottles. Seawater for pre-equilibration was collected from the BATS site in casts prior to those for incubation water and filtered through the capsule filter as noted above. The equilibrated spikes were added to triplicate bottles for each time point using dedicated gas-tight syringes (Hamilton).

During the April incubations, spike concentrations were: $700 \mathrm{fM}{ }^{198} \mathrm{MMHg}$ and $2200 \mathrm{fM}$

${ }^{202} \mathrm{Hg}$ (II). Bottles were fixed to $0.5 \%$ (final) with $\mathrm{H}_{2} \mathrm{SO}_{4}$ (conc., J. T. Baker) after addition of $\mathrm{Hg}$ 
spikes for the t0 time point and after 24-hour incubations in the dark in a cooler at $20^{\circ} \mathrm{C}$ for the t24 time point.

During the October incubations, added spike concentrations were increased to: $1346 \mathrm{fM}$ ${ }^{198} \mathrm{MMHg}$ and $7000 \mathrm{fM}{ }^{202} \mathrm{Hg}(\mathrm{II})$. In order to prevent rapid methylation and demethylation observed in the April incubations, t0 bottles were fixed to $0.5 \%$ (final) with $\mathrm{H}_{2} \mathrm{SO}_{4}$ prior to addition of $\mathrm{Hg}$ isotope spikes. Bottles were incubated for $0,0.5,2,4,8,12$, and 24 hours in the dark in a cooler at $20^{\circ} \mathrm{C}$ after which they were fixed to $0.5 \%$ (final) with $\mathrm{H}_{2} \mathrm{SO}_{4}$.

$\mathrm{Hg}$ species-specific isotope abundances were analyzed in the WHOI Plasma Facility. The cell vent of a Tekran 2700 Automated Methyl Mercury Analyzer was linked via a polyethylene yconnector to the sample Ar gas of a Thermo Element 2. MMHg was derivitized to methylethylHg using ascorbic-acid assisted direct ethylation [Munson - this work, Chapter 2]. Acidified bottles were buffered to $0.01 \%$ with citric acid buffer ( $1 \mathrm{M}$, Fisher, $\mathrm{pH} 5)$ and neutralized to $\mathrm{pH} 5$ with $\mathrm{KOH}(45 \%$, Fisher) prior to the addition of ice-cold $1 \%$ sodium tetraethylborate $(2 \% \mathrm{KOH}$, Fisher). Ascorbic acid (300 $\mu \mathrm{L}$ of $2.5 \%$, Fisher) was added to ensure full extraction of MMHg. All reagents were prepared in de-ionized water $(>18 \mathrm{M} \Omega-\mathrm{cm})$. Samples processing was performed within a class 100 -grade clean room at WHOI and were transported to the plasma lab for analysis.

After at least 20-min reaction time for ethylation, the $\mathrm{MeHg}(\mathrm{DMHg}+\mathrm{MMHg})$ in the incubation bottles was quantified as MMHg by GC separation prior to pyrolysis to $\mathrm{Hg}(0)$ with the Tekran 2700. All $7 \mathrm{Hg}$ isotopes were quantified in the resulting $\mathrm{Hg}(0), \mathrm{MMHg}$ (as methylethylHg), and $\mathrm{Hg}(\mathrm{II})$ (as diethylHg) peaks using the Thermo Element 2.

Methylation and demethylation were determined from changes in the isotopic composition of the $\mathrm{MMHg}$ peak using a linear matrix approach using ${ }^{200} \mathrm{Hg}$ as the tracer of ambient Hg [Hintelmann and Ogrinc, 2003; in detail Munson — this work, Appendix I]. The results of these calculations distinguished between ambient $\mathrm{Me}^{200} \mathrm{Hg}, \mathrm{MM}^{198} \mathrm{Hg}$ remaining from the $\mathrm{MM}^{198} \mathrm{Hg}$ spike, and $\mathrm{Me}^{202} \mathrm{Hg}$ produced from the ${ }^{202} \mathrm{Hg}(\mathrm{II})$ spike for each sample.

Determinations of $\mathrm{MM}^{198} \mathrm{Hg}$ lost and $\mathrm{Me}^{202} \mathrm{Hg}$ produced in at each time point, including t0, were made by comparing the ratios of $\mathrm{MM}^{198} \mathrm{Hg}$ and $\mathrm{Me}^{202} \mathrm{Hg}$ to the reference isotope ${ }^{200} \mathrm{Hg}$ observed in the measured methylethyl $\mathrm{Hg}$ peak to the ratios in the equilibrated spike [Hintelmann and Evans, 1997].

Potential methylation rate constants $\left(\mathrm{k}_{\mathrm{m}}\right)$ were measured in a similar manner to those of Lehnherr et al, 2011 as the change in $\mathrm{MM}^{202} \mathrm{Hg}$ (II) produced relative to available ${ }^{202} \mathrm{Hg}$ (II) 
substrate divided by the incubation time. However, unlike Lehnherr et al, 2011, we did not assume a general loss of ${ }^{202} \mathrm{Hg}$ (II) substrate over time. Instead, we used the observed response in the diethylHg peak of the Tekran 2700 to track the change of ${ }^{202} \mathrm{Hg}$ (II) substrate for each incubation time point. This approach is validated by the linear response to additions of $\mathrm{Hg}$ (II) standards in the diethylmercury peak (Figure 1). Although we did not determine ethylation efficiencies for $\mathrm{Hg}$ (II) conversion to diethylHg, the linear response of the diethylHg to added $\mathrm{Hg}(\mathrm{II})$ allowed us to approximate available ${ }^{202} \mathrm{Hg}(\mathrm{II})$ in each sample bottle as the ${ }^{202} \mathrm{Hg}$ spike component of the diethylHg peak quantified by CVAFS-GC-ICPMS. Values for the ${ }^{202} \mathrm{Hg}$ spike component were calculated from the isotopic composition of the chromatographically separated diethylHg peaks using a similar linear matrix approach as was used to trace $\mathrm{MM}^{198} \mathrm{Hg}$ and $\mathrm{Me}^{202} \mathrm{Hg}$ in the methylethylHg peak [Munson - this work, Appendix I]. Potential demethylation rate constants $\left(k_{d}\right)$ were calculated from the slope of the linear best fit line of $\ln \left(\mathrm{MM}^{198} \mathrm{Hg}\right) \mathrm{vs}$. time.

The $\mathrm{k}_{\mathrm{m}}$ values presented in this work represent the combined production of methylated $\mathrm{Hg}$ species from $\mathrm{Hg}(\mathrm{II})$. Thus, our reported $\mathrm{k}_{\mathrm{m}}$ values do not differentiate between different mechanisms of $\mathrm{MeHg}$ production measured by Lehnherr et al, 2011. No distinction was made between the production of MMHg from $\mathrm{Hg}(\mathrm{II})$, the production of $\mathrm{DMHg}$ from $\mathrm{Hg}(\mathrm{II})$, and the production of DMHg from MMHg. Instead, the acid preservation of samples produced a combined measurement of methylated $\mathrm{Hg}([\mathrm{DMHg}]+[\mathrm{MMHg}])$ at each time point. As a result, the presented $\mathrm{k}_{\mathrm{m}}$ values represent the overall conversion of $\mathrm{Hg}(\mathrm{II})$ to either $\mathrm{DMHg}$ or $\mathrm{MMHg}$, or varying relative proportions of the two species.

\section{Results}

\section{Potential Methylation Rates}

Previous measurements of potential methylation rates have observed "instantaneous" methylation within $\sim 30$ minutes of adding enriched $\mathrm{Hg}$ (II) to seawater incubations [Lehnherr et al, 2011]. Consistent with these observations, we observed significant methylation in t0 sample bottles that occurred within the $\sim 2$ hours that elapsed between ${ }^{202} \mathrm{Hg}(\mathrm{II})$ spike addition and sample preservation with acid during the April incubation experiments (black bars, Figure 2). This pre-t0 methylation was indicated by the difference in the isotopic composition of the produced $\mathrm{MeHg}$ relative to the composition of added $\mathrm{Hg}$ (II) substrate in the equilibrated spike. Although rapid methylation has been attributed to abiotic mechanisms or methylation by inactive 
cells [Lehnherr et al, 2011], incubations of cultured sulfate- and iron-reducing bacteria have demonstrated both a time-lag of $\sim 10$ min between $\mathrm{Hg}(\mathrm{II})$ addition and $\mathrm{MMHg}$ production [Schaefer et al, 2011] and immediate methylation of $\mathrm{Hg}$ (II) substrate with $\sim 1$ min sampling resolution [Graham et al, 2012]. The reasons for such inconsistencies are unknown, but may be due to differences in experimental conditions that influence $\mathrm{Hg}(\mathrm{II})$ substrate uptake, including $\mathrm{Hg}(\mathrm{II})$-ligand interactions and cell density [Graham et al, 2012]. Regardless of the cause, the 2 hour time period between $\mathrm{Hg}(\mathrm{II})$ spike addition and t0 sample preservation during the April incubations likely provided sufficient time for a wide range of potential methylation pathways, including intracellular methylation by microbes, extracellular processes, or abiotic transformations. As a result, we define "initial" methylation as methylation observed in t0 samples rather than "instantaneous" methylation due to our inability to determine the exact pathway and time scale of the observed methylation.

During the April cruise, initial methylation was sufficient to account for all methylation observed over the 24-hour incubation, ranging from $5.62-7.09 \%$ of the available ${ }^{202} \mathrm{Hg}$ (II) substrate for all samples (Figure 2). During the October cruise, t0 samples were fixed with acid prior to addition of the ${ }^{202} \mathrm{Hg}$ (II) spike in order to limit initial methylation to the timescale of ${ }^{202} \mathrm{Hg}$ (II) spike mixing in the sample bottle, and thus more accurately represent "instantaneous" methylation. These t0 samples produced less initial methylation than seen in April, ranging between $0.03-0.27 \%$ of available ${ }^{202} \mathrm{Hg}(\mathrm{II})$, as well as a varied contribution of initial methylation to the total methylation after 24 hours (Figure 3). However, subsequent methylation in the 24hour incubation period was significantly lower in October than April (Figures 2 and 3). Therefore, we cannot determine to what extent the high initial methylation observed in April was due to truly "instantaneous" methylation versus methylation over the 2 hour experiment set up before t0 sample preservation.

Perhaps due to the magnitude of initial methylation, values of $\mathrm{k}_{\mathrm{m}}$ calculated from the methylation of ${ }^{202} \mathrm{Hg}$ (II) over the 24-hour incubation period measured during the April cruise showed no significant difference by depth or between filtered and unfiltered water (Figure 2, Table 3). In contrast, during the October cruise, $k_{m}$ values reflect the continued production of $\mathrm{Me}^{202} \mathrm{Hg}$ within the 24-hour incubation (Figure 3, Table 3).

More frequent sampling over the 24-hour incubation period during the October cruise revealed highly dynamic changes in methylation rates within the 24-hour incubation. Maximum percentages of $\mathrm{Me}^{202} \mathrm{Hg}$ produced from available ${ }^{202} \mathrm{Hg}$ (II) were reached after 4 hours of 
incubation in both filtered and unfiltered water collected from the chlorophyll maximum depth ( $0.2 \mu \mathrm{m}: 0.47 \pm 0.00 \%$; unfiltered: $0.67 \pm 0.06 \%$; Figure 3). This newly formed $\mathrm{Me}^{202} \mathrm{Hg}$ was lost to subsequent demethylation over the remainder of the incubation period, with enhanced demethylation in unfiltered water compared to filtered water (Figure 3).

In water collected from the oxygen minimum depth, initial methylation was similar between filtered and unfiltered water $(0.2 \mu \mathrm{m}: 0.27 \pm 0.01 \%$; unfiltered: $0.27 \pm 0.04 \%)$. Indications of rapid methylation and subsequent demethylation in unfiltered is indicated by the maximum in $\mathrm{Me}^{202} \mathrm{Hg}$ at 0.5 hours that is rapidly lost (Figure 3). However, a more robust signal appears to be the gradual increase in $\mathrm{Me}^{202} \mathrm{Hg}$ produced over the course of the 24-hour incubation (Figure 3). In contrast to the influence of particles on methylated $\mathrm{Hg}$ in waters from the chlorophyll maximum, where $\mathrm{Me}^{202} \mathrm{Hg}$ production and demethylation both appeared to be enhanced within the incubation period, the presence of particles in the low oxygen waters appear to enhance continual production of $\mathrm{Me}^{202} \mathrm{Hg}$ and yield the highest values of $\mathrm{k}_{\mathrm{m}}$ measured in October (Table 2).

\section{Potential Demethylation Rates}

During the spring bloom, potential demethylation rates were higher in unfiltered water $\left(0.32 \mathrm{~d}^{-1}\right)$ compared to $0.2 \mu \mathrm{m}$-filtered water $\left(0.05 \mathrm{~d}^{-1}\right)$ at the chlorophyll maximum depth (Table 3 ). In contrast, values of $\mathrm{k}_{\mathrm{d}}$ measured at the oxygen minimum depth were similar between filtered $\left(0.39 \mathrm{~d}^{-1}\right)$ and unfiltered $\left(0.44 \mathrm{~d}^{-1}\right)$ water (Table 3$)$.

The reported values for $k_{d}$ from the April experiments were calculated from the net loss of $\mathrm{MM}^{198} \mathrm{Hg}$ from t0 to $\mathrm{t} 24$-hours. However, rapid demethylation was observed in all bottles, and t0 $\mathrm{MM}^{198} \mathrm{Hg}$ concentrations ranged from $177 \mathrm{fM}$ in water from the chorophyll maximum depth to between 214-218 fM in water from the oxygen minimum depth. These values represent $25-31 \%$ of the $700 \mathrm{fM}$ concentration of each bottle after $\mathrm{MM}^{198} \mathrm{Hg}$ spike addition, suggesting that although measurable over the 24 hour incubation period, demethylation was occurred quickly after addition of the enriched $\mathrm{MM}^{198} \mathrm{Hg}$ spike.

Demethylation was more difficult to quantify in the October incubations. Despite nearly doubling the initial concentration of $\mathrm{MM}^{198} \mathrm{Hg}$ spike in each bottle (from 2200 to $7000 \mathrm{fM}$ final concentration) rapid demethylation was rapid in waters from both the chlorophyll maximum and oxygen minimum depths. Concentrations of $\mathrm{MM}^{198} \mathrm{Hg}$ in $\mathrm{t} 0$ bottles ranged between 41-44 fM in water from the chlorophyll maximum depth and only 11-23 fM in water from the oxygen 
minimum depth, or $1-3 \%$ of the $1346 \mathrm{fM}$ added $\mathrm{MM}^{198} \mathrm{Hg}$ spike. The values for $\mathrm{k}_{\mathrm{d}}$ shown in Table 3 from October incubations therefore are not directly comparable to those measured in April because they are not integrated over the entire incubation period. Instead, they represent demethylation from secondary methylation of newly produced $\mathrm{MM}^{198} \mathrm{Hg}$ that may have a distinct $\mathrm{k}_{\mathrm{d}}$ value compared to that of demethylation of $\mathrm{MM}^{198} \mathrm{Hg}$ from the pre-equilibrated spike.

The rapid demethylation of $\mathrm{MM}^{198} \mathrm{Hg}$ in the October incubations presumably produced

${ }^{198} \mathrm{Hg}(\mathrm{II})$ (as well as ${ }^{198} \mathrm{Hg}(0)$ ) that could serve as a substrate for methylation, which may account for the slight increases observed in measured $\mathrm{MM}^{198} \mathrm{Hg}$ observed over time, most notably in water from the oxygen minimum depth (Figure 4). However, the substantial variations in measured $\mathrm{MM}^{198} \mathrm{Hg}$ between bottles, resulted in non-significant differences between time points (Figure 4).

\section{Discussion}

In these incubations of marine waters, environmentally relevant concentrations of added $\mathrm{MM}^{198} \mathrm{Hg}$ and ${ }^{202} \mathrm{Hg}(\mathrm{II})$ were pre-equilibrated with natural ligands in filtered seawater prior to addition to incubation bottles in order to more closely mimic conditions by which methylation and demethylation occur in situ. Although we quantify conversion between $\mathrm{Hg}$ (II) and methylated $\mathrm{Hg}$ from spike additions, large values of initial methylation in $0.2 \mu \mathrm{m}$ filtered samples suggests that methylation potential remains heavily influenced by interactions between $\mathrm{Hg}$ (II) and pools of natural ligands in seawater. The initial methylation observed in $0.2 \mu \mathrm{m}$ filtered seawater samples was not observed in the pre-equilibrated spike solutions, which differed from incubation water primarily in the relative concentrations of $\mathrm{Hg}(\mathrm{II})$ to natural ligands. Assuming ligand binding sites occur at maximum concentrations of $0.3 \mathrm{nN}$ in marine waters [Lamborg et al, 2004], the ratio of $\mathrm{Hg}(\mathrm{II})$ to equilibrated ligand binding sites is 124 in the equilibrated spike and decreases to 0.007 in the incubation bottles. Ligands may therefore play an important role in influencing methylation reactions. We observed initial methylation in $0.2 \mu \mathrm{m}$ filtered water from both depths in both sets of incubations, which may indicate a role of dissolved ligands in the process.

We observed higher percentages of initial methylation in April than was found in previous measurements in Arctic waters. Lehnherr et al, 2011 observed methylation of 0.03$0.25 \%$ of added $\mathrm{Hg}(\mathrm{II})$ substrate in $\mathrm{t} 0$ bottles. We observed significantly higher initial percentages, $>5 \%$, in April incubation (Figure 1), although, as noted above, this occurred over the 
relatively long period of time between spike addition and t0 sample preservation ( 2 hours vs 30 minutes). Because Lehnherr et al, 2011 added significantly higher concentrations of $\mathrm{Hg}$ (II) substrate, $380 \mathrm{pM}$ compared to the $2.2 \mathrm{pM}$ used in our experiments, the larger percentages of methylated $\mathrm{Hg}$ observed in our April incubations represent similar total methylted $\mathrm{Hg}$ produced in Arctic waters. The methylated $\mathrm{Hg}$ produced in Arctic waters due to initial methylation represents 29-240 fmole methylated Hg [Lehnherr et al, 2011]. Despite the much larger percentages of methylated $\mathrm{Hg}$ from our April incubations, the total methylated $\mathrm{Hg}$ produced during these experiments represents $\sim 28$ fmole, similar to those observed in the Artic. In contrast, although we observed similar percentages, 0.03-0.27 \% (Figure 3), of methylayed $\mathrm{Hg}$ (II) substrate in October incubations to those of Lehnherr et al, 2011, these represent $\sim 3$ fmole methylated $\mathrm{Hg}$ because of the much lower concentrations of $\mathrm{Hg}(\mathrm{II})$ that we added.

Unlike previous reports, the initial methylation we observed in April incubations was sufficient to result in a net loss of $\mathrm{Me}^{202} \mathrm{Hg}$ over the course of 24-hour incubations (Figure 1). Lehnherr et al, noted demethylation between 12 and 24 hours of incubation of $\mathrm{MeHg}$ that was produced from isotopically enriched $\mathrm{Hg}$ (II) substrate between 0 and 12 hours at 2 sites within the Canadian Arctic Archipelago [Figure 2a, Lehnherr et al, 2011]. The net loss of $\mathrm{Me}^{202} \mathrm{Hg}$ during the 24-hour incubation period indicates not only a similar transition from net methylation to net demethylation in the Sargasso Sea as was seen in some Arctic waters but also that the time scale of this transition is faster in the North Atlantic than the Arctic. However, since methylation in the April incubations was only measured at two time points, we cannot determine whether and for how long net methylation continued beyond the $\sim 2$ hour period over which initial methylation occurred. As a result, higher temporal resolution sampling over the course of 24-hour incubations is needed for water column methylation rate measurements.

Although we observed a decreased capacity for $\mathrm{Hg}$ (II) methylation during October incubations, the higher resolution sampling during the incubation time course show that the transition from net methylation to net demethylation of $\mathrm{Me}^{202} \mathrm{Hg}$ (II) took place between 4 and 8 hours of incubation in waters from the chlorophyll maximum as well as filtered water from the oxygen minimum (Figure 3). This suggests faster cycling of $\mathrm{Hg}$ between $\mathrm{Hg}(\mathrm{II})$ and $\mathrm{MeHg}$ pools in the Sargasso Sea compared to the Arctic, despite lower productivity.

Values of $k_{d}$ measured in April from unfiltered waters are comparable to those measured in the Canadian Arctic Archipelago [Lehnherr et al, 2011], including a slight enhancement in $\mathrm{k}_{\mathrm{d}}$ in the oxygen minimum depth (Table 3 ). The large enhancement in $\mathrm{k}_{\mathrm{d}}$ in unfiltered relative to 
filtered waters from the chlorophyll maximum depth (Table 3) demonstrates the importance of particles in demethylation, perhaps due to the high abundance of phytoplankton at this depth. Photodemethylation is also a potentially important process in surface waters (0.003-0.43 $\left.\mathrm{d}^{-1}\right)$ [Whalin et al, 2007; Monperrus et al, 2007; Lehnherr et al, 2011]. Since our experiments were performed in the dark, we can only speculate as to the relative importance of photodemethylation and demethylation by particles, either abiotic or biotic in origin. However, the low concentrations of methylated Hg species observed in the upper ocean in the Sargasso Sea [Lamborg et al, 2012; Bowman et al, 2013] support photodemethylation as the dominant process in these waters.

Potential demethylation rates were more difficult to quantify during the October cruise compared to the April cruise, with time course measurements suggesting that essentially all of the added $\mathrm{MM}^{198} \mathrm{Hg}$ spike was lost immediately upon addition to bottle incubations despite remaining stable in filtered seawater during the 24-hour spike pre-equilibration. Although demethylation measured as the disappearance of isotopically enriched MMHg has been successfully measured in marine waters [Lehnherr et al, 2011], a more reliable measurement may be the monitoring of production of isotope specific $\mathrm{Hg}$ (II) formed from the breakdown of the enriched MMHg spike [Monperrus et al, 2007].

Analysis of $\mathrm{MM}^{198} \mathrm{Hg}$, especially in waters from the chlorophyll maximum depth, over the October incubation time course more closely resembles that of methylation than predicted demethylation (Figures 3, 4). The increase in $\mathrm{MM}^{198} \mathrm{Hg}$ from t0 to t2-hr for both unfiltered and filtered water as well as the subsequent decrease in $\mathrm{MM}^{198} \mathrm{Hg}$ within 8 hours of incubation (Figure 4) are similar to those observed in time course measurements of $\mathrm{Me}^{202} \mathrm{Hg}$ production from ${ }^{202} \mathrm{Hg}(\mathrm{II})$ substrate (Figure 3).

Because methylation in sedimentary systems is known to occur by bacterial processes, a significant aim of the present study was to determine whether marine Hg methylation is likewise a cellular process. In order to address this question, we compared potential methylation rates in water filtered through a $0.2 \mu \mathrm{m}$ pore size capsule filter to unfiltered water and incubated in the dark to determine the methylation potential of heterotrophic bacteria. The clearest indication of heterotrophic methylation is the sustained methylation in unfiltered waters from the oxygen minimum depth during October sampling (Figure 3).

Together these data suggest that oligotrophic marine waters have the capacity to methylate available $\mathrm{Hg}$ (II) substrate. Despite the inconsistencies in results between the 2 sets of incubations, measureable initial methylation in both filtered and unfiltered water suggests that 
although the yet unidentified compounds in marine water responsible for methyl donation to $\mathrm{Hg}$ (II) might be of biological origin, they do not require intact cells for methylation to take place. However, this $\mathrm{MeHg}$ that is rapidly produced appears to be short-lived in marine waters, especially in the presence of particles, based on the rapid transition from net methylation to net demethylation. Whether or not this $\mathrm{MeHg}$ is available for uptake and bioaccumulation is unknown but has the potential to greatly impact human health as $\mathrm{THg}$ concentrations change in marine waters.

Alternatively, the enhancement of methylation in unfiltered water relative to filtered water in the October incubations is consistent with previous assumptions that heterotrophic bacteria contribute to $\mathrm{Hg}$ methylation in oxic marine waters [Mason and Fitzgerald, 1993; Monperrus et al, 2007]. Furthermore, in low oxygen waters of the Sargasso Sea, heterotrophic bacteria appear to be able to sustain $\mathrm{MeHg}$ production over the course of 24-hour incubations and may therefore supply $\mathrm{MMHg}$ for accumulation through marine food webs.

\section{Acknowledgements}

We thank Rod Johnson, Steve Bell, Gwyn Evans, Kristen Buck, and Mike Lomas for providing ship time, assistance with water sampling, and generous use of lab space and equipment. We also thank Jane Burrows at the Bermuda Institute of Ocean Sciences and Ronni Schwartz at the Massachusetts Institute of Technology for administrative help. This research was funded by the Scurlock Fund from the Massachusetts Institute of Technology, a Graduate Research Fellowship from the National Science Foundation awarded to K. M. Munson, and grant OCE-1031271 from the National Science Foundation awarded to C. H. Lamborg and M. A. Saito.

\section{References}

Bowman, K. R., C. R. Hammerschmidt, C. H. Lamborg, and G. Swarr (2013) New insights on mercury speciation with fully resolved high-resolution profiles across a zonal section of the North Atlantic Ocean. Presentation at the Aquatic Sciences Meeting, New Orleans, LA.

Clarkson, T. W., and J. Magos (2006) The toxicology of mercury and its chemical compounds. Crit. Rev. Toxicol. 36, 609-662.

Cossa, D., L. E. Heimburger, D. Lannuzel, R. S. Rintoul, E. C. V. Bulter, A. R. Bowie, B. Averty, R. J. Watson, and T. Remenyi (2011) Mercury in the Southern Ocean. Geochim. Cosmochim. Acta 75, 4037-4052. 
Graham, A. M., A. L. Bullock, A. C. Maizel, D. A. Elias, C. C. Gilmour (2012) Detailed assessment of the kinetics of $\mathrm{Hg}$-cell association, $\mathrm{Hg}$ methylation, and methylmercury degredation in several Desulfovibrio species, Appl. Environ. Microbiol. 78, 7337-7346.

Hintelmann, H., and R. D. Evans (1997) Application of stable isotopes in environmental tracer studies - measurement of monomethylmercury $\left(\mathrm{CH}_{3} \mathrm{Hg}^{+}\right)$by isotope dilution ICP-MS and detection of species transformation, Fresenius J. Anal. Chem., 358, 378-385.

Hintelmann, H., and N. Ogrinc (2003) Determination of stable mercury isotopes by ICP/MS and their application in environmental studies, in Biogeochemistry of environmentally important trace elements, Eds: Cai, Y., and C. O. Braids, ACS Symp Ser Vol. 835, Washington, DC, p. 321-338.

Krabbenhoft, D. P., and E. M. Sunderland (2013) Global change and mercury. Science, 341, $1457-1458$

Lamborg, C. H., C. R. Hammerschmidt, G. A. Gill, R. P. Mason, and S. Gichuki (2012) An intercomparison of procedures for the determination of total mercury in seawater and recommendations regarding mercury speciation during GEOTRACES cruises, Limnol. Oceanogr.: Methods 10, 90-100.

Laurier, F. J. G., R. P. Mason, G. A. Gill, and L. Whalin (2004) Mercury distributions in the North Pacific Ocean-20 years of observations, Mar. Chem., 90, 3-19.

Lehnherr, I., V. L. St Louis, H. Hintelmann, and J. L. Kirk (2011) Metyhlation of inorganic mercury in polar marine waters, Nature Geosci. 4, 298-302.

Mason, R. P., A. L. Choi, W. F. Fitzgerald, C. R. Hammerschmidt, C. H. Lamborg, A. L. Sørensen, and E. M. Sunderland (2012) Mercury biogeochemical cycling in the ocean and policy implications, Environ. Res.,119, 101-117.

Mason, R. P., and W. F. Fitzgerald (1993) The distribution and cycling of mercury in the equatorial Pacific Ocean. Deep Sea Res. Part I 40, 1897-1924.

Monperrus, M., E. Tessier, D. Amouroux, A. Leynaert, P. Huonnic, and O. F. X. Donard (2007) Mercury methylation, demethylation and reduction rates in coastal and marine surface waters of the Mediterranean Sea, Mar. Chem., 107, 49-63.

Schaefer, J. K., S. S. Rocks, W. Zheng, L. Liang, B. Gu, and F. M. M. Morel (2011) Active transport, substrate specificity, and methylation of $\mathrm{Hg}(\mathrm{II})$ in anaerobic bacteria. Proc. Natl. Acad. Sci., 108, 8714-8719.

Sørensen, A. L., D. J. Jacobs, D. G. Streets, M. L. I. Witt, R. Ebinghaus, R. P. Mason, M. Andersson, and E. M. Sunderland (2012) Multi-decadal decline of mercury in the North Atlantic atmosphere explained by changing subsurface seawater concentrations. Geophys. Res. Lett., 39, L21810.

Sørensen, A. L., E. M. Sunderland, C. D. Holmes, D. J. Jacob, R. M. Tantosca, H. Skov, J. H. Christensen, S. H. Strode, and R. P. Mason (2010) An improved global model for air-sea 
exchange of mercury: High concentrations over the North Atlantic, Enivron. Sci. Technol., 44, 8574-8580.

Sunderland, E. M. (2007) Mercury exposure from domestic and imported estuarine and marine fish in the US seafood market. Environ. Health Perspec. 115, 235-242.

Sunderland, E. M., D. P. Krabbenhoft, J. W. Moreau, S. A. Strode, and W. M. Landing (2009) Mercury sources, distribution, and bioavailability in the North Pacific Ocean: insights from data and models. Gobal Biogeochem. Cy., 23, GB2010.

Whalin, L., E.-H. Kim, and R. P. Mason (2007) Factors influencing the oxidation, reduction, methylation and demethylation of mercury species in coastal waters. Mar. Chem., 107, 278-294. 


\section{Figures and Figure Legends}

Figure 1: Quantification of Hg(II) standard. Integrations of the diethylHg peak area from chromatographic separation of $\mathrm{Hg}$ species detected after direct ethylation with the Tekran 2700 methylmercury analyzer show a strong linear relationship with concentrations of added $\mathrm{Hg}$ (II) standard. Although ethylation efficiency for $\mathrm{Hg}(\mathrm{II})$ was not determined, the linear response suggests ethylation was consistent across a range of $\mathrm{Hg}(\mathrm{II})$ concentrations. As a result, the diethylHg peaks can be used as minimum estimates of available $\mathrm{Hg}$ (II) substrate for normalization of methylated $\mathrm{Hg}$ production.

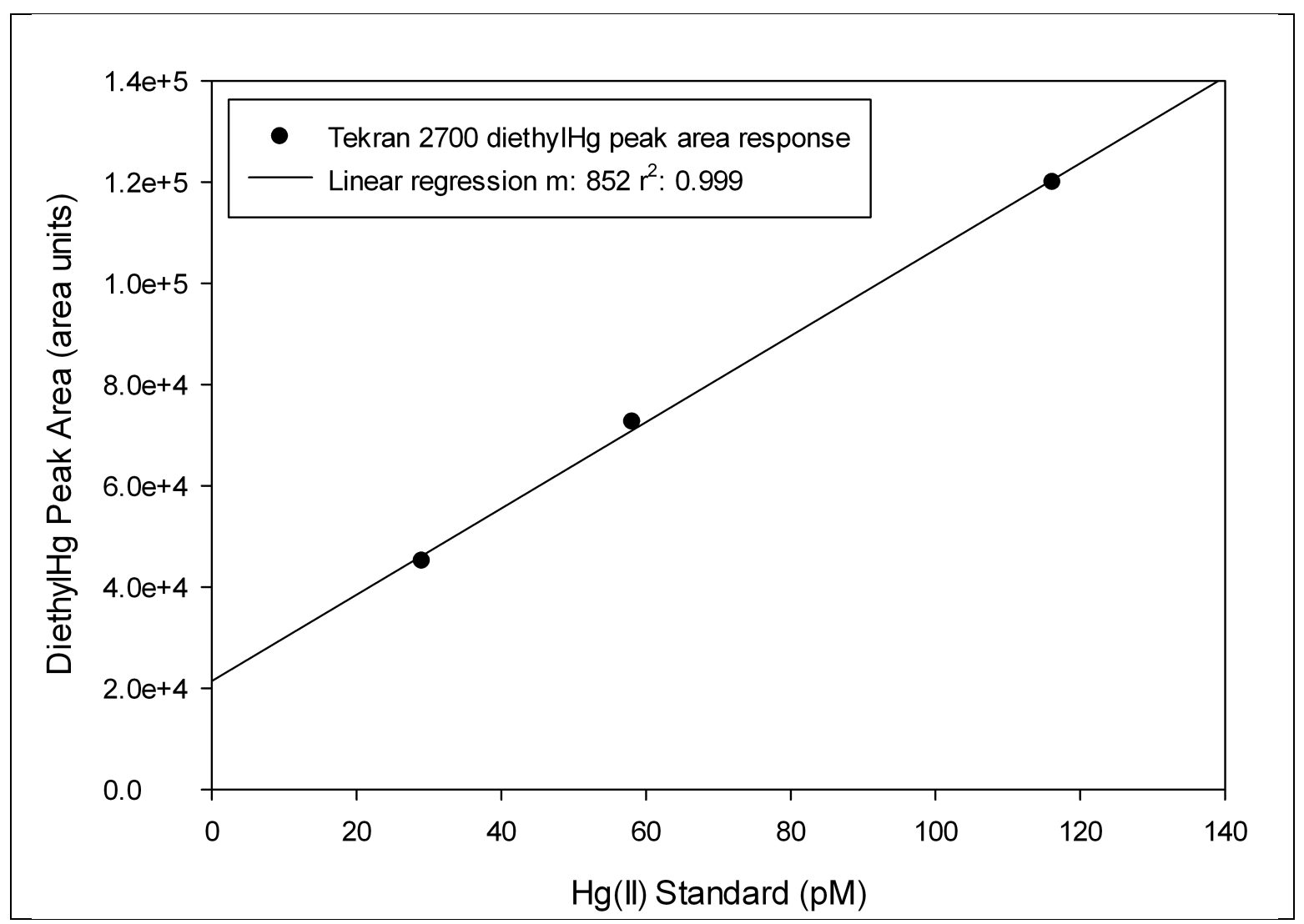


Figure 2: Methylated mercury production from the BATS site during the April spring bloom. $\mathrm{Me}^{202} \mathrm{Hg}$ produced from ${ }^{202} \mathrm{Hg}$ (II) added to water collected from the chlorophyll maximum (CMX, $105 \mathrm{~m}$ ) and oxygen minimum zone (OMZ, $800 \mathrm{~m}$ ) depths at the BATS site in April 2012. Initial methylation (black bars) was measured as a percentage of available ${ }^{202} \mathrm{Hg}$ (II) converted to $\mathrm{Me}^{202} \mathrm{Hg}$ at the t0 time point. 24-hour methylation (grey bars) was measured as the percentage of available ${ }^{202} \mathrm{Hg}(\mathrm{II})$ converted to $\mathrm{MM}^{202} \mathrm{Hg}$ after 24 hours of incubation. High initial methylation was observed in all samples and was sufficient to account for the total $\mathrm{MeHg}$ production over the course of 24-hour incubations. The error bars represent 1 standard deviation from triplicate incubation bottles.




Figure 3: Methylated mercury production during 24-hour time course in the fall. Production of $\mathrm{Me}^{202} \mathrm{Hg}$ relative to ${ }^{202} \mathrm{Hg}$ (II) substrate over a 24-hour time course incubation of water from the chlorophyll maximum (CMX, $120 \mathrm{~m}$, circles) and the oxygen minimum depth (OMZ, $800 \mathrm{~m}$, triangles) at the BATS site. Initial methylation was observed in both $0.2 \mu \mathrm{m}$ filtered (black symbols) and unfiltered (white symbols) seawater from both depths at the BATS site in October 2012. Methylation continues through the first 4 hours for $0.2 \mu \mathrm{m}$ filtered seawater at both depths before demethylation of newly synthesized $\mathrm{Me}^{202} \mathrm{Hg}$ begins. The presence of particulate matter in unfiltered waters from the chlorophyll maximum appears to enhance demethylation. In contrast, with the exception of a spike in both methylation and demethylation at $0.5 \mathrm{hr}$, the presence of particulate matter, which likely includes heterotrophic bacteria sustains methylation throughout the 24-hour incubation. The error bars represent 1 standard deviation from triplicate incubation bottles.

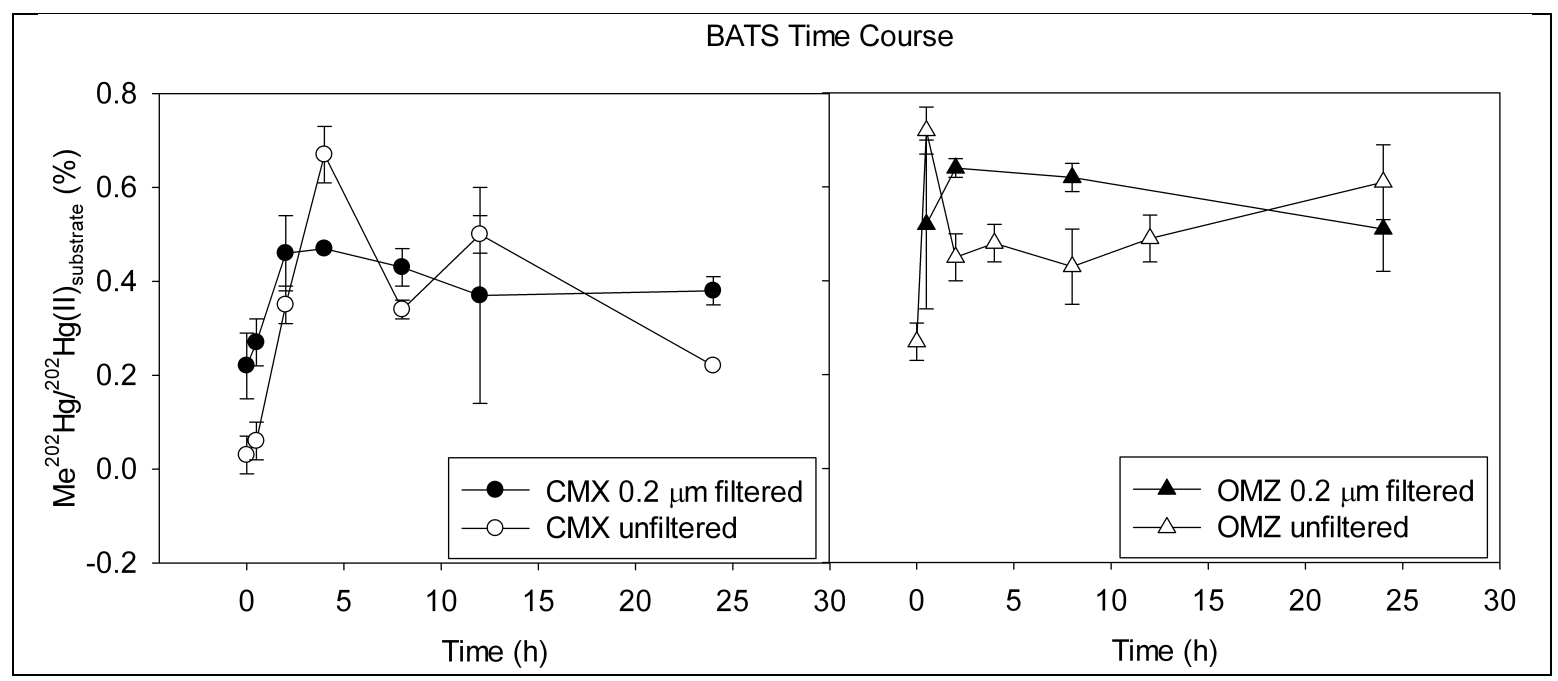


Figure 4: Methylmercury degradation during 24-hour time course incubation in the fall. Total changes in $\mathrm{MM}^{198} \mathrm{Hg}$ concentration with time in $0.2 \mathrm{um}$ filtered (black symbols) and unfiltered (white symbols) from the depths of the chlorophyll maximum and oxygen minimum at the BATS site in October 2012. Triplicate bottles show large variability that result in no significant change in waters from the chlorophyll maximum and oxygen minimum depths at the BATS site. Concentrations of $\mathrm{MM}^{198} \mathrm{Hg}$ are a small percentage, $1-3 \%$, of the total $1230 \mathrm{fM}$ added in the $\mathrm{MM}^{198} \mathrm{Hg}$ spike even in by the $\mathrm{t} 0$ time point. The ${ }^{198} \mathrm{Hg}(\mathrm{II})$ produced from this demethylation appears available for subsequent methylation between $\mathrm{t} 0$ and $\mathrm{t} 2 \mathrm{-t} \mathrm{t} \mathrm{hr}$ in waters from the chlorophyll maximum depth. Secondary demethylation, occurs after t2-t $4 \mathrm{hr}$ and indicates that methylation and demethylation cycles are dynamic within the euphotic zone of oligotrophic waters. The error bars represent 1 standard deviation from triplicate incubation bottles.

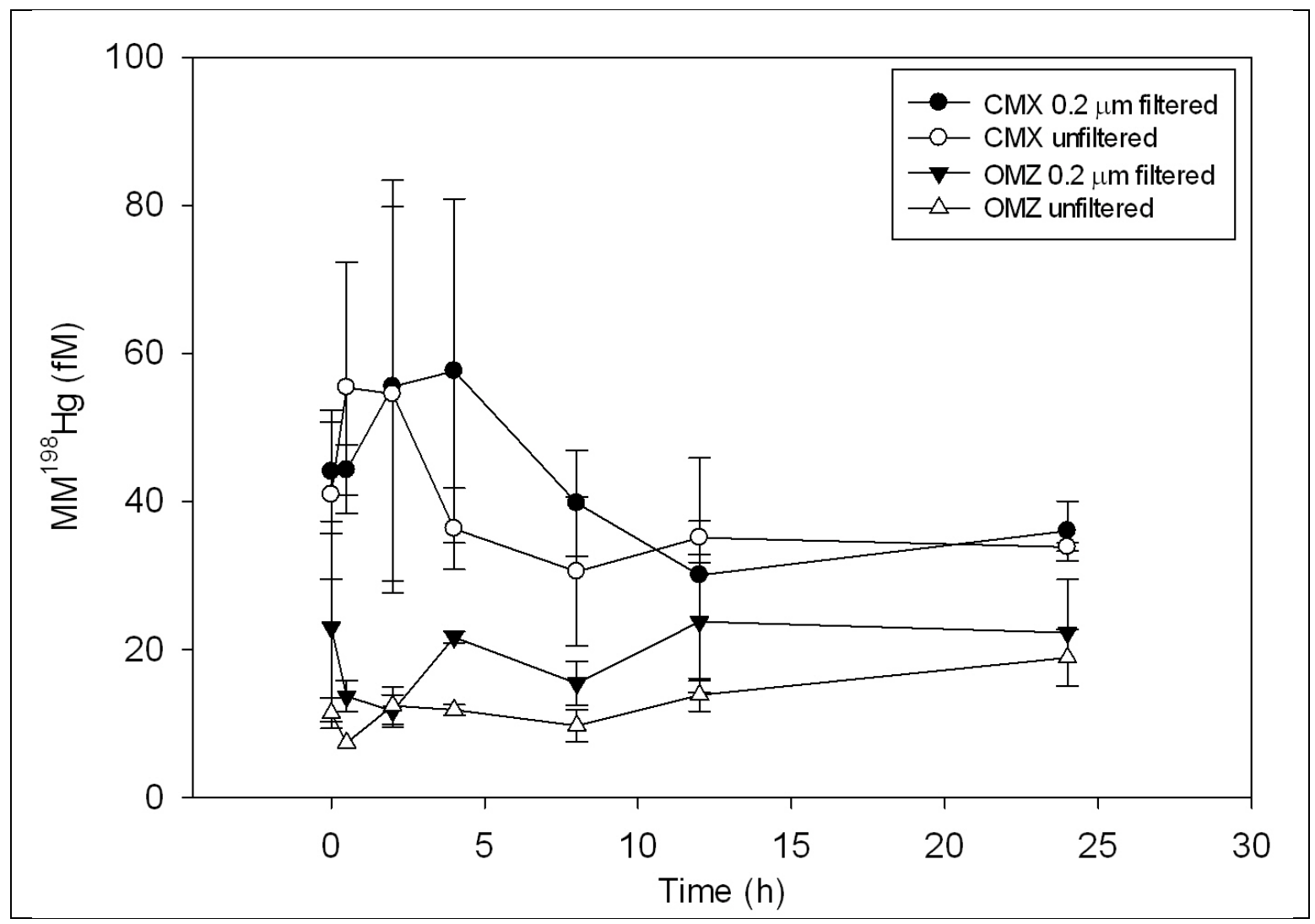


Tables and Table Legends

Table 1: Experimental details for measurements of mercury methylation and demethylation potential in waters from the BATS site.

\begin{tabular}{|c|c|c|c|c|c|c|}
\hline Cruise & Depth (m) & $\begin{array}{l}\text { MMHg } \\
\text { (fM) }\end{array}$ & $\begin{array}{l}\mathrm{Hg}(\mathrm{II}) \\
(\mathrm{pM})\end{array}$ & $\begin{array}{l}O_{2} \\
(\mu \mathrm{mol} / \mathrm{kg})\end{array}$ & $\begin{array}{l}\mathrm{MM}^{198} \mathrm{Hg} \\
\text { (fmol) }\end{array}$ & $\begin{array}{l}{ }^{202} \mathrm{Hg}(\mathrm{II}) \\
\text { (fmol) }\end{array}$ \\
\hline \multirow[t]{2}{*}{ April } & 120 & $15.8 \pm 1.6$ & 0.41 & 220 & 126 & 396 \\
\hline & 800 & $54.7 \pm 1.0$ & 0.40 & 148 & 126 & 396 \\
\hline \multirow[t]{2}{*}{ October } & 105 & $22.9 \pm 1.5$ & 2.06 & 215 & 242 & 1260 \\
\hline & 800 & $26.2 \pm 0.9$ & 1.52 & 148 & 242 & 1260 \\
\hline
\end{tabular}


Table 2: Potential demethylation rates from water collected from the BATS site. Potential demethylation rates were measured from the loss of $\mathrm{MM}^{198} \mathrm{Hg}$ in incubations of water from the chlorophyll maximum and oxygen minimum depths at the BATS site in April and October 2012. are greater in unfiltered water compared

\begin{tabular}{|l|l|l|}
\hline Sample & $\begin{array}{l}\text { April } \\
\mathbf{k}_{\mathbf{d}}\left(\mathbf{d}^{-1}\right)\end{array}$ & $\begin{array}{l}\text { October } \\
\mathbf{k}_{\mathbf{d}}\left(\mathbf{d}^{-1}\right)^{*}\end{array}$ \\
\hline CMX 0.2 $\boldsymbol{\mu m}$ filtered & $\mathbf{0 . 0 5}$ & $\mathbf{1 . 6}$ \\
\hline CMX unfiltered & 0.32 & 2.1 \\
\hline OMZ 0.2 $\boldsymbol{\mu m}$ filtered & 0.39 & $\mathbf{n d}^{* *}$ \\
\hline OMZ unfiltered & $\mathbf{0 . 4 4}$ & $\mathbf{n d}^{* *}$ \\
\hline
\end{tabular}

${ }^{*} \mathrm{k}_{\mathrm{d}}$ for October were calculated over the time period where $\mathrm{MM}^{198} \mathrm{Hg}$ decreased, between $\mathrm{t} 4 \mathrm{hr}-$ $\mathrm{t} 12 \mathrm{hr}$ for CMX $0.2 \mu \mathrm{m}$ filtered, t0.5 hr-t8 $\mathrm{hr}$ for CMX unfiltered. April $\mathrm{k}_{\mathrm{d}}$ values were calculated over 24-hours.

**nd showed no significant decrease in $\mathrm{MM}^{198} \mathrm{Hg}$ over the incubation time course 
Table 3: Potential methylation rates for water collected from the BATS site. Methylation rates $\left(\mathrm{k}_{\mathrm{m}}\right)$ calculated from total methylated mercury production over 24 hours of dark incubation in filtered and unfiltered water from the chlorophyll maximum (CMX) and oxygen minimum (OMZ) depths during the April bloom cruise and the October cruise.

\begin{tabular}{|l|l|l|}
\hline Sample & $\begin{array}{l}\text { April total } \\
\mathbf{k}_{\mathrm{m}}\left(\mathbf{x 1 0}^{-2} \mathrm{~d}^{-1}\right)\end{array}$ & $\begin{array}{l}\text { October total } \\
\mathbf{k}_{\mathrm{m}}\left(\mathbf{x 1 0}^{-2} \mathrm{~d}^{-1}\right)\end{array}$ \\
\hline CMX 0.2 $\mu \mathrm{m}$ filtered & $\mathbf{5 . 0 0} \pm \mathbf{0 . 9 0}$ & $\mathbf{0 . 3 8} \pm \mathbf{0 . 0 3}$ \\
\hline CMX unfiltered & $5.17 \pm 1.03$ & $\mathbf{0 . 2 2} \pm \mathbf{0 . 0 0}$ \\
\hline OMZ 0.2 $\mu \mathrm{m}$ filtered & $5.05 \pm 1.46$ & $\mathbf{0 . 5 1} \pm \mathbf{0 . 0 9}$ \\
\hline OMZ unfiltered & $4.58 \pm 1.87$ & $\mathbf{0 . 6 1} \pm \mathbf{0 . 0 8}$ \\
\hline
\end{tabular}




\title{
Chapter 4
}

Mercury Species Concentrations and Fluxes in the Central Tropical Pacific Ocean

Kathleen M. Munson, ${ }^{1,2}$ Carl H. Lamborg, ${ }^{1}$ Gretchen J. Swarr, ${ }^{1}$ Mak A. Saito ${ }^{1}$

1. Department of Marine Chemistry and Geochemistry, Woods Hole Oceanographic Institution, Woods Hole, MA 02543

2. MIT/WHOI Joint Program in Chemical Oceanography

Preparation for submission to Global Biogeochemical Cycles

\begin{abstract}
:
Consumption of marine fish exposes humans to potentially harmful concentrations of monomethylmercury (MMHg). The complex cycling of mercury $(\mathrm{Hg})$ in marine environments poses analytical challenges that limit our understanding of the temporal trends in mercury cycling and its potential for entering marine foods webs. We present dissolved mercury speciation data from 10 stations in the North and South Equatorial Pacific. In addition, we compare the mercury content in suspended particles from 6 stations and sinking particles from 3 stations to constrain the sources and sinks of mercury along large water mass differences and gradients in oxygen utilization. In general, concentrations of methylated $\mathrm{Hg}$ are low with maximum concentrations, $\sim 0.18 \mathrm{pM}$ for both $\mathrm{MMHg}$ and dimethylmercury (DMHg) species, observed in the equatorial Pacific. South of the Equator, concentrations of MMHg and DMHg fall to $0.1 \mathrm{pM}$. Notably, both $\mathrm{THg}$ and methylated $\mathrm{Hg}$ species in the upper $1000 \mathrm{~m}$ show a significant decrease from those measured in the North Pacific Intermediate Water (Sunderland et al, 2009). Combined, THg and methylated $\mathrm{Hg}$ concentrations in the surface and intermediate waters suggest $\mathrm{Hg}$ cycling distinct from that of the North Pacific gyre. Suspended particulate THg and MMHg comprise a small percentage of the dissolved concentrations but show distinct trends, increasing in importance with depth. Sinking fluxes of THg can reasonably explain the shape of dissolved THg profiles, but those of MMHg are far too low to account for dissolved MMHg profiles. In contrast to the upper ocean full depth profiles reveal, for the first time, elevated concentrations of $\mathrm{THg}$ extending into deep waters of the North Pacific and tapering off in the South Pacific. These deep water data reveal the contrast between anthropogenically impacted and unimpacted waters. Despite higher $\mathrm{THg}$ concentrations at depth, concentrations measured between the surface- $1000 \mathrm{~m}$ compared to those observed in previous cruises in the North and Equatorial Pacific suggest minimal temporal changes in this region on decadal time scales.
\end{abstract}




\section{Introduction}

The exposure of humans to the toxic element mercury is linked to its chemical speciation in marine environments. Humans are exposed to the bioaccumulating organic monomethylmercury (MMHg) through consumption of fish. Despite its elevated concentrations in a variety of piscivorous fish, $\mathrm{MMHg}$ is often found at concentrations composing $<15 \%$ of total mercury (THg) in the water column of the Atlantic and Pacific Oceans [Hammerschmidt and Bowman, 2012; Cossa et al, 1997; Mason and Sullivan, 1999; Sunderland et al, 2009; Mason and Fitzgerald 1991; Mason and Fitzgerald, 1993]. Unlike freshwater systems, marine environments can also contain significant concentrations of the dissolved gaseous organic form dimethylmercury, DMHg [Cossa et al, 1997; Mason and Fitzgerald, 1990; 1993; Mason and Sullivan, 1999; Hammerschmidt and Bowman, 2012].

Water column methylation of inorganic divalent $\mathrm{Hg}$ (II) has long been invoked to account for elevated MMHg and DMHg concentrations observed in the marine water column [Mason and Fitzgerald, 1993; Sunderland et al, 2009; Hammerschmidt and Bowman, 2012; Cossa et al, 2011]. Although resulting MMHg concentrations depend on the availability of the $\mathrm{Hg}$ (II) substrate for methylation, prediction of methylation is complicated by the redox chemistry of $\mathrm{Hg}(\mathrm{II})$, which can be reduced to gaseous elemental $\mathrm{Hg}(\mathrm{Hg}(0))$. As a result of its multiple identities in marine environments, the bioaccumulation of $\mathrm{Hg}$ in marine foods webs and ultimate exposure of humans to mercury depends on the transformations between $\mathrm{Hg}$ pools.

Despite the importance of quantifying the speciation of $\mathrm{Hg}$ to understand its potential for entering marine food webs, measurements of all four methylated and inorganic $\mathrm{Hg}$ chemical species are limited to a few areas in the open ocean. Mason and Fitzgerald (1993) first measured MMHg and DMHg in the Pacific. However, their relatively high detection limits of $50 \mathrm{fM}$ resulted in measurable concentrations of $\mathrm{MMHg}$ in only $30 \%$ of water depths analyzed [Mason and Fitzgerald, 1993]. Hammerschmidt and Bowman, 2012, provided dissolved speciation of methylated and total $\mathrm{Hg}$ as well as particulate THg and MMHg at a single site in the North Pacific. However, recent efforts to determine sources of MMHg are hampered by analytical challenges in preserving $\mathrm{Hg}$ speciation. Due to its instability in acidic conditions, DMHg cannot be easily preserved for shore-based determination. As a result, studies of MMHg production have relied on total methylated $\mathrm{Hg}$ concentrations ([DMHg] $+[\mathrm{MMHg}])$ [Sunderland et al, 2009; Cossa et al, 2011]. 
The long-standing model for MMHg production attributes marine MMHg to the breakdown of DMHg, which in turn is produced directly from $\mathrm{Hg}$ (II) [Mason and Fitzgerald, 1993]. More recently, measurements of water column methylation have suggested that direct production of MMHg from $\mathrm{Hg}(\mathrm{II})$ dominates in the Arctic water column [Lehnherr et al, 2011]. $\mathrm{MMHg}$, but not $\mathrm{DMHg}$, bioaccumulates in marine phytoplankton. As a result, distinguishing between distributions and production of these methylated $\mathrm{Hg}$ species has the potential to provide important insight into the link between dissolved $\mathrm{Hg}$ concentrations and resulting fish $\mathrm{MMHg}$ concentrations.

Even less frequently reported than full speciation data sets are studies that include particulate concentrations and sinking fluxes of $\mathrm{Hg}$ species. Including such measurements can help resolve potential movement and in situ generation of $\mathrm{Hg}$ species within the ocean. From a site in the North Pacific. Hammerschmidt and Bowman, 2012 observed increases in the ratio of particulate $\mathrm{MMHg}$ to particulate carbon that indicate either the preferential retention of $\mathrm{MMHg}$ on particles, particle scavenging of MMHg win the water column, or production of MMHg on sinking particles [Hammerschmidt and Bowman, 2012].

A recent analysis of North Pacific water found that increased Asian emissions, roughly a doubling over the past 25 years [Pacyna et al, 2006], had resulted in increased methylated $\mathrm{Hg}$ concentrations in the North Pacific Intermediate Waters (NPIW) due to water column in situ methylation [Sunderland et al, 2009]. While not overlapping, the stations occupied in the presented work extend the transect of Sunderland et al, 2009 as well sample waters measured two decades prior by Mason and Fitzgerald [1990; 1993] in 1990. As a result, we are able to evaluate whether those increases observed by Sunderland et al, 2009 extend throughout the North Atlantic or are limited in geographic range.

In the present study, we explore the full dissolved and particulate speciation of $\mathrm{Hg}$ across significant biogeochemical gradients in the Central Tropical North and South Pacific. We use these measurements to evaluate the fluxes of mercury species from the surface to the intermediate waters, explore potential sources of methylated $\mathrm{Hg}$, and assess the impact of anthropogenic emissions on the North and Tropical Pacific Ocean.

\section{Materials and Methods}

Dissolved and particulate mercury speciation was measured from a subset of stations (Table 1) occupied in the North and South Central Pacific Ocean between 3-24 October 2011 on 
board the $R / V$ Kilo Moana (Figure 1). These stations were occupied as part of the Metzyme cruise (Lamborg and Saito, chief scientists), whose goal was to explore the distribution and activity of micronutrients and metalloproteins in the ocean across a gradient of primary productivity and subsurface respiration. Water for dissolved $\mathrm{Hg}$ determination was sampled from 8 stations roughly following a North to Southwest transect beginning southeast of Hawaii at $17^{\circ} \mathrm{N} 154^{\circ} \mathrm{W}$ and ending at $12^{\circ} \mathrm{S} 168^{\circ} \mathrm{W}$ and 2 stations heading west along $15^{\circ} \mathrm{S}$ south of Samoa. Suspended particles for Hg and MMHg determination were collected by deployment of large volume in situ pumps at various depths at 6 stations spanning the North to Southwest cruise transect. Sinking particles for THg and MMHg determination were collected in sediment traps deployed at 3 stations between $17^{\circ} \mathrm{N}$ and the Equator.

Water for dissolved mercury speciation measurements was collected in acid-rinsed 8-L X-Niskin bottles attached to a dedicated epoxy-coated trace-metal sampling rosette (SeaBird) and deployed on Amsteel line. Bottle sampling was triggered by a SeaBird Autofiring Module programmed to activate bottles by pressure during up-casts. Niskin bottles were decanted in a positive pressure, HEPA-filtered water sampling bubble constructed from plastic sheeting. Decanting took place under ultra-clean $\mathrm{N}_{2}$ pressure through $0.2 \mu \mathrm{m}$ polyethersulfone filters (Supor).

Suspended particles were sampled from between 4-14 depths at 6 stations along the cruise track (Table 1) using in situ pumps (McLane Research Laboratories, Inc.). Sampling of suspended particles was biased towards stations north of the equator. Suspended particles were collected on combusted, acid-cleaned quartz microfiber filters (1- $\mu \mathrm{m}$, Whatman QMA) after an in-line acid-cleaned polyester mesh pre-filters $(51-\mu \mathrm{m}$, Sefar Petex 07-51/33) to provide particles of two particulate size fractions. Subsamples of the large size fraction $(>51-\mu \mathrm{m})$ were not available for $\mathrm{Hg}$ analysis, thus we present particulate $\mathrm{Hg}$ data for the $<51-\mu \mathrm{m}$ size fraction. The pumps were deployed for up to 3 hours in order to pump $\sim 1000 \mathrm{~L}$ of seawater through the filters. Filters that were installed and deployed but through which no water was pumped, were processed as blanks.

Sinking particles were collected in acid-cleaned polycarbonate particle collection tubes with removable $250-\mathrm{mL}$ low density polyethylene bottles as collection cups arranged in PVC frames at depths of $60 \mathrm{~m}, 150 \mathrm{~m}$, and $500 \mathrm{~m}$ at stations 1,3, and 5 using a surface-tethered system [Lamborg et al, 2008]. Twelve tubes at each depth were deployed containing a layer of $250 \mathrm{~mL}$ of borate-buffered $(\mathrm{pH}=8.2)$ seawater brine prepared from freezing filtered seawater and collecting 
the concentrated seawater as it melts. Above the brine, each tube was filled with borate buffered filtered seawater ( $\mathrm{pH}$ 8.2) [Lamborg et al, 2008]. Three capped tubes were deployed in the trap array as process blanks. Upon recovery, the tubes were allowed to sit for 1 hour to allow any particles in the tube to finish sinking. The bottles were then removed and portions of the contents filtered on either pre-weighed polycarbonate membranes ( $1 \mu \mathrm{m}$, Nuclepore) or combusted quartz fiber filters (QMA). The membranes were used to determine mass and $\mathrm{Hg}$ species fluxes. The QMA filtered were used for $\mathrm{C}$ and $\mathrm{N}$ flux determinations.

\section{Hydrographic Data}

Depth, salinity, conductivity, and dissolved oxygen were measured by a SeaBird Electronics deployed on the trace metal rosette. Nutrient samples were filled with filtered seawater during Niskin decanting, frozen on board, and measured by the laboratory of Joe Jennings at Oregon State University.

From dissolved nitrate $\left(\mathrm{NO}_{3}{ }^{-}\right)$concentrations measured along the cruise transect, we calculated the parameter N* [Gruber and Sarmiento, 1997, Deutsch et al, 2001] to investigate the potential influences of nitrogen cycling on $\mathrm{Hg}$ speciation. The parameter is calculated by the following equation:

$$
\mathrm{N}^{*}=\left[\mathrm{NO}_{3}{ }^{-}\right]-\left(\left[\mathrm{PO}_{4}{ }^{3-}\right]^{*} 16\right)+2.9 \mathrm{mmol} \mathrm{m}{ }^{-3}
$$

Comparing the observed $\mathrm{NO}_{3}{ }^{-}$to the expected dissolved nutrient ratio according to Redfield stoichiometry can account for additions or absence of $\mathrm{NO}_{3}{ }^{-}$. As a result, $\mathrm{N}_{2}$ fixation increases $N^{*}$ values while denitrification decreases $N^{*}$ values [Gruber and Sarmiento, 1997].

\section{Total Mercury Determination}

Filtered water for dissolved mercury speciation was decanted from the X-Niskin bottles into acid-cleaned 2-L Teflon bottles. Subsamples for total mercury (THg) were poured off into acid-cleaned 250 -mL glass bottles (I-Chem) and oxidized with $0.1 \mathrm{~mL}$ bromine monochloride (\%) for $>12$ hours and pre-reduced with $\mathrm{NH}_{2} \mathrm{OH}$ ( $1 \mathrm{~mL} \mathrm{30 \%} \mathrm{wt:vol).} \mathrm{Samples} \mathrm{were} \mathrm{then} \mathrm{reduced} \mathrm{with}$ $\mathrm{SnCl}_{2}$ and total mercury concentrations were determined by dual Au-amalgamation cold vapor atomic fluorescence spectrometry (CVAFS) with a Tekran 2600 against both gaseous $\mathrm{Hg}$ and aqueous $\mathrm{Hg}(\mathrm{II})$ standards. 


\section{Gaseous Mercury Determination}

Gaseous elemental $\left(\mathrm{Hg}^{\circ}\right)$ and dimethylmercury (DMHg) were purged directly from the remaining seawater in the 2-L Teflon bottles using a multi-port cap (Omnifit Q-series; Danbury, $\mathrm{CT}$ ) and impinger with a fine pore frit that extends to the bottom of the bottle. $\mathrm{Hg}^{\circ}$ and $\mathrm{DMHg}$ were purged from the seawater sample using ultra-pure $\mathrm{N}_{2}$ gas $\left(0.5 \mathrm{~L} \mathrm{~min}^{-1}\right)$ for 1 hour. The gaseous species were separated and pre-concentrated onto a gold-coated sand trap attached downstream of a Tenax trap in outlet of the purge cap [Lamborg et al, 2008]. After purging, traps were dried with $\mathrm{Ar}$ gas flow for $2 \mathrm{~min} . \mathrm{Hg}^{\circ}$ was determined using a Tekran 2600, while DMHg was determined using a Tekran 2500 following isothermal GC separation and pyrolysis to $\mathrm{Hg}^{\circ}$. Both analytical systems were calibrated with $\mathrm{Hg}^{\circ}$ standard addition.

\section{Methylmercury Determination}

Following purging of gaseous mercury species, $\sim 200 \mathrm{~mL}$ subsamples for monomethylmercury (MMHg) determination were poured from the 2-L Teflon bottles into acidcleaned $250-\mathrm{mL}$ glass bottles (I-Chem) and acidified to $0.5 \%$ with concentrated $\mathrm{H}_{2} \mathrm{SO}_{4}$ (trace metal grade, Fisher Scientific). Samples were stored at $-40^{\circ} \mathrm{C}$ and analyzed at the Woods Hole Oceanographic Institution using ascorbic acid-assisted direct ethylation [Munson - this work, Chapter 2]. Samples were buffered with either $2 \mathrm{M}$ acetic acid or $1 \mathrm{M}$ citric acid buffer (pH 5) and neutralized with $\mathrm{KOH}(45 \%)$ to $\mathrm{pH} 5$. The addition of ascorbic acid $(0.167 \%$ final v/v) allowed for enhanced MMHg determination from seawater after direct derivitization with sodium tetraethylborate $(1 \%$, in $2 \% \mathrm{KOH})$.

Sample bottles were fitted with Teflon backed silicon septa caps (I-Chem) and run on a Tekran 2700 Automated Methylmercury Analyzer equipped with a custom autosampler tray. $\mathrm{MMHg}$ concentrations were determined versus linear standard curves prepared daily with $\mathrm{MMHg}$ standards solution.

\section{Suspended and Sinking Particulate Mercury}

$\mathrm{MMHg}$ and $\mathrm{THg}$ in suspended and sinking particles were determined by digesting weighed filter portions in $\mathrm{HNO}_{3}\left(2 \mathrm{~N}\right.$, trace metal grade, Fisher) for 4 hours at $60^{\circ} \mathrm{C}$ with intermittent sonication. Digests were either oxidized with $\mathrm{BrCl}$ and processed as described above for $\mathrm{THg}$ determination or processed as described above for $\mathrm{MMHg}$ determination with direct 
ethylation. Suspended particulate $\mathrm{Hg}$ species are presented as concentrations representing the measured $\mathrm{Hg}$ or MMHg collected on filters from known volumes of filtered seawater. Total filtered mass was not determined.

\section{Results}

\section{Hydrographic Parameters}

Salinity profiles of the cruise transect reveal a sharp transition between Station $1\left(17^{\circ} \mathrm{N}\right)$ and Station $2\left(12^{\circ} \mathrm{N}\right)$ (Figure 2). Station 1 displays the southern extent of the North Pacific Intermediate Waters in intermediate waters and high salinity surface waters. However, Stations 2 and 3 reveal lower salinity surface water at the surface, representing the convergence of the North Equatorial Current and the North Equatorial Counter Current. Waters with salinity values $\sim 34.5$ reach the surface at Stations 2 and $3\left(12^{\circ} \mathrm{N}\right.$ and $8^{\circ} \mathrm{N}$, respectively) appears to segregate shallow waters $(<400 \mathrm{~m})$ of the North Pacific from the Equatorial Pacific. Shoaling of nutrients and seasonal thermocline is observed at the edge of the North Pacific Subtropical Gyre. Upwelling of dissolved nutrients is apparent in the upper $150 \mathrm{~m}$ at Station $5\left(0^{\circ} \mathrm{N}\right)$, where concentrations of $\mathrm{H}_{3} \mathrm{PO}_{4},>0.6 \mu \mathrm{mol} / \mathrm{L}$, and $\mathrm{HNO}_{3},>6 \mu \mathrm{mol} / \mathrm{L}$ persist (Figure 2). South of the Equator, high salinity waters are observed above a seasonal thermocline that extends deeper in the water column moving south.

\section{Dissolved Mercury Speciation}

\section{Total Mercury}

Surface concentrations of THg are low, $<0.5 \mathrm{pM}$, for all stations (Figure 5). These low concentrations extend through the mixed layer, $\sim 75 \mathrm{~m}$ north of the Equator and to depths $\sim 125 \mathrm{~m}$ south of the Equator. Below the mixed layer, THg concentrations approach $\sim 1 \mathrm{pM}$ reaching a maximum of $\sim 1.5 \mathrm{pM}$ in regions of the intermediate waters $(<1000 \mathrm{~m}$ in depth).

Elevated concentrations of THg (1.5-2 pM) are observed in deep waters (bellow $2000 \mathrm{~m}$ ) at the northern end of the transect $\left(17^{\circ} \mathrm{N}\right)$ and decrease (1.25-1.5 pM) moving south in deep waters south of the equator $\left(5^{\circ} \mathrm{S}\right)$ (Figures 4,8$)$. These relatively high $\mathrm{THg}$ concentrations result from North Pacific Bottom Water moving south until they are replaced at depth $(>4500 \mathrm{~m})$ with Antarctic Bottom Water ( $\mathrm{S}=34.7$, P15 WOCE, Jan-Mar 1996 S section, Sept/Oct 1994 N section). The resulting lower THg concentrations $(\sim 1 \mathrm{pM})$ in deep water south of $5 \mathrm{~S}$ fall within the range of those measured in the AABW (0.98-1.99 pM) [Cossa et al, 2011]. 


\section{Elemental Mercury}

Concentrations of $\mathrm{Hg}^{\circ}$, like those of $\mathrm{THg}$, are low in the mixed layer with highest surface concentrations at Stations 1 and 2 where $\mathrm{Hg}^{\circ}$ approaches $0.1 \mathrm{pM}$ (Figure 5). Concentrations of $\mathrm{Hg}^{\circ}$ generally increase below the mixed layer, reaching maximum concentrations in the upper water column immediately below the thermocline.

Two features are noted within this region immediately below the thermocline in the upper ocean profiles of $\mathrm{Hg}^{\circ}$. At Station $2\left(12^{\circ} \mathrm{N}\right)$, a large $\mathrm{Hg}^{\circ}$ maximum of $0.2-0.4 \mathrm{pM}$ is focused at depths between 200-400 m (Figure 8). This maximum also extends to Stations 1 and 3. A second maximum of 0.2-0.35 $\mathrm{pM} \mathrm{Hg}^{\circ}$ was measured between 150 and $350 \mathrm{~m}$ at Station 10 (Figure 8).

Minimum concentrations of $\mathrm{Hg}^{\circ}$ are generally observed immediately beneath the maximum concentrations at the base of the mixed layer (Figures 5, 8). In the South Pacific, this minimum is broad and extends to depths of $1000 \mathrm{~m}$. In the North Atlantic, this minimum in narrow and concentrations quickly increase from $\sim 0.1 \mathrm{pM}$ to $0.2 \mathrm{pM}$. In addition, at several depths within the region of the deep North Pacific where elevated $\mathrm{THg}$ was measured, $\mathrm{Hg}^{\circ}$ concentrations increase to $0.2-0.3 \mathrm{pM}$.

With the exception of the two features noted above, $\mathrm{Hg}^{\circ}$ concentrations appear to be controlled largely by temperature. Distributions of $\% \mathrm{Hg}^{\circ}$ saturation (Figure 9) are similar to those of $\mathrm{Hg}^{\circ}$ concentrations (Figure 8) and do not appear to be influenced by $\mathrm{THg}$, as $\% \mathrm{Hg}^{\circ}$ saturation normalized to $\mathrm{THg}$ (Figure 9) are similar to those of $\% \mathrm{Hg}^{\circ}$ saturation (Figure 8).

\section{Monomethylmercury}

Concentrations of MMHg approach detection limits in much of the surface ocean, with the exception of the Equator, where concentrations vary between 15-70 fM in the upper $200 \mathrm{~m}$ (Figure 7).

In the upper $1000 \mathrm{~m}$ of the ocean, MMHg appears to be distributed slightly asymmetrically around the equator, with elevated $\mathrm{MMHg}$ concentrations north of the Equator relative to south (Figure 8). The highest concentrations of MMHg observed along the cruise transect, 150-165 fM, are seen at the depths of the oxygen minimum at the equatorial station.

$\mathrm{MMHg}$ concentrations in the deep equatorial region are also elevated with respect to adjacent stations. MMHg concentrations increase from 50 fM to 85-155 fM between 2000-3500 $\mathrm{m}$ at the equator (Figure 6). 


\section{Dimethylmercury}

Concentrations of DMHg are generally higher than those of MMHg. In contrast to MMHg, DMHg in the surface ocean $(>20 \mathrm{~m})$ was often above our detection limit, generally $\sim 0.2$ pM (Figure 7). DMHg, like MMHg, reaches its maximum concentrations, 0.12-0.16 pM, at depths with low oxygen concentrations. However, it is important to note that the highest $\mathrm{DMHg}$ concentrations are found at depths with intermediate dissolved $\mathrm{O}_{2}$ concentrations $(\sim 60 \mu \mathrm{mol} / \mathrm{kg})$ rather than minimum dissolved $\mathrm{O}_{2}$ concentrations. Like $\mathrm{MMHg}, \mathrm{DMHg}$ is distributed asymmetrically with the maximum concentrations measured north of the Equator at Station 4 $\left(4^{\circ} \mathrm{N}\right)$ (Figure 8$)$.

Beneath the mixed layer, DMHg concentrations average $\sim 0.075 \mathrm{pM}$ with slightly lower concentrations in south of the Equator.

In the deep ocean, elevated DMHg concentrations of $\sim 0.1 \mathrm{pM}$ were measured at several depths within waters with elevated THg concentrations, most notably at Station $3\left(8^{\circ} \mathrm{N}\right)$ (Figure $6)$.

\section{Suspended Particulate Mercury Speciation}

Suspended particles collected from in situ pumps have low concentrations of both $\mathrm{THg}$ $\left(\mathrm{THg}_{\text {susp }}\right)$ and $\mathrm{MMHg}\left(\mathrm{MMHg}_{\text {susp }}\right)$. $\mathrm{THg}_{\text {susp }}$ ranged from 0.01-0.05 $\mathrm{pM}$ from all stations and averaged $5.3 \%$ (range: 1.0-27.4 \%) of dissolved THg concentrations (Figure 11). $\mathrm{MMHg}_{\text {susp }}$ ranged from 0.1-3.1 fM and averaged 3.7 \% (range: 0.2-12.8 \%) of dissolved MMHg concentrations (Figure 11). Previous measurements of $\mathrm{Hg}$ species in the Pacific have not distinguished between dissolved and particulate species [Mason and Fitzgerald, 1993; Laurier et

al, 2004; Sunderland et al, 2009]. However, the low percentages of $\mathrm{THg}_{\text {susp }}$ and $\mathrm{MMHg}_{\text {susp }}$ allow us to compare our measured values to those previously determined in the Pacific. Such comparisons are least accurate in surface waters, where suspended particles make up a greater percentage of total $\mathrm{Hg}$ species because of low dissolved species concentrations.

Concentrations of $\mathrm{THg}_{\text {susp }}$, decrease slightly from the northern to southern ends of the cruise transect. $\mathrm{THg}_{\text {susp }}$ concentrations average $0.03 \pm 0.001 \mathrm{pM}$ at Stations $1(\mathrm{n}=8), 3(\mathrm{n}=14), 5$ $(\mathrm{n}=13)$. South of the Equator, the concentration falls to $0.02 \pm 0.002 \mathrm{pM}$ at stations $6(\mathrm{n}=4), 8$ $(\mathrm{n}=4), 9(\mathrm{n}=3)$. 
Average $\mathrm{MMHg}_{\text {susp }}$ concentrations, with the exception of Station 1 ( $\left.0.7 \mathrm{fM}, \mathrm{n}=8\right)$, roughly decrease from Station $3(1.6 \mathrm{fM}, \mathrm{n}=14)$ to Station 9 (0.4 fM, n=2).

Although the concentrations of $\mathrm{THg}_{\text {susp }}$ and $\mathrm{MMHg}_{\text {susp }}$ are negligible compared to the dissolved species concentrations, the depth distributions of each suggest differences in the cycling of difference $\mathrm{Hg}$ species. $\mathrm{THg}_{\text {susp }}$ concentrations are generally highest within the upper $50 \mathrm{~m}$ of the water column (Figure 11). In contrast, $\mathrm{MMHg}_{\text {susp }}$ concentrations are highest within $100 \mathrm{~m}$ of the depth of minimum dissolved $\mathrm{O}_{2}$ concentration at each station measured (Figure 11). The only exception to these trends are at Station 1, where $\mathrm{THg}_{\text {susp }}$ could not be measured within the upper $50 \mathrm{~m}$ and Station 9, where $\mathrm{MMHg}_{\text {susp }}$ was not measured at $400 \mathrm{~m}$, where the dissolved $\mathrm{O}_{2}$ concentration was lowest.

\section{Sinking Particulate Mercury Speciation}

Sinking particulate $\mathrm{Hg}$ fluxes attenuate with depth at each station, approaching 31.3 $\mathrm{pmol} / \mathrm{m}^{2} / \mathrm{d}( \pm 12.0)$ at $500 \mathrm{~m}$ for all three stations (Figure 13). Fluxes from the mixed layer were highest $\left(156.6 \mathrm{pmol} / \mathrm{m}^{2} / \mathrm{d}\right)$ at Station 5 and lowest $\left(36.7 \mathrm{pmol} / \mathrm{m}^{2} / \mathrm{d}\right)$ at Station 1 . Assuming $80 \%$ of wet and dry $\mathrm{Hg}$ deposition is rapidly evaded in the surface ocean [Mason and Sheu, 2002; Strode et al, 2007; Sørensen, et al 2010], measured particulate fluxes at all stations exceed deposited Hg, modeled by GEOS-Chem [Sørensen et al, 2012; Anne Sørensen, personal communication] (Figure 13). The observed fluxes therefore require additional inputs of $\mathrm{Hg}$ to Tropical Pacific waters, most notably at the Equator, where upwelling and lateral transport likely entrain THg.

Measured values of sinking particulate MMHg fluxes ranged between $0-1.63 \mathrm{pmol} / \mathrm{m}^{2} / \mathrm{d}$. A relatively high detection limit of $1.52 \mathrm{pmol} / \mathrm{m}^{2} / \mathrm{d}$ prevents quantitative analysis of measured values. However, particle fluxes of MMHg appear to be small throughout the upper water column.

\section{Apparent Oxygen Utilization}

Elevated concentrations of methylated $\mathrm{Hg}$ species have commonly been measured in low oxygen regions of the open ocean water column [Mason and Fitzgerald, 1993; Sunderland et al, 2009; Hammerschmidt and Bowman, 2012; Cossa et al, 2011]. Possible explanations for in situ methylation in these regions include distinct microbial communities, release of $\mathrm{Hg}$ (II) substrate for methylation from organic matter during remineralization, or a combination of these factors. 
The cruise transect bisected a variety of oxygen regimes (Figure 3). Beginning at Station 1, North Pacific Subtropical Gyre circulation distributes $\mathrm{O}_{2}$ in the upper $200 \mathrm{~m}$ of the water column. At this southern limit of the Gyre, we observed dissolved $\mathrm{O}_{2}$ concentrations, $\sim 20$ $\mu \mathrm{mol} / \mathrm{kg}$ between $400-800 \mathrm{~m}$. Moving to the edge of the Gyre, at Station 2 is the strongest oxygen minimum zone of the cruise, with dissolved $\mathrm{O}_{2}$ concentrations $<2 \mu \mathrm{mol} / \mathrm{kg}$ extending broadly between 200-900 m. At Station 3, the oxygen minimum zone remains broad 150-700 $\mathrm{m}$ but has dissolved $\mathrm{O}_{2}$ concentrations again in the range of $20 \mu \mathrm{mol} / \mathrm{kg}$. From Station 4 southward, the oxygen minimum zones weaken, with dissolved $\mathrm{O}_{2}$ concentrations never falling below 50 $\mu \mathrm{mol} / \mathrm{kg}$.

Beginning at Station 8 , elevated $\mathrm{O}_{2}$ concentrations $(>80 \mu \mathrm{mol} / \mathrm{kg})$ persist in the upper water column, increasing southward.

Apparent oxygen utilization $\left(\left[\mathrm{O}_{2}\right]_{\mathrm{sat}}-\left[\mathrm{O}_{2}\right]_{\text {meas }}\right)$ can be used to estimate the extent of dissolved $\mathrm{O}_{2}$ utilization for means of organic matter remineralization [Garcia and Gordon, 1992 as modified by Sarmiento and Gruber, 2006]. Highest concentrations of methylated $\mathrm{Hg}$ were seen at intermediate values of apparent oxygen utilization (Figure 14)

As has been seen in previous studies, concentrations of methylated $\mathrm{Hg}([\mathrm{DMHg}]+$ [MMHg]) increases to a degree with AOU. However we observe an overall linear relationship between $([\mathrm{DMHg}]+[\mathrm{MMHg}])$ versus AOU rather than the parabolic relationship observed by Sunderland et al, 2009. In addition, the relationship appears to differ significantly depending on station. Measurements from the CLIVAR P16N cruise found clustering of methylated $\mathrm{Hg}$ versus AOU by depth, perhaps due to largely sampling a single water mass of North Pacific Intermediate Water [Sunderland et al, 2009]. In contrast, we observe a tighter clustering of all depths by station, with wider ranges of AOU waters sampled in southern stations (Figure 14).

\section{Relative Concentrations of Monomethylmercury and Dimethylmercury}

Generally, at northern stations (Station 2-6), MMHg concentrations are similar to those of DMHg, with the exception of Station 4 (Figure 7). South of Station 6, MMHg concentrations fall more rapidly than DMHg, resulting in significantly higher DMHg concentrations compared to MMHg. At Station 12, MMHg concentrations are once again comparable to those of DMHg.

From their $\mathrm{Hg}$ speciation analysis at the SAFe station in the North Atlantic, Hammerschmidt and Bowman reported MMHg:DMHg molar ratios that they used to distinguish between a steady-state exchange of $\mathrm{CH}_{3}$-groups between $\mathrm{DMHg}$ and $\mathrm{MMHg}$ throughout the 
water column in contrast to the oxygen minimum zone, where an elevated MMHg:DMHg molar ratio was interpreted to suggest a different mechanism of $\mathrm{CH}_{3}$-group transfer during in situ methylation [Hammerschmidt and Bowman, 2012]. They reported a MMHg:DMHg molar ratio $\sim 2$ throughout the water column, with the exception of the oxygen minimum zone, where the ratio increased to $\sim 5$ [Hammerschmidt and Bowman, 2012]. We observed MMHg:DMHg molar ratios that varied between stations, but were generally lower than those observed at the SAFe station. MMHg:DMHg molar ratio varied between 0.2-1, with maximum values near 3.5 (Figure 15 , Station 3, $600 \mathrm{~m}$ ). The ratio values generally decrease along the cruise track.

\section{Discussion}

\section{Factors Controlling Mercury Speciation}

Salinity contours of the cruise track show that the Station 1 sampled the southern boundary of North Pacific Intermediate Water, while Stations 2 and 3 show the influence of the North Pacific Subtropical Gyre in the upper $200 \mathrm{~m}$ of the water column.

The maximum of $\mathrm{Hg}^{\circ}$ observed at Station 2 at the edge of gyre circulation occurs at a minimum of dissolved $\mathrm{O}_{2},<2 \mu \mathrm{m} / \mathrm{kg}$, a region of potential alternative metabolisms that might influence the production of $\mathrm{Hg}(0)$. From the distribution of $\mathrm{N}^{*}$, we see that the maximum in $\mathrm{Hg}^{\circ}$ at Station 2 between $100-400 \mathrm{~m}$ corresponds with a deficit in $\left[\mathrm{NO}_{3}{ }^{-}\right], \mathrm{N}^{*}$ : range -6 to $-8 \mathrm{mmol} \mathrm{m}^{-3}$ (Figure 10), which suggests denitrification at this depth. Analysis of $\delta \mathrm{O}$ and $\delta \mathrm{N}$ from these waters also reveal fractionation signals indicative of denitrification [P. Rafter, personal communication].

No direct link between marine denitrification and $\mathrm{Hg}$ reduction has been noted previously in the literature, although microbial mediated $\mathrm{Hg}$ reduction has observed in marine systems [Mason et al, 1995; Rolfhus and Fitzgerald, 2004; Poulain et al, 2007], Denitrification has been implicated as a pathway of $\mathrm{Hg}$ (II) reduction by mer operon-mediated reduction in bacteria [Schaefer et al, 2002; Kritee et al, 2008]. Therefore, it is plausible that the observed peak in $\operatorname{Hg}(0)$ at Station 2 is induced by the strong denitrification signal represented by the values of $\mathrm{N}^{*}$ at this location. However, calculations of $\mathrm{N}^{*}$ in waters across the transect show no additional regions where denitrification occurs to the extent that it does at Station 2. As a result, the potential for denitrification to influence $\mathrm{Hg}$ speciation on basin scales will rely on future measurements of $\mathrm{Hg}(0)$ in regions of denitrification.

In contrast to the maximum of $\mathrm{Hg}(0)$ at Station 2, the maximum at Station $10\left(15^{\circ} \mathrm{S}\right)$ appears in waters of relatively high dissolved $\mathrm{O}_{2}$ concentrations, $164 \mu \mathrm{M} / \mathrm{kg}$, and no decreases in 
$\mathrm{N}^{*}$ value, indicated $\mathrm{Hg}(\mathrm{II})$ reduction that is independent of denitrification. $\operatorname{This} \mathrm{Hg}(0)$ maximum in the South Pacific co-occurs with local maxima in both dissolved $\mathrm{PO}_{4}$ and $\mathrm{NO}_{3}$ (Figure 10). This maximum in $\operatorname{Hg}(0)$ occurs at a depth of $250 \mathrm{~m}$, deeper than light penetration to drive photodemethylation and subsequent $\mathrm{Hg}$ (II) reduction. However, abiotic reduction mechanisms have also been found to dominate in some systems [Monperrus et al, 2007; Whalin et al, 2007; Qureshi et al, 2010].

The elevated concentrations of THg observed at depth demonstrate the clear distinction between waters extending from the North Pacific, where elevated concentrations of $\mathrm{THg}$ have been attributed to anthropogenic influences [Sunderland et al, 2009] and those in the Equatorial and South Pacific. However, these high THg concentrations are surprising given previous observations that tracers of entrainment of anthropogenic activity have not yet penetrated below $1000 \mathrm{~m}$ in the North Pacific [Mason et al, 2012].

The salinity data suggest that the observed attenuation of the elevated THg seen in depth profiles is likely the displacement of waters moving south from North Pacific with more dense Antarctic Bottom Water (AABW, S 34.65-34.75). Likewise, the concentration of THg in these higher salinity waters ( $<1.3 \mathrm{pM}$ from Station $8,4500-5000 \mathrm{~m}$ southward) is within the range measured recently in AABW [Cossa et al, 2011].

\section{Fluxes of Mercury in the Central Pacific}

Particulate THg fluxes closely agree with modeled fluxes from the mixed layer and are greater than regional wet and dry deposition [Sørensen et al, 2012; Anne Sørensen, personal communication] (Figure 13). Particulate THg fluxes are influential for both removal of $\mathrm{Hg}$ species through sorption onto sinking organic matter as well as $\mathrm{Hg}(\mathrm{II})$ delivery to intermediate waters for methylation [Sunderland et al, 2009]. However, the particulate fluxes of THg are surprising given the methylated $\mathrm{Hg}$ concentrations. Despite low particulate $\mathrm{THg}$ delivery at Station $1\left(17^{\circ} \mathrm{N}\right.$, Figure 13), intermediate waters in the North Pacific have substantially higher methylated Hg species concentrations [Sunderland et al, 2009; Munson — this work, Chapter 5] than those measured in Equatorial and South Pacific stations (Figure 18). Conversely, higher particulate THg fluxes were measured at Station $3\left(8^{\circ} \mathrm{N}\right)$ compared to Station 1 but did not result in higher methylated $\mathrm{Hg}$ concentrations (Figure 7). This indicates additional requirements, beyond $\mathrm{Hg}(\mathrm{II})$ substrate delivery, for $\mathrm{Hg}$ methylation in intermediate waters. 


\section{Temporal Trends in Dissolved Mercury Speciation}

Despite the fact that it was one of the first regions where full $\mathrm{Hg}$ speciation was measured [Kim and Fitzgerald, 1986; 1988; Gill and Fitzgerald, 1988; Mason and Fitzgerald 1990, 1991, 1993], there have been no subsequent measurements of $\mathrm{Hg}$ in the Equatorial and South Pacific in the past two decades.

Comparisons of the closest stations sampled in 1990 to those sampled in 2011 show a decrease in $\mathrm{THg}$ concentrations both in the thermocline and in oxygen deficient waters. Above the thermocline $(200 \mathrm{~m})$, we observed a decrease from $1.72 \mathrm{pM} \mathrm{THg}(1.45 \mathrm{pM}$ excluding St 4 outlier) to $0.24 \mathrm{pM}$ (Figure 16). Below the thermocline, we observed a decrease of $1.23 \mathrm{pM}$ (1.17 $\mathrm{pM}$ excluding St 4 outlier) to $0.66 \mathrm{pM}$ (Figure 16).

Overall comparisons of profiles from the two cruises (Figure 16) shows that our measured $\mathrm{THg}$ concentrations in the upper water column are significantly lower than those in nearest stations of Mason and Fitzgerald, 1993. Deeper in the water column, however, some concentrations are similar, resulting in changes in both the shapes and the overall concentrations of mercury in 2011 compared to 1990 . A clear maximum in $\mathrm{THg}$ at $500 \mathrm{~m}$ was observed by Mason and Fitzgerald in the South Pacific waters between 0 and $10^{\circ} \mathrm{S}$ and $140^{\circ} \mathrm{W}$ and $170^{\circ} \mathrm{E}$ [Mason and Fitzgerald, 1993, Stations 4, 6, 8, 9]. This feature is absent from the depth profiles of THg from Stations 7 or 8, which fall within the area sampled by Mason and Fitzgerald (Figure 16). Instead, the shape of the profiles measured by Mason and Fitzgerald most closely resemble our profiles from Station 1-5 (Figure 5). However, even in the stations where the shape of the profiles resemble those of Mason and Fitzgerald, our data show a much lower THg concentrations in the upper $200 \mathrm{~m}(<2 \mathrm{pM})$.

Sunderland et al, 2009 calculated a significant increase in $\mathrm{THg}$ concentrations measured during the North Pacific Intergovernmental Oceanographic Commission (IOC) cruise in 2002 [Laurier et al, 2004] and those measured from similar latitudes during the CLIVAR 2006 [Sunderland et al, 2009]. The THg concentrations from our Station 1 fall between those measured during IOC (Station 9) and CLIVAR P16N (Figure 18), suggesting that the temporal increase observed between 2002 and 2006 either did not penetrate to $17^{\circ} \mathrm{N}$, the northernmost station along our transect, or has not continued in the subsequent period between measurements in this region. Similarities in the shape of the total mercury profile at Station 1 and Station 45 of the CLIVAR P16N cruise (Figure 18) suggest that similar processes determine the mercury distributions at both locations. North Pacific THg concentrations have been found to vary by up to factor of 2 at 
open ocean stations separated by $\sim 1000 \mathrm{~km}$ [Hammerschmidt and Bowman, 2012]. Since the IOC, CLIVAR, and Metzyme stations are separated from each other by $\sim 750 \mathrm{~km}$, it is possible that the differences in THg concentrations reflect spatial rather then temporal differences in North Pacific THg.

In addition, Sunderland et al, 2009 characterized the temporal increase in $\mathrm{THg}$ concentrations within the North Pacific Intermediate Water, a specific water mass that extends southward at $\sim 155^{\circ} \mathrm{W}$ only to $\sim 20^{\circ} \mathrm{N}$ [Talley, 1993]. As a result, we would not expect to see the impact of high THg or methylated Hg from NPIW to persist southward along the Metzyme cruise track. Instead the Central and Equatorial Pacific appears to be a region with distinct $\mathrm{Hg}$ cycling than the North Pacific (Figure 18).

Full $\mathrm{Hg}$ speciation from this transect of the Tropical Pacific Ocean reveals a region of low THg and methylated $\mathrm{Hg}$ relative to previous reports from the North Pacific [Sunderland et al, 2009]. The general decrease in THg, DMHg, and MMHg from the North Pacific toward the South Pacific follow increasing trends in dissolved oxygen concentrations. However, from sinking particulate THg fluxes, we observe that low concentrations, most notably of $\mathrm{DMHg}$ and $\mathrm{MMHg}$, are not the result of limited THg supply to low oxygen regions of the ocean. Instead, THg availability to methylation appears to be limited. Indeed, in extremely low oxygen waters, denitrification appears to decrease DMHg and MMHg concentrations either by reduction of $\mathrm{Hg}$ (II) substrate or by demethylation and subsequent reduction of methylated $\mathrm{Hg}$. Such processes must be taken into account when considering how changes in $\mathrm{Hg}$ emissions and ocean chemistry will ultimately impact MMHg bioaccumulation over time.

\section{Acknowledgements}

Financial support for this study was provided by the National Science Foundation in a grant from the Chemical Oceanography Program (OCE-1031271) to C. H. Lamborg and M. A. Saito and a Graduate Student Fellowship to K. M. Munson. We thank Erin Bertrand, Rene Boiteau, Tyler Goepfert, Nick Hawco, Dawn Moran, and David Wang for their assistance in water sampling, filtration, and pump deployment. We also thank Vic Polidoro, Trevor Young, Captain Drewry, and crew of the $R / V$ Kilo Moana for making sample collection possible. We thank Anne Sørensen and Elsie Sunderland for providing electronic versions of published data. 
We thank Bill Jenkins and John Bullister for advice and assistance with water mass age calculations.

\section{References}

Cossa, D., J.-M. Martin, K. Takayanagi, and J. Sanjuan (1997) The distribution and cycling of mercury species in the western Mediterranean. Deep Sea Res. II, 44, 721-740.

Cossa, D., L.-E. Heimburger, D. Lannuzel, S. R. Rintoul, E. C. V. Butler, A. R. Bowie, B. Averty, R. J. Watson, and T. Remenyi (2011) Mercury in the Southern Ocean. Geochim. Cosmochim. Acta 75, 4037-4052.

Deutsch, C., N. Gruber, R. M. Key, and J. L. Sarmiento (2001) Denitrification and $\mathrm{N}_{2}$ fixation in the Pacific Ocean, Global Biogeochem. Cycles, 18, GB4012.

Garcia, H. E., and L. I. Gordon (1992) Oxygen solubility in seawater: better fitting equations, Limnol. Oceanogr., 37(6), 1307-1312.

Gill, G. A., and W. F. Fitzgerald (1988) Vertical mercury distributions in the oceans. Geochim, Cosmochim. Acta 52, 1719-1728.

Gruber, N., and J. L. Sarmiento (1997) Global patterns of marine nitrogen fixation and denitrification, Global Biogeochem. Cycles, 11, 235-266.

Hammerschmidt, C. R., and K. L. Bowman (2012) Vertical methylmercury distributions in the subtropical North Pacific Ocean, Mar. Chem., 132-133, 77-82.

Kim, J. P., and W. F. Fitzgerald (1986) Sea-air partitioning of mercury in the equatorial Pacific Ocean. Science 231, 1131-1133.

Kritee, K., J. D. Blum, M. W. Johnson, B. A. Bergquist, and T. Barkay (2007) Mercury stable isotope fractionation during reduction of $\mathrm{Hg}(\mathrm{II})$ to $\mathrm{Hg}^{\circ}$ by mercury resistant microorganisms, Environ. Sci. Technol., 41, 1889-1895.

Lamborg, C. H., K. O. Buesseler, and P. J. Lam (2008), Sinking fluxes of minor and trace elements in the North Pacific Ocean measured during the VERTIGO program. Deep-Sea Res. II, $55,1564-1577$.

Laurier, F. J. G., R. P. Mason, G. A. Gill, and L. Whalin (2004) Mercury distributions in the North Pacific Ocean-20 years of observations, Mar. Chem., 90, 3-19.

Lehnherr, I., V. L. St. Louis, H. Hintelmann, and J. L. Kirk (2011) Methylation of inorganic mercury in polar marine waters, Nat. Geosci., 4, 298-302.

Mason, R. P., and W. F. Fitzgerald (1990) Alkylmercury species in the equatorial Pacific. Nature $347,457-459$. 
Mason, R. P., and W. F. Fitzgerald (1991) Mercury speciation in open ocean waters. Water, Air, Soil Pollut., 56, 779-789.

Mason, R. P., and W. F. Fitzgerald (1993) The distribution and cycling of mercury in the equatorial Pacific Ocean, Deep Sea Res., Part I, 40(9), 1897-1924.

Mason, R. P., F. M. M. Morel, and H. F. Hemond (1995) The role of microorganisms in elemental mercury formation in natural waters, Air Water Soil Pollut., 80, 775-787.

Mason, R. P., and G.-R. Sheu (2002) Role of the ocean in the global mercury cycle. Global Biogeochem. Cy., 4, 1093.

Mason, R. P., K. A. Sullivan (1999) The distribution and speciation of mercury in the south and equatorial Atlantic. Deep Sea Res II, 46, 937-956.

Munson, K. M., D. Babi, C. H. Lamborg, (in review) Monomethylmercury determination from seawater using ascorbic-acid assisted direct ethylation.

Pacyna, E. G., J. M. Pacyna, F. Steenhuisen, and S. Wilson (2006) Anthropogenic mercury emission inventory for 2000. Atmos. Environ., 22, 4048-4063.

Poulain, A. J., S. M. Ni Chadhain, P. A. Ariya, M. Amyot, E. Garcia, P. G. C. Campbell, G. J. Zylstra, and T. Barkay (2007) Potential for mercury reduction by microbes in the high Arctic. Appl. Environ. Microbiol., 73, 2230-2238.

Qureshi, A., N. J. O’Driscoll, M. Macleod, Y.-M. Neuhold, and K. Hungerbuhler (2010)

Photoreactions of mercury in surface ocean water: gross reaction kinetics and possible pathways. Environ. Sci. Technol. 44, 644-649.

Rolfhus, K. R., and W. F. Fitzgerald (2004) Mechanisms and temporal variability of dissolved gaseous mercury production in coastal seawater, Mar. Chem., 90, 125-136.

Sarmiento, J. L., and N. Gruber (2006) Ocean Biogeochemical Dynamics, 526pp., Princeton University Press, Princeton, New Jersey.

Schaefer, J. K., J. Letowski, T. Barkay (2002) mer-mediated resistance and volatilization of $\mathrm{Hg}$ (II) under anaerobic conditions, Geomicrobiol. J. 12, 8-102.

Schlitzer, R. (2004) Ocean Data View, http://odv.awi-bremerhaven.de.

Sørensen, A. L., D. J. Jacob, D. G. Streets, M. L. I. Witt, R. Ebinghaus, R. P. Mason, M. Andersson, and E. M. Sunderland (2012) Multi-decadal decline of mercury in the North Atlantic atmosphere explained by changing subsurface seawater concentrations. Geophys. Res. Letts. 39, L21810. 
Sunderland, E. M., D. P. Krabbenhoft, J. W. Moreau, S. A. Strode, and W. M. Landing (2009) Mercury sources, distribution, and bioavailability in the North Pacific Ocean: Insights from data and models, Global Biogeochem. Cycles, 23, GB2010, doi: 10.1029/2008GB003425.

Talley, L. D. (1993) Distribution and formation of North Pacific Intermediate Water, J. Phys. Oceanogr., 23, 517-537.

Whalin, L., E.-H. Kim, and R. P. Mason (2007) Factors influenced the oxidation, reduction, methylation, and demethylation of mercury species in coastal waters. Mar. Chem., 107: 278-294. 
Figures and Figure Legends

Figure 1: Map of Metzyme cruise stations. The Metzyme cruise left Honolulu, Hawai'i 1 October and arrived in Apia, Samoa 25 October, 2011. Dissolved, suspended particulate, and sinking particulate Hg species were collected at various stations along the cruise track (Table 1).

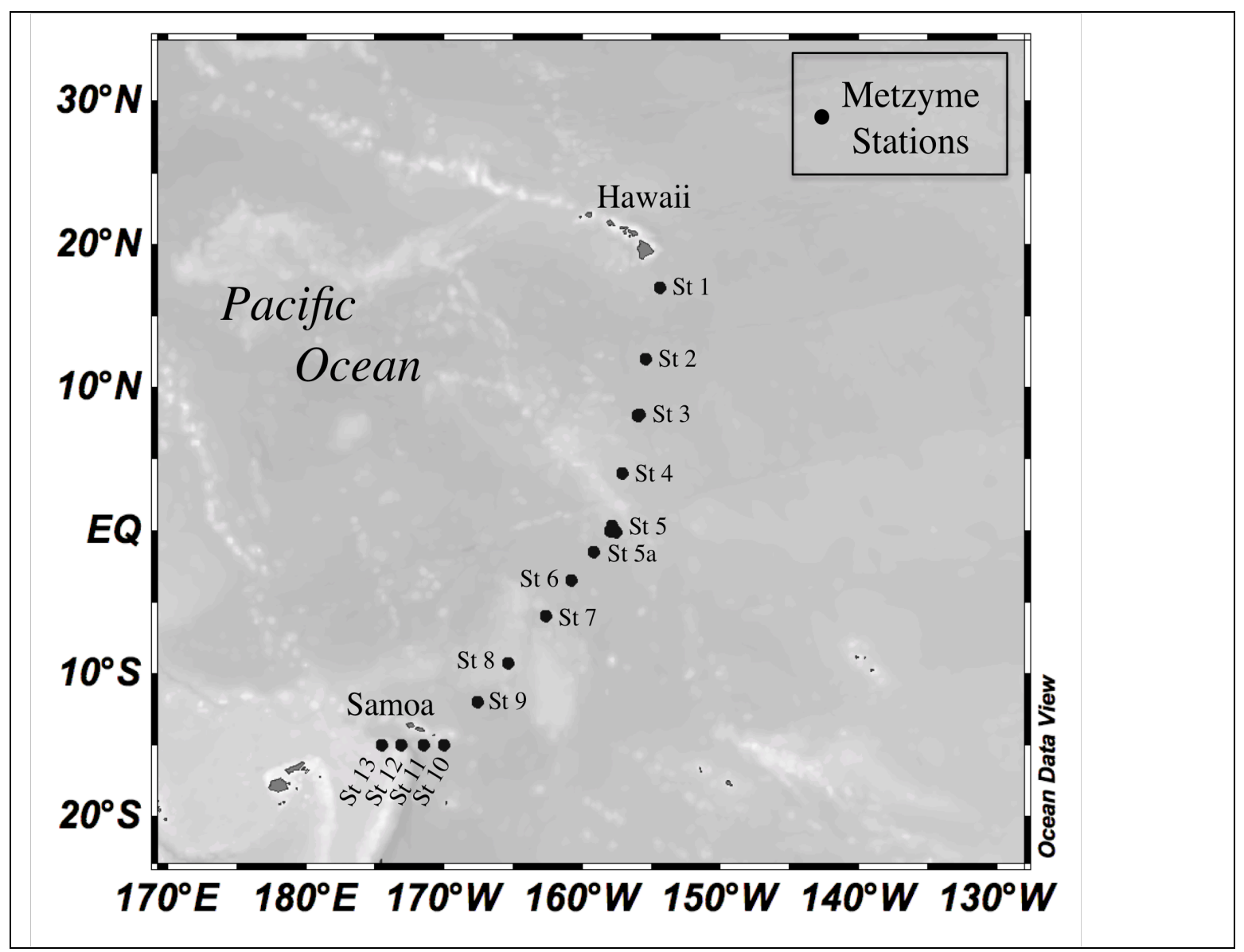


Figure 2: Hydrographic characteristics of the North to South transect of the Metzyme

cruise. Temperature, salinity, and major nutrients phosphate and nitrate concentrations at Stations 1-10 for the upper $1000 \mathrm{~m}$ (upper panel) and full water column (bottom panel).

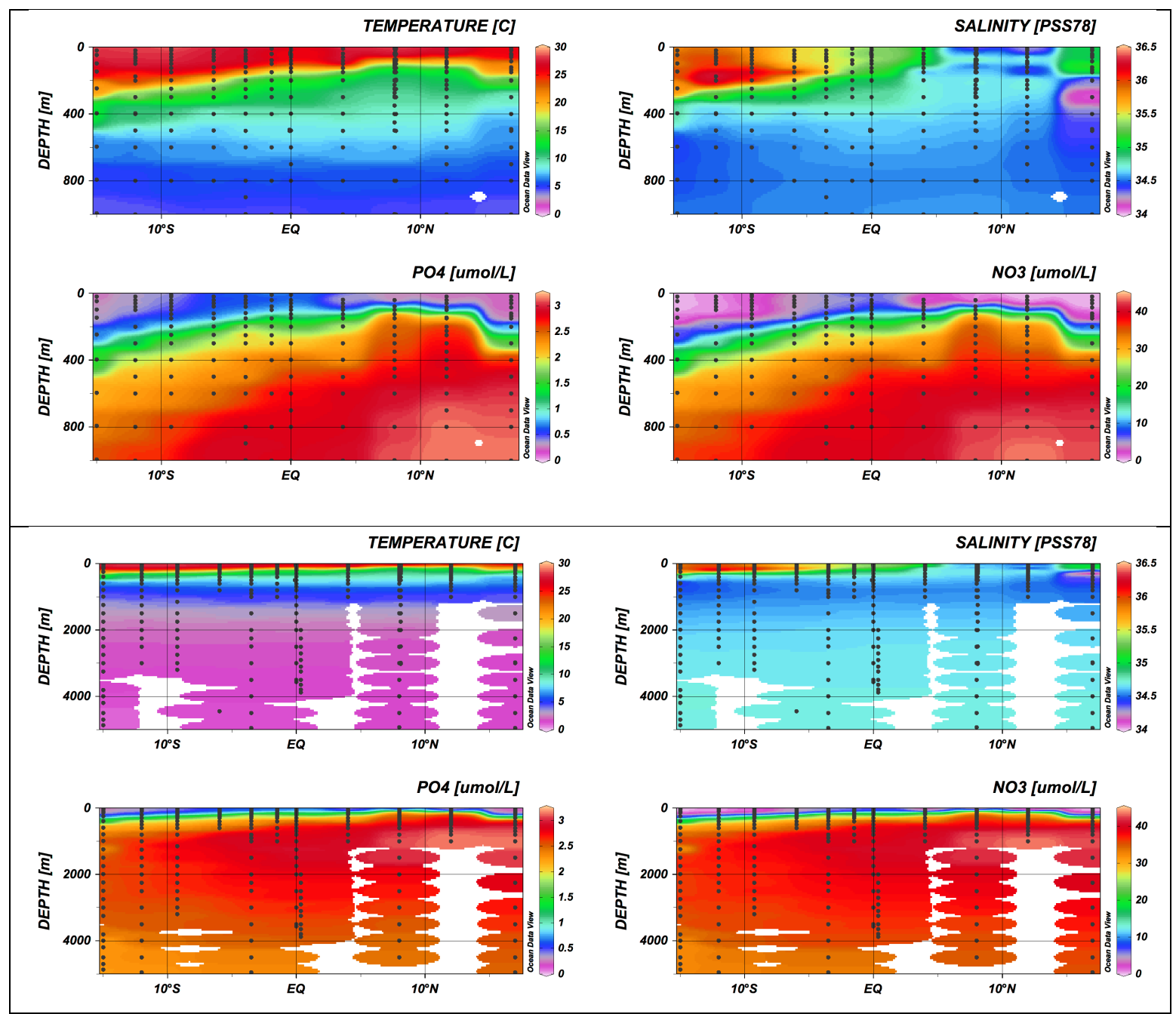


Figure 3: Oxygen and apparent oxygen utilization along the North to South transect of the Metzyme cruise. Dissolved oxygen and calculated AOU for upper $1000 \mathrm{~m}$ of Stations 1-10. Values of AOU are closely related to dissolved oxygen concentrations, with highest oxygen utilization centered at Station $2\left(12^{\circ} \mathrm{N}\right)$ and extends to below the North Pacific Subtropical Gyre at Station $1\left(17^{\circ} \mathrm{N}\right)$ and beneath the sharp oxycline at Station $3\left(8^{\circ} \mathrm{N}\right)$. South of the Equator, gradients of both dissolved oxygen concentrations and AOU are weak throughout intermediate waters.

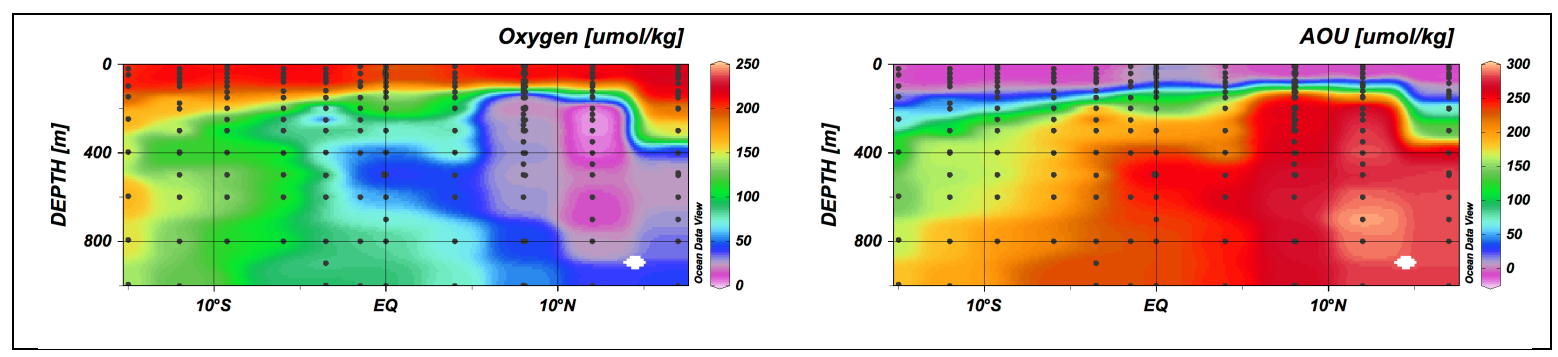


Figure 4: Full water column depth profiles of total mercury and elemental mercury at all stations along the Metzyme cruise track. Total Hg concentrations (black circles) are low at the surface and increase with depth. $\mathrm{Hg}^{\circ}$ concentrations (white circles) often exhibit subsurface maxima as well as increasing concentrations in deep waters $(>2000 \mathrm{~m})$.

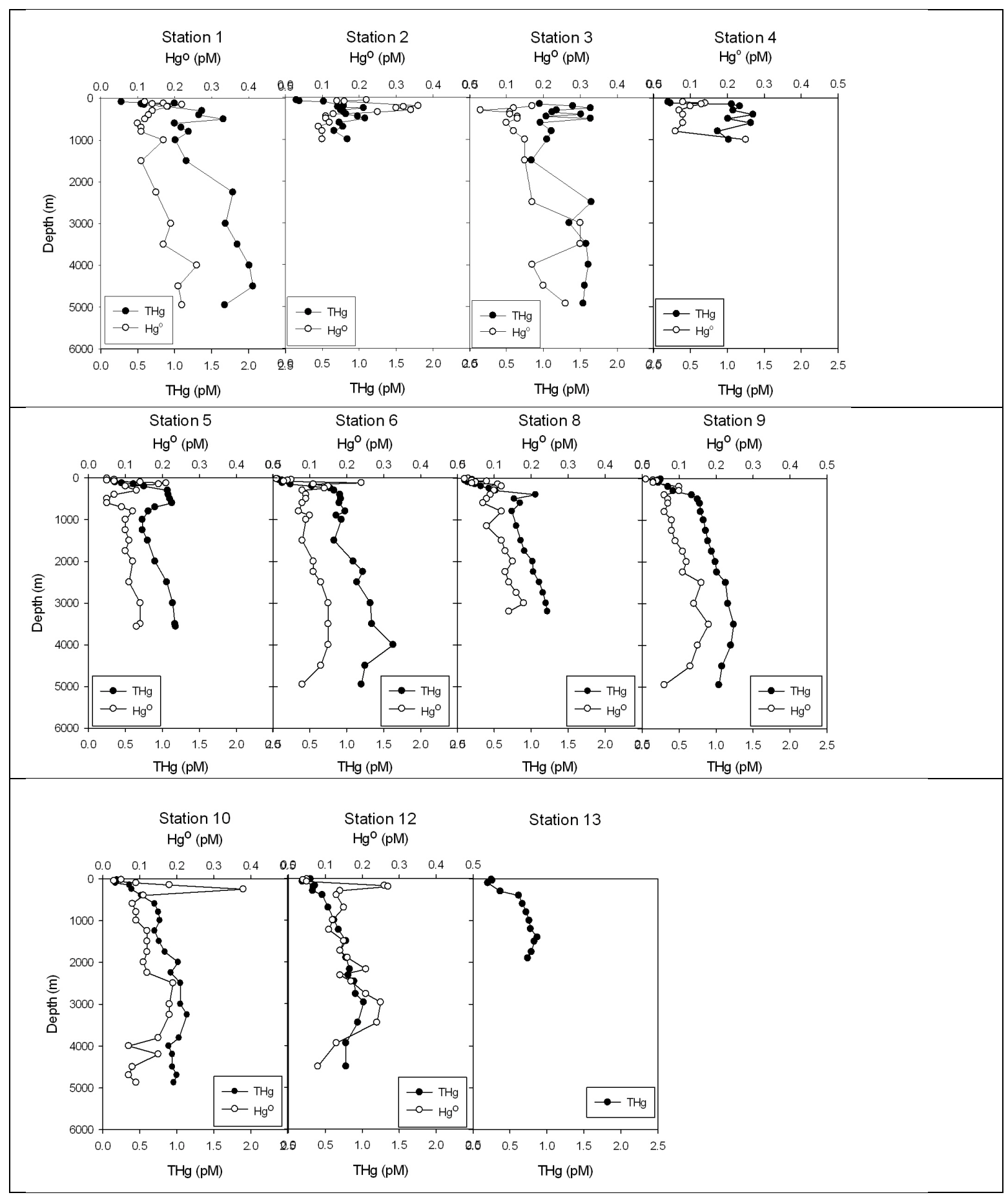


Figure 5: Upper $1500 \mathrm{~m}$ water column profiles of total mercury and elemental mercury at all stations along the Metzyme cruise track. Total $\mathrm{Hg}$ concentrations (black circles) are low at the surface and increase with depth. Surface $\mathrm{THg}$ concentrations are low and $\mathrm{Hg}^{\circ}$ concentrations (white circles) often subsurface maxima in both the North and South Pacific away.

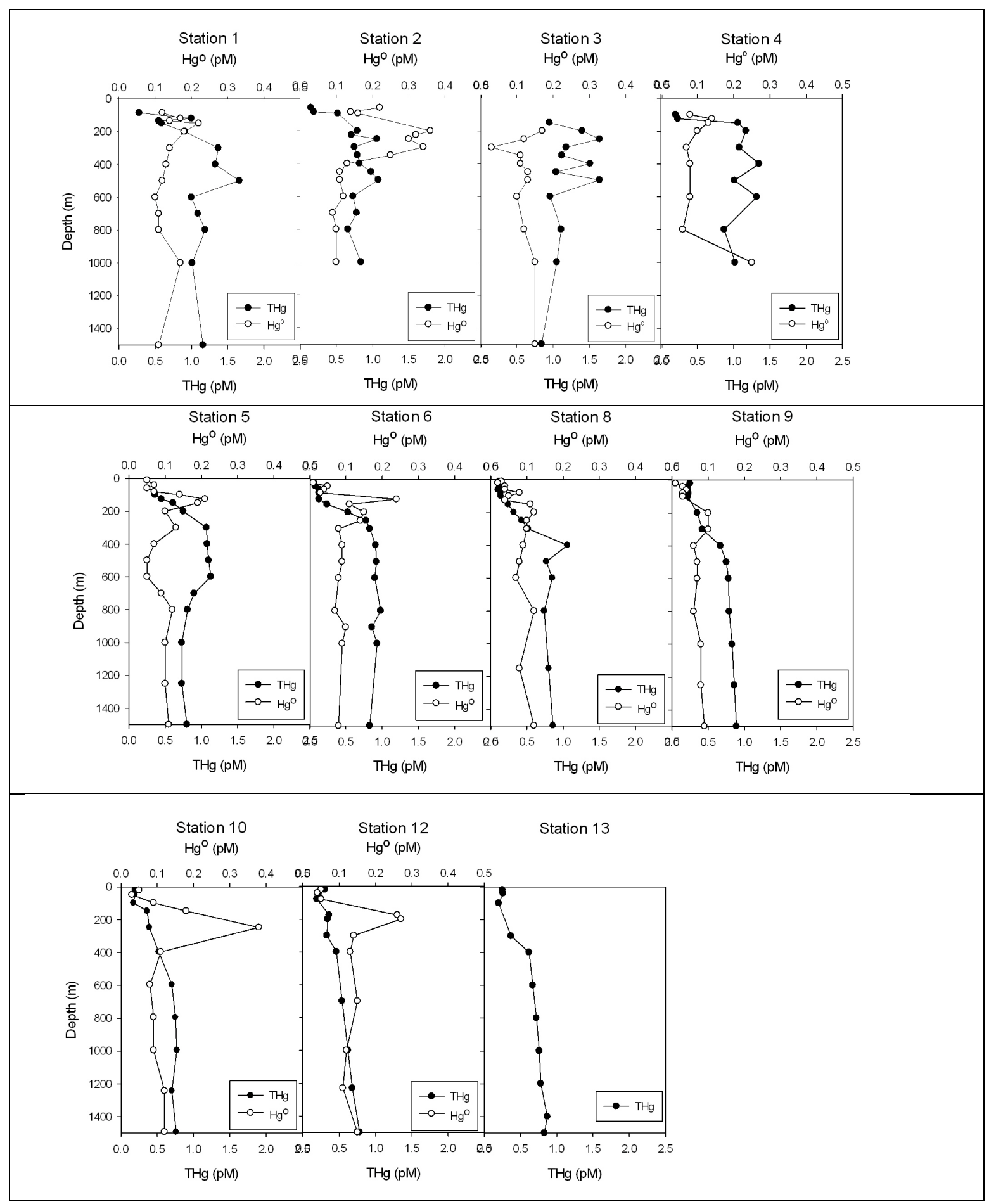


Figure 6: Full water column depth profiles of monomethylmercury and dimethylmercury at all stations along the Metzyme cruise track. MMHg concentrations (black circles) are highest at the Equatorial station and exhibit maxima in low oxygen waters primarily in the North Pacific. $\mathrm{DMHg}$ concentrations (white circles) are comparable or higher than those of $\mathrm{MMHg}$ and exhibit maxima in low oxygen waters in the North Pacific.

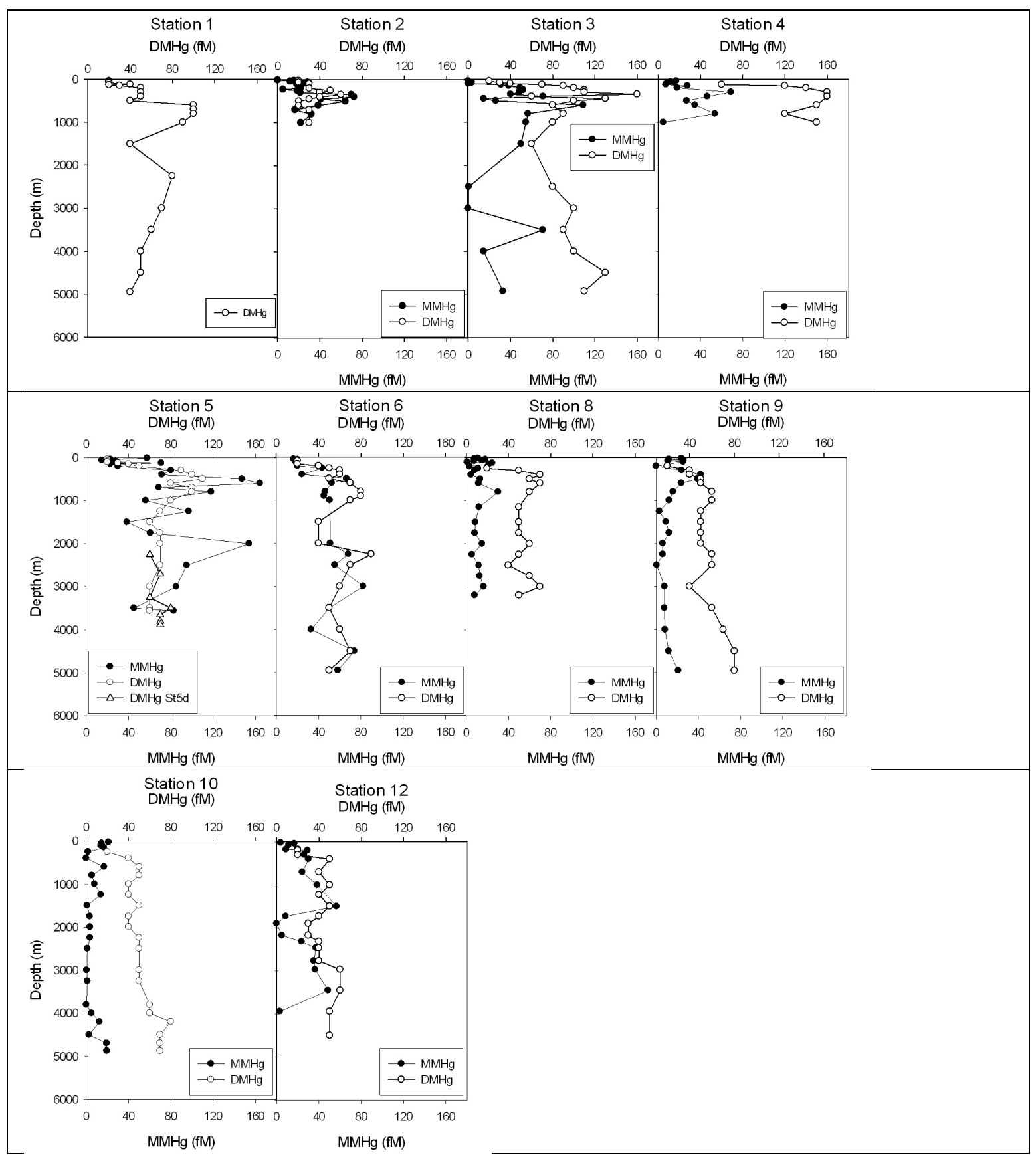


Figure 7: Upper water column depth profiles of monomethylmercury and dimethylmercury at all stations along the Metzyme cruise track. Both MMHg (black circles) and DMHg (white circles) concentrations are low in surface waters and increase in intermediate waters, most notably in North Pacific and Equatorial waters and are low in South Pacific waters.

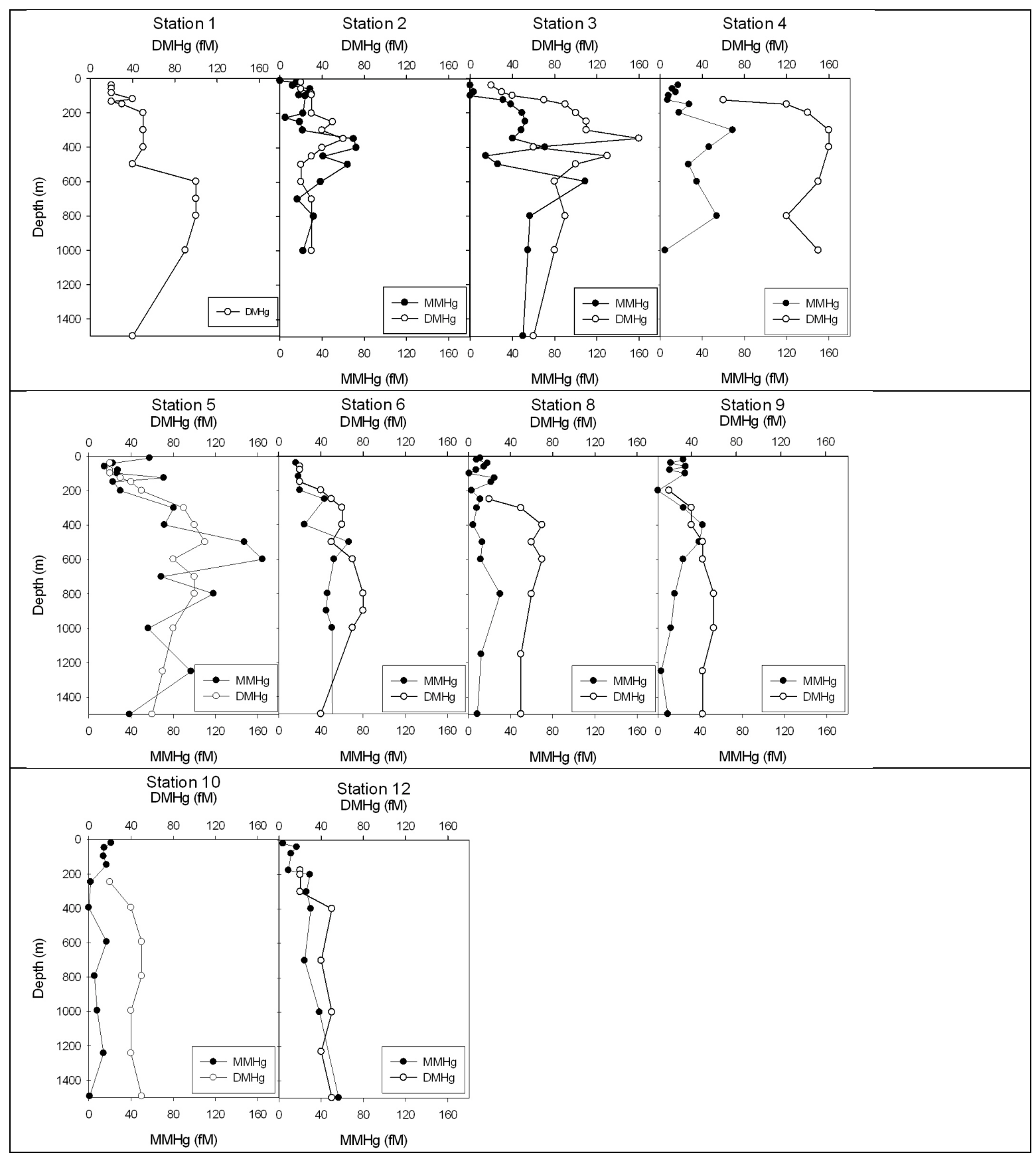


Figure 8: Ocean Data View gridded sections of mercury species concentrations along North to South transect of the Metzyme cruise. Upper water column (surface-1000 m; top panel) and full water column (bottom panel) of the Metzyme North to South transect $\left(17^{\circ} \mathrm{N}\right.$ to $\left.15^{\circ} \mathrm{S}\right)$. Methylated species, $\mathrm{DMHg}$ and $\mathrm{MMHg}$, have patterns that are distinct from $\mathrm{THg} . \mathrm{Hg}(0)$ distributions reveal localized maxima of reduction at Station $2\left(12^{\circ} \mathrm{N}\right)$ and Station $10\left(15^{\circ} \mathrm{S}\right)$. The full depth section of $\mathrm{THg}$ reveals the relatively high concentrations in the North Pacific.

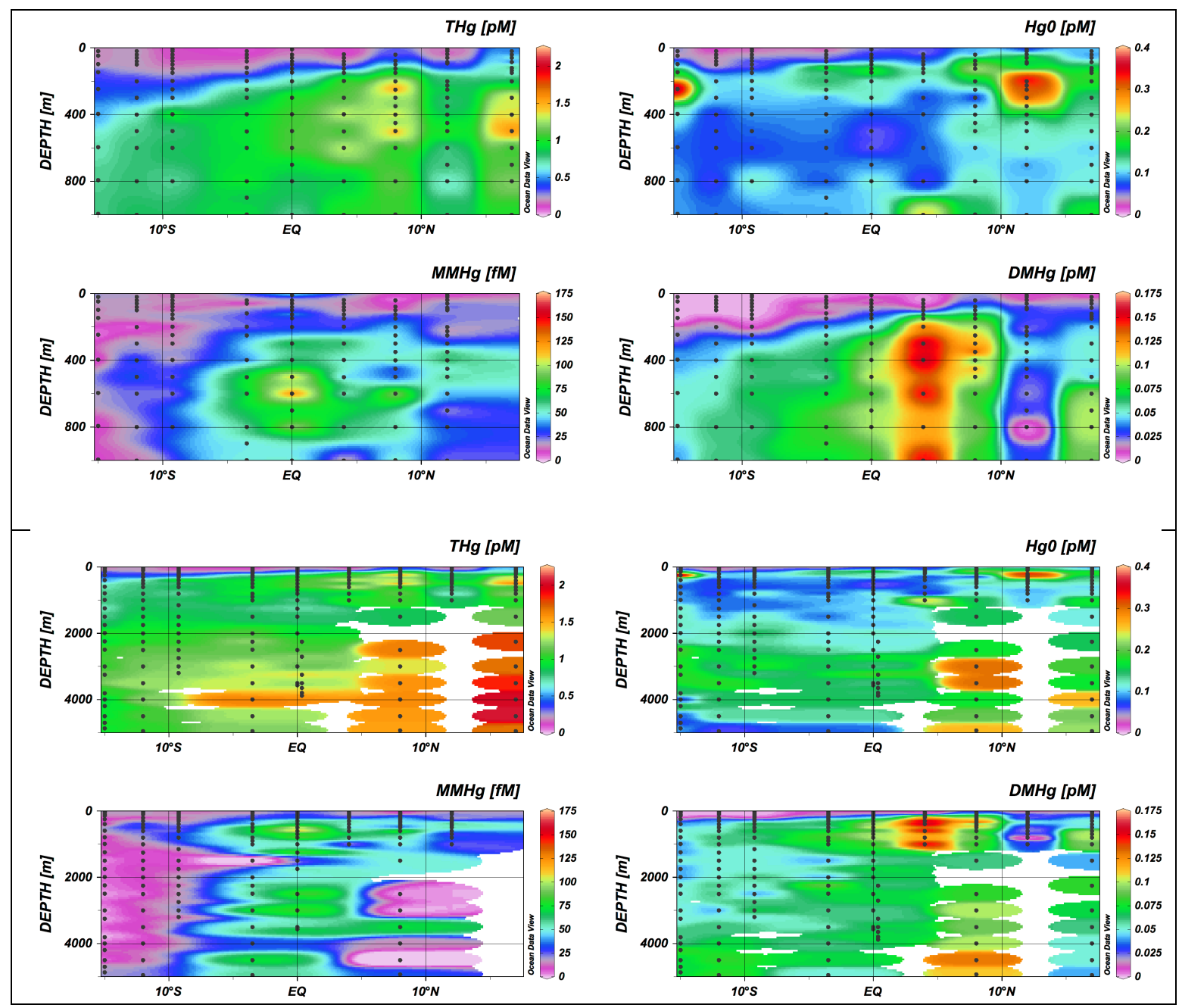


Figure 9: Percent saturation of $\mathrm{Hg}^{\circ}$ in the water column of the Tropical Pacific Ocean. Percent saturation of $\operatorname{Hg}(0)$ in the upper $1000 \mathrm{~m}$ (top panel) and the full water column (middle panel). The distribution patters are similar to that of $\mathrm{Hg}(0)$ (Figure 8). Normalization to $\mathrm{THg}$ (bottom panel), reveals that percent saturation of $\mathrm{Hg}(0)$ is independent of $\mathrm{THg}$ distributions.

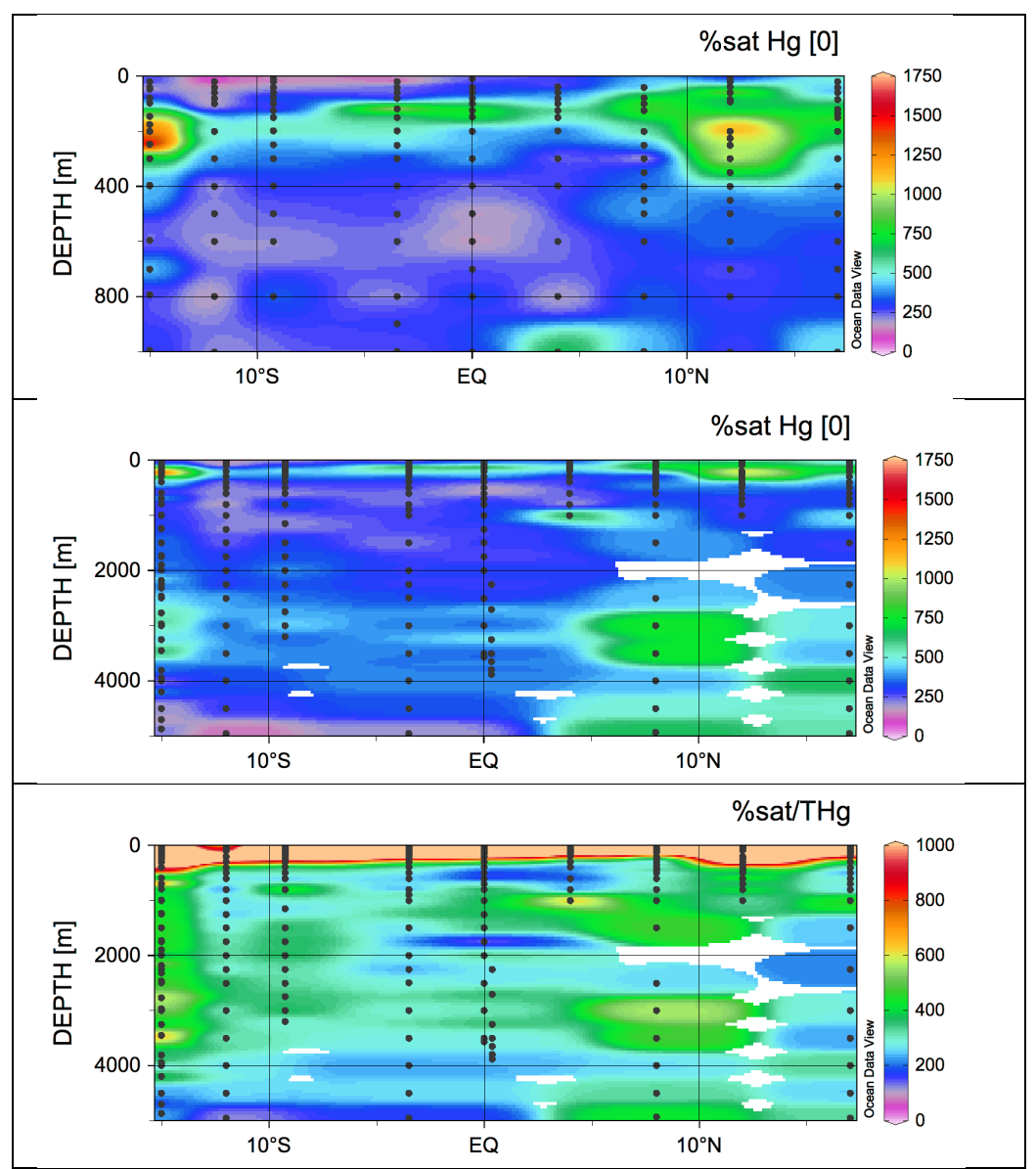


Figure 10: Mercury reduction driven by denitrification at the southern base of the North Pacific Subtropical Gyre. Upper 1000m of transect from Station 1 to Station 10 showing A) measured $\mathrm{Hg}^{\circ}$ concentrations and $\left.\mathrm{B}\right) \mathrm{N}^{*}$ calculated from measured $\left[\mathrm{PO}_{4}{ }^{3-}\right]$ and $\left[\mathrm{NO}_{3}{ }^{-}\right]$. Maximum in $\mathrm{Hg}(0)$ concentrations between $200-400 \mathrm{~m}$ at Station 2 correspond with indications of denitrification from $\mathrm{N}^{*}$. In contrast to $\mathrm{Hg}^{\circ}$ maximum at Station 2, maximum at Station 10 does not correspond to denitrification.




Figure 11: Suspended particulate total mercury and monomethylmercury collected from five stations using in situ pumps. Suspended particulate THg (black circles) and MMHg (white circles) concentrations measured from in situ pump deployments are low throughout surface and intermediate waters. Neither particulate pool contributes significantly to total concentrations of the species in Tropical Pacific waters.

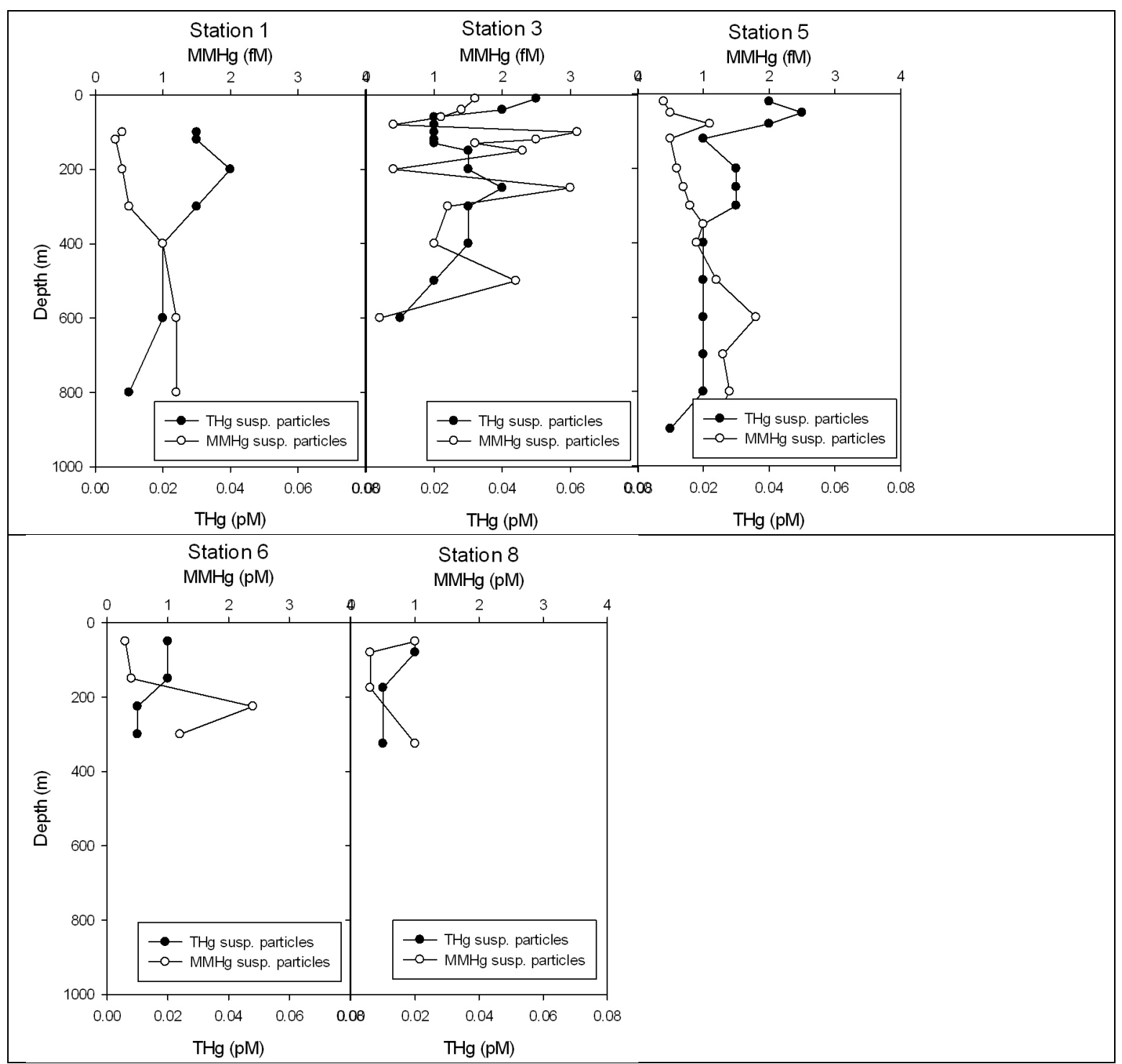


Figure 12: Ratios of monomethylmercury to total mercury in dissolved and suspended particulate pools. Ratios of MMHg to $\mathrm{THg}$ in the dissolved pool (white circles) are typically higher than ratios of $\mathrm{MMHg}$ to $\mathrm{THg}$ in the suspended particulate pool (black circles) in the surface ocean and approach one another below $200 \mathrm{~m}$.

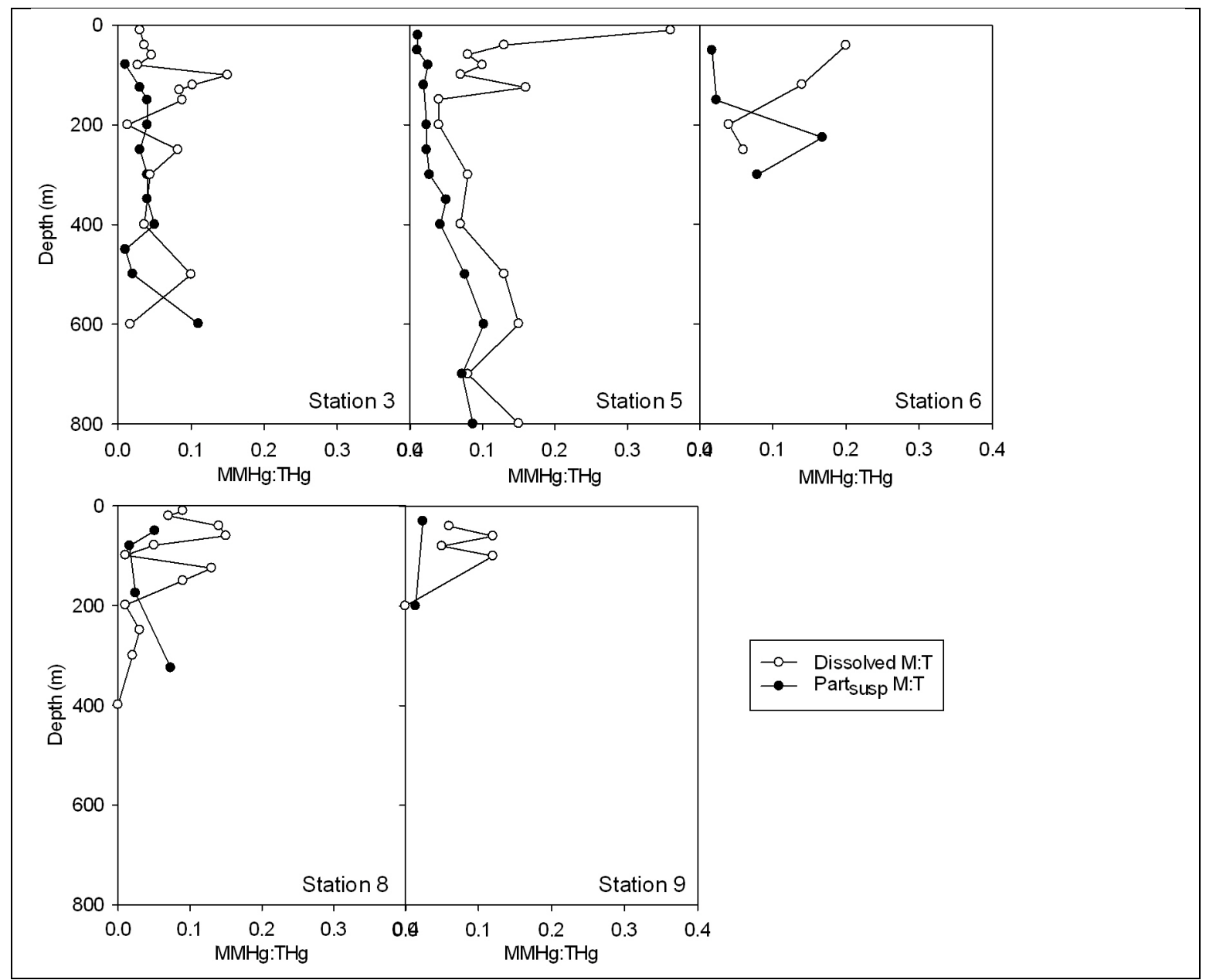




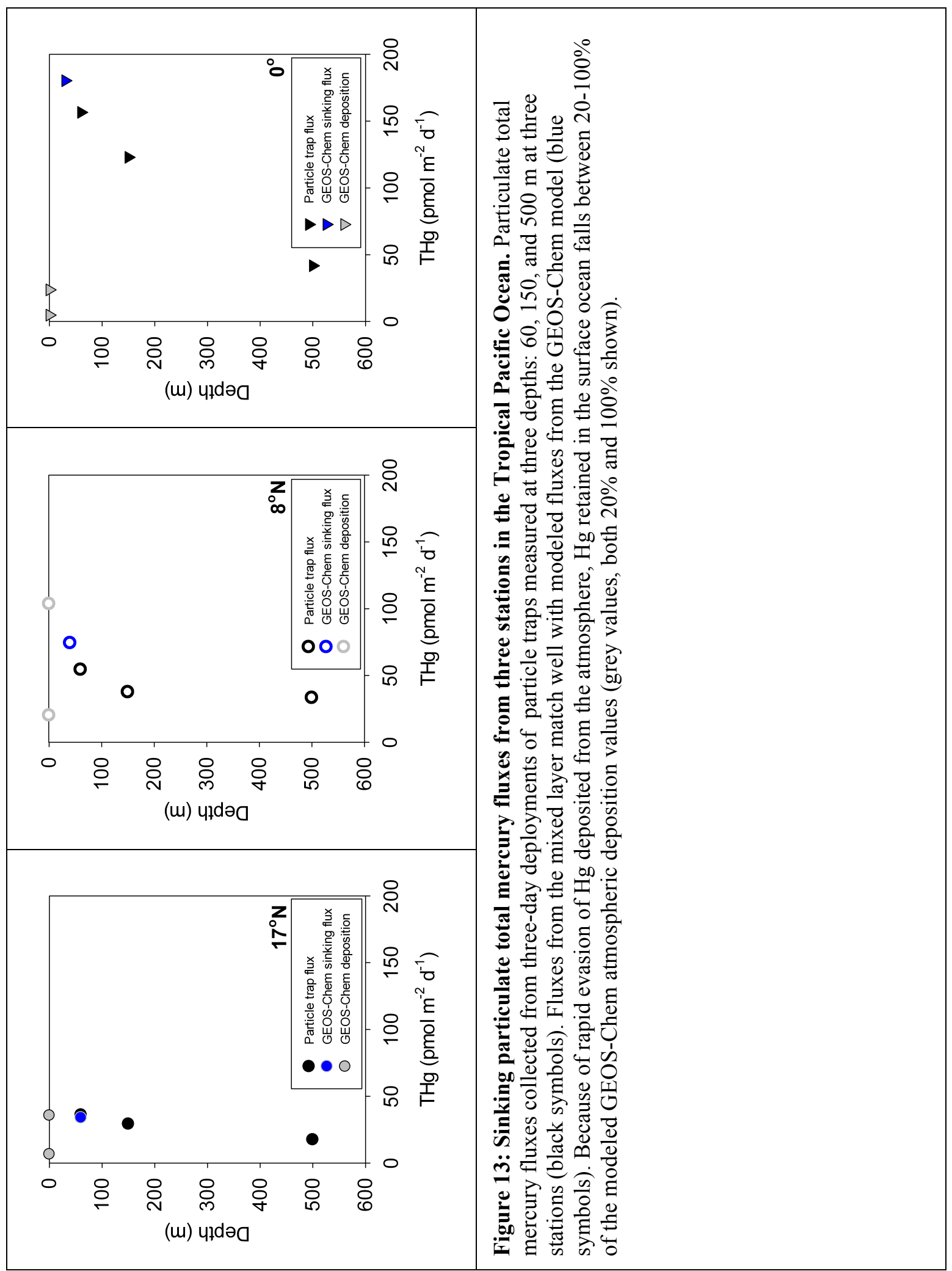


Figure 14: Total methylated mercury concentrations versus apparent oxygen utilization for all stations along Metzyme cruise track. Sum of methylated mercury (measured separately as $\mathrm{DMHg}$ and $\mathrm{MMHg}$ ) versus AOU (top image). Methylated mercury concentrations increase linearly with AOU at all intermediate depths and clump by station, most noticeably in the North Pacific. THg versus AOU (bottom image) show a similar relationship as MMHg versus AOU. The similar relationships suggest that remineralization does not stimulate methylation from $\mathrm{Hg}$ (II) substrate as has been hypothesized from North Pacific data [Sunderland et al, 2009].

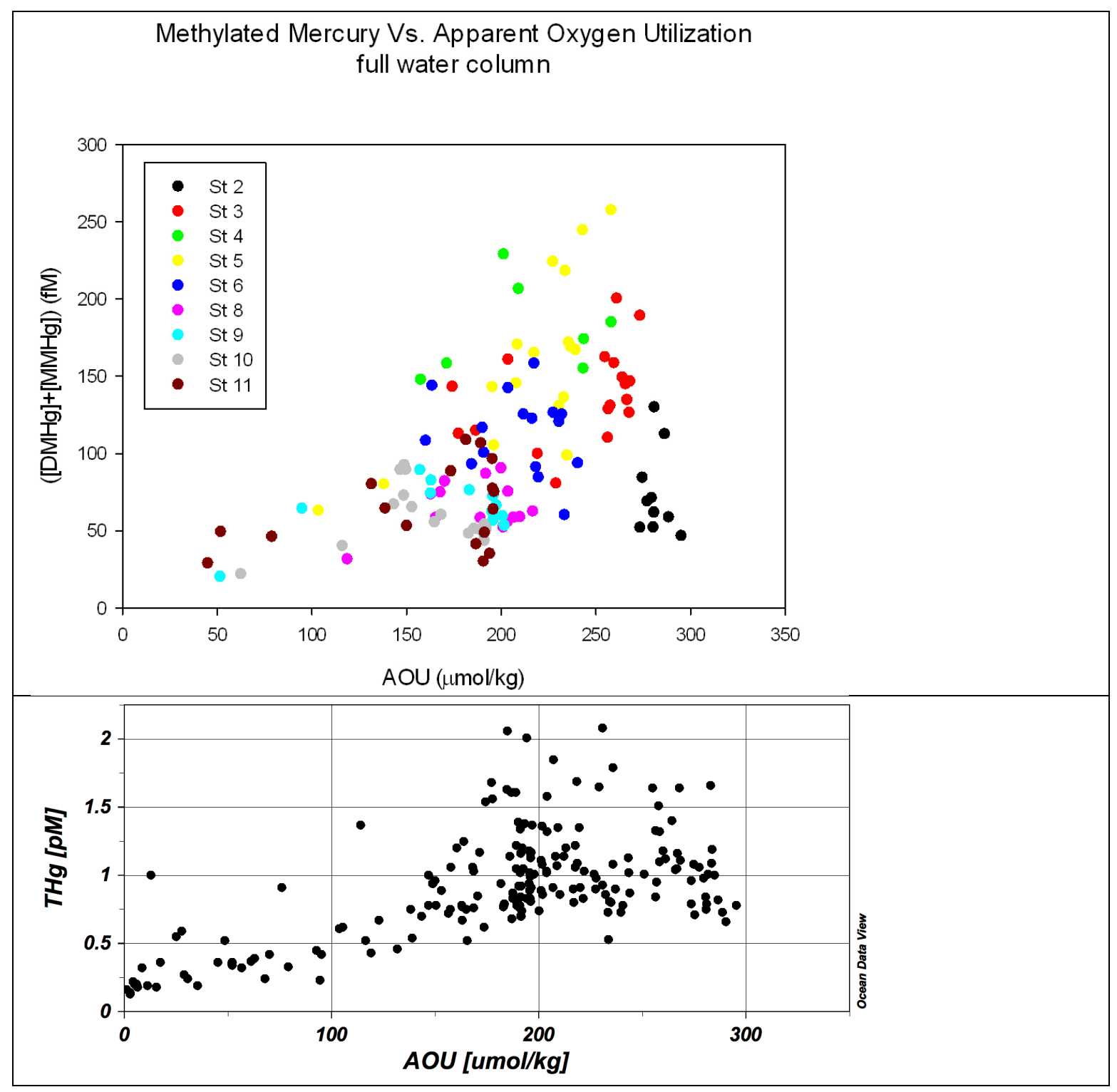


Figure 15: Ratios of monomethylmercury to dimethylmercury versus depth for four stations along the Metzyme cruise track. The ratios of dissolved MMHg:DMHg were generally low throughout the water column. Highest values were found at Station 3 (black circles) and Station 5 (white circles) compared to those observed in the South Pacific (triangles). The maximum and average values are both lower than those observed throughout the water column at the SAFe site North Pacific [Hammerschmidt and Bowman, 2012].

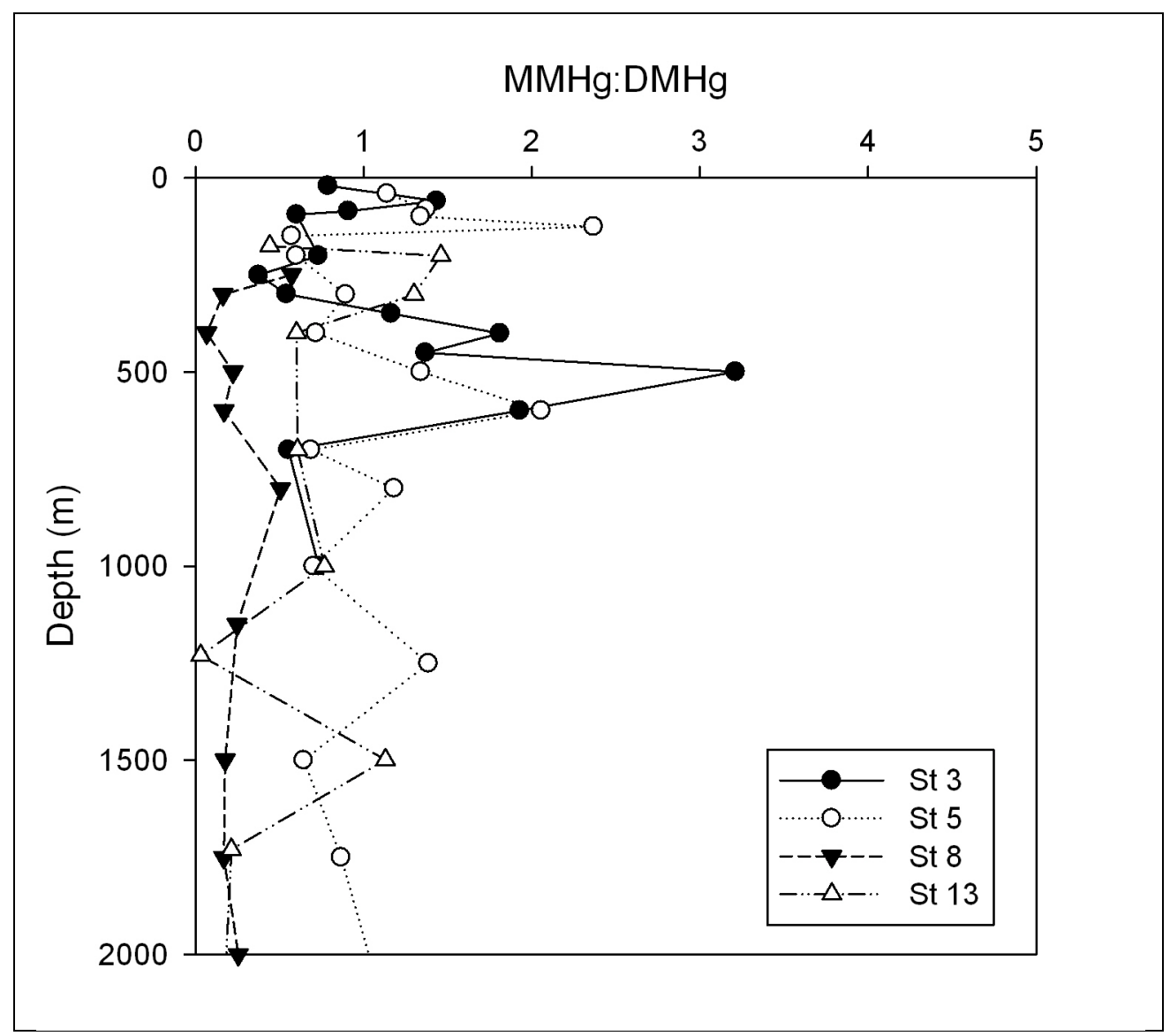


Figure 16: Depth profiles in the upper $1000 \mathrm{~m}$ of the Equatorial Pacific water column measured in 1990 by Mason and Fitzgerald and 2011 during the Metzyme cruise. Depth profiles of THg concentrations from stations measured during the 1990 Malcolm Balride cruise [Mason and Fitzgerald, 1993] compared to those stations closest in distance measured during the 2011 Metzyme cruise. Concentrations measured in 2011 appear lower than those measured 2 decades previously. In addition to differences in concentration, the earlier profiles of Mason and Fitzgerald display a more significant increase in THg concentrations both between 100-200 $\mathrm{m}$ as well as $\sim 500 \mathrm{~m}$. These features are absent from more recent distributions.

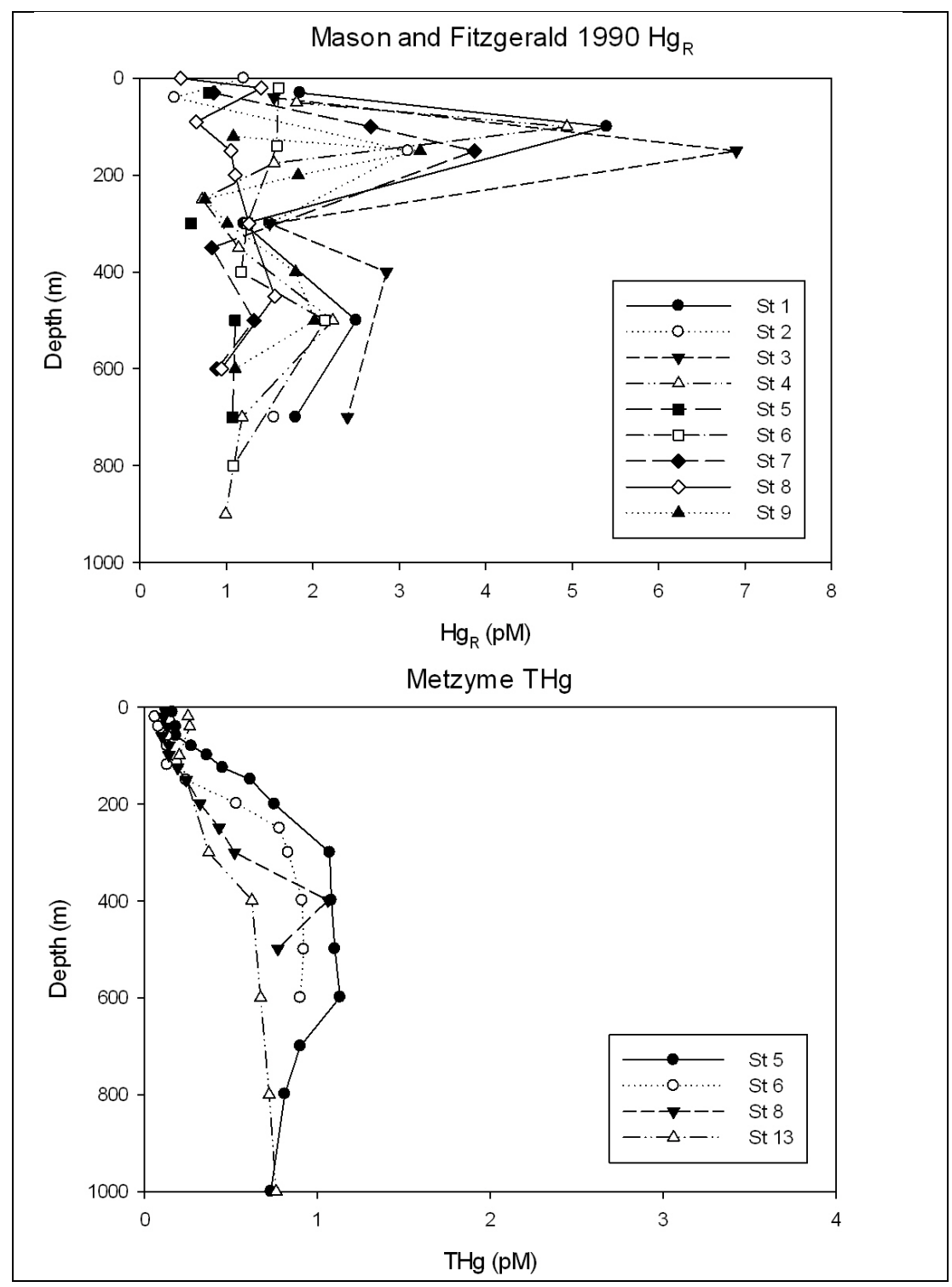


Figure 17: Total dissolved mercury concentrations in the water column measured at three sites in the North Pacific over a nine-year span. The International Oceanographic Commission 2002 (IOC 2002) data from Station Aloha [Laurier et al, 2004], the CLIVAR P16N 2006 data from Station 45 [Sunderland et al, 2009] and Station 1 of Metzyme sampled stations located within $\sim 750 \mathrm{~km}$ of one another.




Figure 18: Total dissolved methylated mercury and total mercury concentrations from the CLIVAR P16N section in the North Pacific and the Metzyme cruise in the Tropical Pacific. $\mathrm{THg}$ concentrations (top image) and methylated $\mathrm{Hg}$ (middle image) in intermediate waters from the CLIVAR P16N section [Sunderland et al, 2004] and continuing southwest with Metzyme stations. THg concentrations reveal the southward extent of North Pacific Intermediate Water is limited to $\sim 15^{\circ} \mathrm{N}$. Like THg, methylatedHg shows distinct distributions in the equatorial Pacific compared to those of the North Pacific Intermediate Water mass as indicated by salinity values (bottom right).

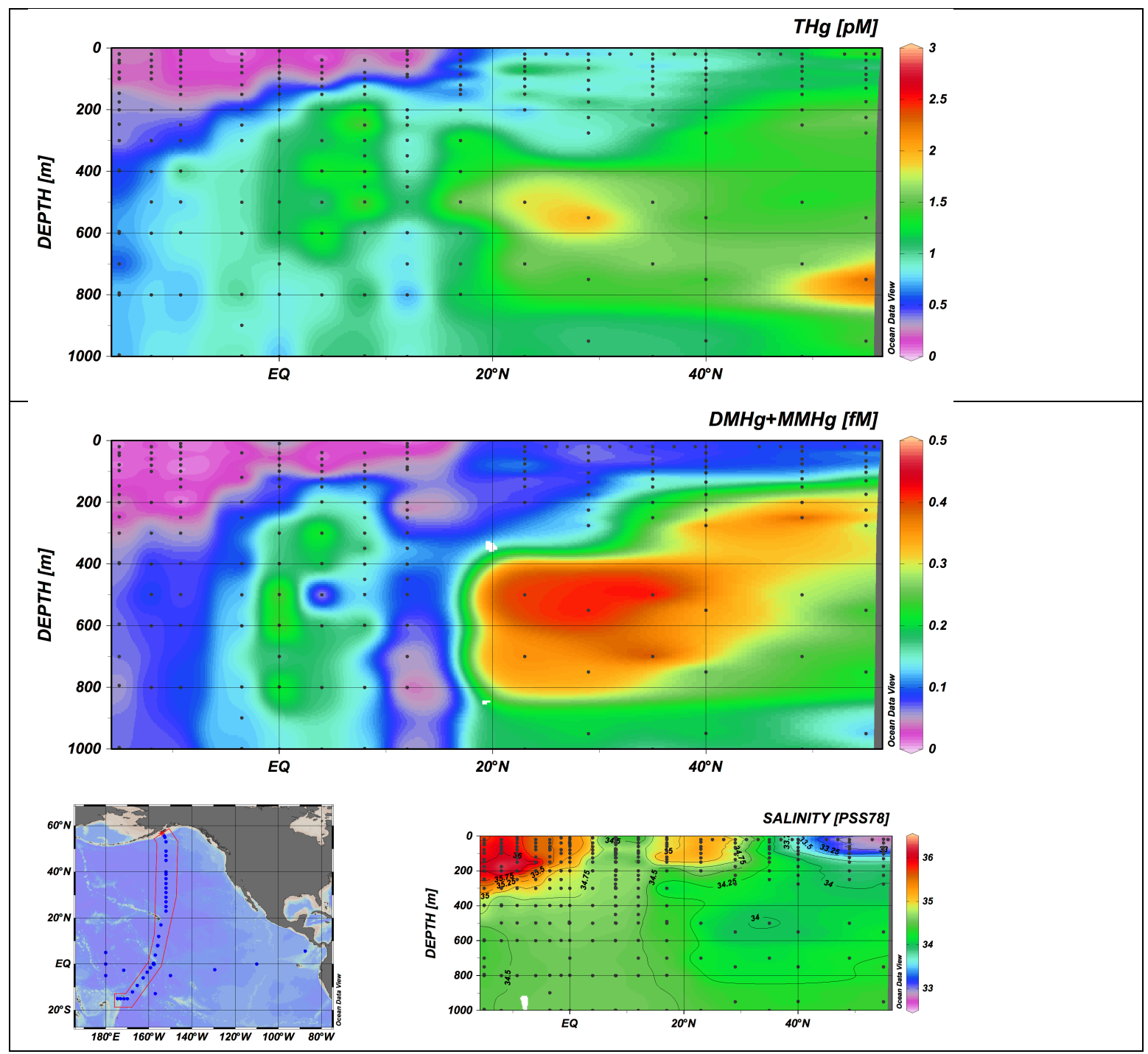




\section{Tables and Table Legends}

Table 1: Station coordinates and speciation samples collected at each station of Metzyme cruise.

\begin{tabular}{|l|l|l|l|}
\hline Station & Lat & Long & Samples \\
\hline 1 & $17^{\circ} \mathrm{N}$ & $154^{\circ} 24^{\prime} \mathrm{W}$ & $\mathrm{THg}, \mathrm{Hg}^{\circ}, \mathrm{DMHg}, \mathrm{THg}_{\text {part }}$, sed traps \\
\hline 2 & $12^{\circ} \mathrm{N}$ & $155^{\circ} 27^{\prime} \mathrm{W}$ & $\mathrm{THg}, \mathrm{Hg}^{\circ}, \mathrm{DMHg}, \mathrm{MMHg}(0-1000 \mathrm{~m})$ \\
\hline 3 & $8^{\circ} \mathrm{N}$ & $156 \mathrm{~W}$ & $\mathrm{THg}, \mathrm{Hg}^{\circ}, \mathrm{DMHg}, \mathrm{MMHg}, \mathrm{THg}$ part $_{\text {, }}$, sed traps \\
\hline 4 & $4^{\circ} \mathrm{N}$ & $157^{\circ} 05^{\prime} \mathrm{W}$ & $\mathrm{THg}, \mathrm{Hg}^{\circ}, \mathrm{DMHg}, \mathrm{MMHg}(0-1000 \mathrm{~m})$ \\
\hline 5 & 0 & $158^{\circ} \mathrm{W}$ & $\mathrm{THg}, \mathrm{Hg}^{\circ}, \mathrm{DMHg}, \mathrm{MMHg}, \mathrm{THg}_{\text {part }}$, sed traps $(0-3500 \mathrm{~m})$ \\
\hline 6 & $3^{\circ} 30^{\prime} \mathrm{S}$ & $160^{\circ} 46^{\prime} \mathrm{W}$ & $\mathrm{THg}, \mathrm{Hg}^{\circ}, \mathrm{DMHg}, \mathrm{MMHg}, \mathrm{THg}_{\text {part }}$ \\
\hline 7 & $5^{\circ} 58^{\prime} \mathrm{S}$ & $162^{\circ} 37^{\prime} \mathrm{W}$ & $\mathrm{No} \mathrm{Hg}$ samples collected \\
\hline 8 & $9^{\circ} 15^{\prime} \mathrm{S}$ & $165^{\circ} 22^{\prime} \mathrm{W}$ & $\mathrm{THg}, \mathrm{Hg}^{\circ}, \mathrm{DMHg}, \mathrm{MMHg}, \mathrm{THg}_{\text {part }}$ \\
\hline 9 & $12^{\circ} \mathrm{S}$ & $167^{\circ} 34 \mathrm{~W}$ & $\mathrm{THg}, \mathrm{Hg}^{\circ}, \mathrm{DMHg}, \mathrm{MMHg}, \mathrm{THg}_{\text {part }}$ \\
\hline 10 & $15^{\circ} \mathrm{S}$ & $170 \mathrm{~W}$ & $\mathrm{THg}, \mathrm{Hg}^{\circ}, \mathrm{DMHg}, \mathrm{MMHg}$ \\
\hline 11 & $15^{\circ} \mathrm{S}$ & $171^{\circ} 30^{\prime} \mathrm{W}$ & $\mathrm{No} \mathrm{Hg} \mathrm{samples} \mathrm{collected}$ \\
\hline 12 & $15^{\circ} \mathrm{S}$ & $173^{\circ} 06^{\prime} \mathrm{W}$ & $\mathrm{THg}, \mathrm{Hg}^{\circ}, \mathrm{DMHg}, \mathrm{MMHg}$ \\
\hline 13 & $15^{\circ} \mathrm{S}$ & $174^{\circ} 30^{\prime} \mathrm{W}$ & $\mathrm{THg}$ \\
\hline
\end{tabular}




\title{
Chapter 5 \\ Controsls on Mercury Methylation in the Tropical Pacific Ocean
}

\begin{abstract}
:
We measured potential mercury $(\mathrm{Hg})$ methylation rates along a transect in the Pacific Ocean. Using additions of isotopically enriched inorganic ( $\mathrm{Hg}(\mathrm{II}))$ and monomethylmercury $(\mathrm{MMHg})$ substrates to bottle incubations, we evaluated the potential role of heterotrophic bacteria in mercury methylation from dark incubations. Resulting methylation rates were measured using a linked gas chromatography cold vapor atomic fluorescent spectrometry inductively coupled plasma mass spectrometry (GC-CVAFS-ICPMS) method. Methylated Hg species concentrations are highest at depths of low dissolved oxygen concentrations in all waters along the transect. However, no significant differences in methylation potential were observed between unfiltered water collected from the deep chlorophyll maximum compared to water collected from the oxygen minimum zone within an individual station. Marine waters at a variety of depths have methylation potential despite significant differences in measured $\mathrm{MMHg}$ concentrations.

We also measured significant methylation potential in both $0.2 \mu \mathrm{m}$ filtered and unfiltered water collected from chlorophyll maximum and oxygen minimum depths, suggesting that methylation is not limited to cellular conversion in these waters. Additions of compounds such as cysteine and methylcobalamin, known to influence $\mathrm{MMHg}$ production in cultures of methylating anaerobic bacteria, do not indicate analogous mechanisms for marine methylation to that in anoxic sediments. More striking was the observation that addition of bulk organic matter collected from each station did not appear to enhance methylation, suggesting that methylation in Tropical Pacific waters is not unique to zones of net remineralization.

High-resolution sampling of methylation over a 36-hour incubation reveals dynamic methylation and demethylation of added $\mathrm{Hg}$ species even at locations with low ambient concentrations of DMHg and MMHg. These results suggest that MMHg available for bioaccumulation is likely controlled by competition between bioaccumulation, particle scavenging, and demethylation.
\end{abstract}




\section{Introduction}

Monomethylmercury (MMHg), the bioaccumulating form of mercury $(\mathrm{Hg})$, was first measured in the open ocean water column over two decades ago [Mason and Fitzgerald, 1990]. Since then, measurements of methylated $\mathrm{Hg}$, measured as either $\mathrm{MMHg}$, the nonbioaccumulating organic species dimethylmercury (DMHg), or the sum of $\mathrm{MMHg}$ and $\mathrm{DMHg}$ ( $\mathrm{MeHg}$ ), have revealed local maxima of methylated $\mathrm{Hg}$ species within regions of low oxygen [Mason and Fitzgerald 1993; Mason et al, 1998; Mason and Sullivan, 1999; Cossa et al, 1997; Cossa et al, 2009; Cossa et al, 2011; Sunderland et al, 2009; Hammerschmidt and Bowman, 2012; Munson, this work-Chapter 4]. As a result, MMHg production has been linked to active organic matter remineralization [e. g. Sunderland et al, 2009]. Limited direct water column measurements of mercury methylation have been performed in the Canadian Arctic Archipelago [Lehnherr et al, 2011] and coastal and open water sites in the Mediterranean [Monperrus et al, 2007a, b] from bottle incubations using additions of isotopically enriched mercury species. However, no mechanistic studies have been performed to identify environmental factors that control the production of $\mathrm{MMHg}$ in these regions of the water column.

Anthropogenic loadings of $\mathrm{Hg}$ to marine environments are thought to have increased 3fold since the Industrial Revolution [Lamborg et al, 2002] Various animal records, such as bird feathers [Vo et al, 2011] and egg shells [Xu et al, 2011] suggest that these THg increases result in subsequent increases in $\mathrm{MMHg}$ concentrations within marine food webs. Isotopic signatures of $\mathrm{Hg}$ in fish collected from the North Pacific indicate water column methylation as the primary source of MMHg [Blum et al, 2013], although the rate of increase in marine fish is debated [Kraepiel et al, 2003]. The transfer between dissolved Hg pools, biota, which result in elevated fish tissues concentrations is complex. Therefore, the controls on MMHg production and thus the available MMHg for bioaccumulation is essential to accurately predict how changes in total global $\mathrm{Hg}$ emissions will impact human MMHg exposure.

Anaerobic bacteria are known to methylate mercury in culture and anoxic sediments [Gilmour et al, 2013]. However, MMHg distributions measured in the Pacific Ocean to date have revealed elevated $\mathrm{MMHg}$ in open-ocean regions with dissolved $\mathrm{O}_{2}$ concentrations well above those classified as anoxic [Mason and Fitzgerald, 1993; Sunderland et al, 2009; Hammerschmidt and Bowman, 2012; Munson - this work, Chapter 4]. Analogous to other anaerobic processes, such as sulfate reduction, mercury methylation potentially occurs throughout the marine water column within anoxic microzones on particulate matter [e.g. Shanks and Reeder, 1993]. 
Alternatively, the requirement of low redox conditions for methylation by sulfate-reducing bacteria may limit their methylation activity in open-ocean regions, such as to areas of denitrification [Malcolm et al, 2010]. Recent measurements of potential methylation rates in high oxygen waters from marine euphotic zones have raised the question of the potential for aerobic mechanisms for $\mathrm{Hg}$ methylation that may be unique to marine systems [Monperrus et al, 2007; Lehnherr et al, 2011].

A substantial amount of work with cultured bacteria has revealed the important roles for specific chemical compounds with active marine cycling in anaerobic methylation. Sulfate- and iron-reducing bacteria utilize methylcobalamin (vitamin $\mathrm{B}_{12}$ ) as the methyl donor for [Ekstrom et al, 2003; Ekstrom and Morel 2008]. The recently identified $h g c$ methylation genes in anaerobes have clarified the link between methylcobalamin and $\mathrm{Hg}$ methylation as it encodes a cobalamin utilizing methyltransferase [Parks et al, 2013]. Methylcobalamin is produced by cyanobacteria found throughout marine euphotic zones [Bonnet et al, 2010]. However due to its universal requirements among marine phytoplankton, methylcobalamin is actively scavenged, most notably by diatoms [Bertrand et al, 2009]. As a result, concentrations of the vitamin in the open ocean can be limiting [Panzeca et al, 2009].

In addition to its roll in intracellular methylation, methylcobalamin is known to abiotically methylate $\mathrm{Hg}(\mathrm{II})$ at $\mathrm{pH} 4$ and has been considered as a potential abiotic mechanism of $\mathrm{MMHg}$ production in natural systems from laboratory studies and theoretical calculations [Celo et al, 2006; Jiménez-Moreno, 2013]. However, in marine waters where methylcobalamin is limiting, its dissolved concentrations might be too low to support a high degree of $\mathrm{Hg}$ methylation.

Low molecular weight thiols such as the amino acid cysteine and glutathione have been found to alternately stimulate or hinder active $\mathrm{Hg}$ (II) uptake by different species of anaerobic bacteria in culture [Schaefer and Morel, 2009; Schaefer et al, 2011]. The potential for stimulation of methylation in natural systems by thiol availability has not been investigated, but may be limited in oxic marine waters. Thiol mediated enhancement or suppression of $\mathrm{Hg}$ (II) uptake is specific to reduced species [Schaefer and Morel, 2009; Schaefer et al, 2011] and thiols found in marine waters may be oxidized in its primary role as a copper-binding ligand in low $\mathrm{Hg}$ marine waters [Kading, 2013]. Although previous measurements of dissolved thiols in marine waters have found that up to half may persist in their reduced forms [Dupont et al, 2006], distributions of small thiols such as cysteine and glutathione are found at nanomolar concentrations in the surface ocean, with depletion at depth [Kading, 2013; Swarr et al, 2012]. As a result, thiols may not 
impact marine methylation. However, the relatively small amount of $\mathrm{Hg}$ (II) methylation that is required to account for observed concentrations of $\mathrm{MeHg}$ in low oxygen waters, $<<1 \mathrm{pM}$ [Munson-this work, Chapter 4], and the ability of cysteine to increase methylation in E. coli under oxic conditions [Ndu et al, 2012] make thiols a target for studies of methylation in natural systems.

The potential for methylcobalamin and thiols to influence marine $\mathrm{Hg}$ methylation, either biotically or abiotically, has not been studied previously. A correlation between methylated $\mathrm{Hg}$ (as [DMHg $+\mathrm{MMHg}]$ ) and rates of organic matter remineralization has been observed in the North Pacific [Sunderland et al, 2009]. Bulk organic matter remineralization could potentially release MMHg outright or $\mathrm{Hg}(\mathrm{II})$ substrate for methylation by microbes. In contrast, remineralization may release a specific compound, such as methylcobalamin or a small thiol, that specifically promotes MMHg production.

We used isotopically enriched $\mathrm{Hg}$ species to simultaneously measure potential rates of methylation and demethylation from incubations of water collected along a cruise transect from the tropical North to the tropical South Pacific. In addition to measuring rates of net methylation and demethylation, we also investigated the impact of added organic matter, collected during the cruise as well as individual compounds known to stimulate methylation in culture experiments, including methylcobalamin [Ekstrom and Morel, 2008], and thiols [Schaefer and Morel, 2009, Schaefer et al, 2011]. We took the approach of a limitation experiment in order to determine whether methylation and demethylation in the marine water column are stimulated by bulk organic matter remineralization or the release of a specific compound that controls $\mathrm{Hg}$ dynamics. In addition, we compared potential rates of methylation in filtered and unfiltered water to determine the extent of cellular methylation in these environments.

\section{Methods}

Isotopically enriched $\mathrm{MM}^{198} \mathrm{Hg}$ and $\mathrm{MM}^{199} \mathrm{Hg}$ were prepared from ${ }^{198} \mathrm{HgO}$ and ${ }^{199} \mathrm{HgO}$

(Oak Ridge National Laboratory), respectively, by methylation with methylcobalamin [Hintelmann and Ogrinc, 2003]. A mass of $100 \mu \mathrm{g}$ of enriched $\mathrm{HgO}$ was dissolved in $10 \mu \mathrm{L} \mathrm{HCl}$ (conc, J. T. Baker) and diluted in $500 \mu \mathrm{L}$ sodium acetate buffer $(0.1 \mathrm{M}, \mathrm{pH}$ 5). A mass of $500 \mu \mathrm{g}$ of methylcobalamin (Sigma) was dissolved in $500 \mu \mathrm{L}$ sodium acetate buffer and added to the $\mathrm{Hg}$ solution. The reaction proceeded for 3 hours at room temperature before being stopped with 200 $\mu \mathrm{L} \mathrm{KBr}\left(0.3 \mathrm{M} \mathrm{KBr}\right.$ in $\left.2 \mathrm{M} \mathrm{H}_{2} \mathrm{SO}_{4}\right)$. The synthesized enriched MMHg was extracted with toluene 
(400 $\mu \mathrm{L}, 3 \mathrm{x}$ ). Extracts were combined and dried over sodium sulfate. A $100 \mu \mathrm{L}$ aliquot of this primary stock was dissolved in $10 \mathrm{~mL}$ isopropanol to produce a secondary stock solution. Because methylcobalmain was a target of our investigation for its potential role in in situ methylation, carryover of methylcobalamin from reaction solution was found to be minimal $(<1$ pM) from ICPMS analysis with a mixed metal standard.

Water for incubation experiments was collected on board the $R / V$ Kilo Moana between 124 October 2011 (Figure 1). Water filtration, decanting, and treatment additions were performed under positive pressure from HEPA-filter laminar flow hoods within clean bubbles constructed on board. Concentrations of THg and DMHg were measured at sea using established methods [Lamborg et al, 2012]. MMHg concentrations were measured on shore using ascorbic acidassisted direct ethylation [Munson - this work, Chapter 2], with the exception of $17^{\circ} \mathrm{N}$, where no $\mathrm{MMHg}$ samples were preserved. An estimate of MMHg at the Station 1 depths at which incubation experiments were performed was therefore calculated from the CVAFS peak data from incubation samples after correction for the added $\mathrm{MM}^{198} \mathrm{Hg}$ spike (Table). The calculated values fall within the range of methylHg (sum of DMHg and $\mathrm{MMHg}$ ) previously measured in North Pacific waters [Sunderland et al, 2009].

Water was collected from two depths at each station: 1) chlorophyll $a$ maximum and, 2) the oxygen minimum each identified from the SeaBird package data on prior water sampling casts at each station (Table 1). Water was collected in acid-washed X-Niskin bottles deployed on a dedicated trace metal sampling rosette using Amsteel metal-free wire.

Sufficient water for incubations was decanted under $\mathrm{N}_{2}$ pressure either unfiltered or filtered through a $0.2 \mu \mathrm{m}$ capsule filter ( $47-\mathrm{mm}$, Supor polycarbonate membrane, Pall Corporation) into 20-L acid-washed polycarbonate mixing carboys (Nalgene). The carboys were kept covered in dark plastic bags as much as possible during incubation preparation to minimize exposure to light.

Pre-equilibrated spikes of isotopically enriched $\mathrm{MM}^{198} \mathrm{Hg}$ and ${ }^{202} \mathrm{Hg}(\mathrm{II})$ were prepared by adding concentrated ${ }^{202} \mathrm{Hg}(\mathrm{II})$ and $\mathrm{MM}^{198} \mathrm{Hg}$ to $0.2-\mu \mathrm{m}$ filtered seawater and equilibrating at $16^{\circ} \mathrm{C}$ in the dark for 24 hours prior to use. Spikes were added using gas-tight syringes dedicated for use in isotope enrichment experiments (Hamilton).

Incubations were performed in triplicate in $250-\mathrm{mL}$ amber glass bottles (I-Chem) filled to the shoulder from mixing carboys. All bottles had approximately $25 \mathrm{~mL}$ of headspace. As a result, in situ redox conditions were not maintained during incubation. After water addition, pre- 
equilibrated spikes of ${ }^{202} \mathrm{Hg}$ (II) (396 fmoles) and $\mathrm{MM}^{198} \mathrm{Hg}$ (126 fmoles) were added. Treatments of C (as succinate), Cys, GSH, Co, $\mathrm{B}_{12}, 1 \frac{1}{2}$ of $2-\mathrm{cm}$ punches from McLane in situ pumps [Munson - this work, chapter 4], and additive treatments $\mathrm{C}+\mathrm{Co}$ and Cys $+\mathrm{Co}$ were added to triplicate bottles (Table 2). Prior to addition C, Cys, and GSH treatments were passed through a Chelex 100 resin (Bio Rad) column to remove Co and other divalent cations to avoid contamination by Co or other divalent metals.

Bottles for $t 0$ measurements were fixed after treatment addition with $1 \mathrm{~mL}(\sim 0.5 \%$, final) $\mathrm{H}_{2} \mathrm{SO}_{4}$ (conc., Fisher TM grade) and were stored at $-4^{\circ} \mathrm{C}$ until analysis except for bottles amended with methylcobalamin, which were frozen at $-40^{\circ} \mathrm{C}$ to avoid abiotic methylation under acidic conditions during storage. Station 1, 3, 5 bottles were incubated in the dark for $24 \mathrm{hr}$ at temperatures maintained in refrigerators set at their highest temperature setting (Table 1). Station 9 bottles were incubated in the dark up to $36 \mathrm{hr}$ in a time course study. After incubation, bottles for all time points were fixed with $\mathrm{H}_{2} \mathrm{SO}_{4}$ and stored at $-4^{\circ} \mathrm{C}$ or $-40^{\circ} \mathrm{C}$ for methylcobalamin as noted above. Because DMHg decomposes to MMHg in acidic conditions [Black et al, 2009], all measured MMHg concentrations represent the sum of DMHg and MMHg present at in each bottle at the time of acidification.

Analysis of MMHg concentrations and isotopic composition was performed on a Thermo Element 2 ICPMS in the Plasma Laboratory at the Woods Hole Oceanographic Institution. The inlet of the ICPMS was linked via a polyethylene y-junction to a Tekran 2700 Automated Methyl Mercury Detector.

Samples were prepared as for MMHg determination (above) using ascorbic-assisted direct ethylating of MMHg and simultaneous measurement of MMHg concentrations as well as isotopic composition by ICPMS.

$\mathrm{Hg}$ isotopes were measured individually and were integrated using MATLAB scripts to quantify relative isotopic ratios in the $\mathrm{MMHg}$ (as methylethylHg) and $\mathrm{Hg}$ (II) (as diethylHg) peaks. Resulting methylation of ${ }^{202} \mathrm{Hg}(\mathrm{II})$ and demethylation of $\mathrm{MM}^{198} \mathrm{Hg}$ were quantified using a matrix linear approach [Hintelmann and Ogrinc, 2003, see Appendix I for explicit calculations]. We added $\mathrm{MM}^{199} \mathrm{Hg}$ as an internal standard to samples and equilibrated for 24-hours prior to MMHg determination for isotope ratio-ICPMS [Hintelmann and Evans, 1997].

The two previously reported marine methylation rate measurements have used different methods to calculate $\mathrm{k}_{\mathrm{m}}$ values. Lehnherr et al, 2011 considered decreases in the available ${ }^{198} \mathrm{Hg}$ (II) substrate in their rate measurements. From CVAFS measurements of decreases in 
${ }^{198} \mathrm{Hg}$ (II) concentrations overtime from separate incubations of seawater, Lehnherr et al, 2011 fitted an exponential curve to the decrease in ${ }^{198} \mathrm{Hg}$ (II) that they incorporated into their calculations of $\mathrm{k}_{\mathrm{m}}$ [Lehnherr et al, 2011]. This was necessary because MMHg and $\mathrm{Hg}(\mathrm{II})$ could not be simultaneously determined with their analytical set up in individual bottles. In contrast, earlier measurements from Monperrus et al, 2007, assumed no decrease in $\mathrm{Hg}$ (II) substrate availability. $\mathrm{Hg}$ (II) is typically measured from tin chloride reduction followed by CVAFS analysis. Although not analytically identical, we observed quantitative recovery of $\mathrm{Hg}$ (II) from the diethylHg peak of the Tekran 2700 instrument used for CVAFS analysis (Figure 2A, also Figure 1 Munson - this work, Chapter 3). As a result, our rate measurements are presented as a modification of the Lehnherr et al, 2011 method. Instead of fitting a generalized curve of ${ }^{202} \mathrm{Hg}$ (II) substrate availability, we calculated methylation of ${ }^{202} \mathrm{Hg}$ (II) relative to available ${ }^{202} \mathrm{Hg}$ (II) measured in individual bottles. Results are presented as percentages of methylated ${ }^{202} \mathrm{Hg}$ (II) substrate. Potential methylation rate constants, $\mathrm{k}_{\mathrm{m}}$, were calculated as the percentage of methylated ${ }^{202} \mathrm{Hg}(\mathrm{II})$ substrate over the incubation time.

Potential demethylation rates were calculated assuming first order kinetics from the slope of the linear best fit line of $\operatorname{Ln}\left(\mathrm{MM}^{198} \mathrm{Hg}\right)$ vs. time.

\section{Results}

\section{Mercury Methylation: Unamended Samples}

Potential rates were measured across a variety of hydrographic parameters [Munsonthis work, Chapter 4] as well as ambient dissolved $\mathrm{Hg}$ concentrations. In general, concentrations of methylated $\mathrm{Hg}$, $\mathrm{THg}$, dissolved $\mathrm{O}_{2}$, and apparent oxygen utilization (AOU) [Sarmiento and Gruber, 2006; Garcia and Gordon, 1992] decreased north to south (Figure 3). A region of low oxygen intermediate waters centered at $12^{\circ} \mathrm{N}$ set apart high methylated $\mathrm{Hg}$ intermediate waters in the North Pacific [Sunderland et al, 2009] seen at $17^{\circ} \mathrm{N}$ (Figure 4) from a band of lower methylated $\mathrm{Hg}$ species concentrations between $8^{\circ} \mathrm{N}$ and $5^{\circ} \mathrm{S}$. Methylated $\mathrm{Hg}$ concentrations are higher in waters from oxygen minimum depths (82-310 $\mathrm{fM}$ methylated $\mathrm{Hg}$ ) relative to chlorophyll maximum depths (26-45 fM methylated Hg; Figure 4).

Production of $\mathrm{Me}^{202} \mathrm{Hg}$ (II) during 24-hour incubations did not correspond to ambient methylated $\mathrm{Hg}$ concentrations (Figure 10). Within the chlorophyll maximum, values for $\mathrm{k}_{\mathrm{m}}$ were highest at $8^{\circ} \mathrm{N}$ (CMX: $\left.5.71-10.19 \% / \mathrm{d}\right)$ and lowest at $17^{\circ} \mathrm{N}$ in the North Pacific (CMX: 0.39-0.43 $\% / \mathrm{d}$; Table 3) despite nearly identical ambient concentrations of methylated $\mathrm{Hg}$ (Table 1). Values 
for $\mathrm{k}_{\mathrm{m}}$ in oxygen minimums depths generally increased as ambient methylated $\mathrm{Hg}$ concentrations decreased, with the highest $\mathrm{k}_{\mathrm{m}}$ values measured at $8^{\circ} \mathrm{N}$ in the Tropical Pacific (OMZ: 3.77-7.40 $\% / \mathrm{d}$ ), intermediate $\mathrm{k}_{\mathrm{m}}$ values at the Equator (OMZ: 1.00-1.74 \%/d) and South Pacific (OMZ: $1.12-2.28 \% / \mathrm{d}$ ), and the lowest $\mathrm{k}_{\mathrm{m}}$ values measured at $17^{\circ} \mathrm{N}$ in the North Pacific (OMZ: 0.64-0.95 $\% /$ d) despite the fact that methylated $\mathrm{Hg}$ concentrations at $17^{\circ} \mathrm{N}$ were four times higher than those measured at $12^{\circ} \mathrm{S}$ (Table 1$)$.

Difference in $\mathrm{k}_{\mathrm{m}}$ values between $0.2 \mu \mathrm{m}$ filtered and unfiltered waters were largely insignificant at either depth measured (Table 3). Nor were there clear trends in $\mathrm{k}_{\mathrm{m}}$ values measured in waters from chlorophyll maximum depths compared to those measured from low oxygen depths.

Consistent with our methylation measurements from the Sargasso Sea [Munson- - this work, Chapter 3], we observed significant initial production of $\mathrm{Me}^{202} \mathrm{Hg}$ relative to added ${ }^{202} \mathrm{Hg}$ (II) spike within the $\sim 2$ hours of time between ${ }^{202} \mathrm{Hg}$ (II) spike addition and t0 sample preservation with acid (Figures 5). Initial methylation, like that of potential methylation rates, were highest at $8^{\circ} \mathrm{N}$ (CMX: 8.27-12.17\%/d; OMZ: 2.45-6.84\%/d), where it accounts for all methylation observed during the 24-hour incubations in the chlorophyll maximum waters (Figure 5). Initial methylation was lowest at $17^{\circ} \mathrm{N}$ (CMX: 0.28-0.47\%/d; OMZ: 0.54-0.66 \%/d), where methylation continued throughout the incubation period (Figure 5) as indicated by significant increases in methylation between $\mathrm{t} 0$ and $\mathrm{t} 24-\mathrm{hr}$ bottles.

Higher temporal resolution of sampling at the South Pacific station, $12^{\circ} \mathrm{S}$, reveals that methylation of added ${ }^{202} \mathrm{Hg}(\mathrm{II})$ is rapid, with maximum methylation reached within 6 hours, in unfiltered waters and subsequent demethylation of $\mathrm{Me}^{202} \mathrm{Hg}$ occurs within $\sim 12$ hours of total incubation time (Figure 6, white triangles). In contrast, $\mathrm{Me}^{202} \mathrm{Hg}$ produced in filtered waters is not rapidly demethylated and persists over the course of the incubation (Figure 6, black triangles). In contrast to Sargasso Sea waters, in which unfiltered waters appeared to support methylation throughout 24-hour incubations [Munson-this work, Chapter 3], the presence of particulate matter, either biotic or abiotic in origin, appears to enhance demethylation.

\section{Mercury Methylation: Amended Samples}

In general, the addition of compounds and bulk organic matter did not enhance the continual methylation of $\mathrm{Hg}$ (II) in 24-hour incubations. Since methylated $\mathrm{Hg}$ concentrations are typically highest in oxygen minimum zones of the water column, we hypothesized that the release 
of specific compounds, such as methylcobalamin and cysteine, could increase measured methylation rates at the chlorophyll maximum as these are areas of maximum plankton growth which may limit the availability of these compounds in $\mathrm{Hg}$ cycling. Limitation by any one of these compounds would have been indicated by increased $\mathrm{Me}^{202} \mathrm{Hg}$ production in amended waters collected from the chlorophyll maximum compared to those from the oxygen minimum. Amendment addition of all treatments, with the exception of methylcobalamin, appeared to increase initial methylation in both filtered and unfiltered waters (Figure 8, left panels) in waters from the chlorophyll maximum at $17^{\circ} \mathrm{N}$ and $12^{\circ} \mathrm{S}$. The magnitude of methylation upon treatment addition was enhanced in unfiltered waters compared to filtered waters (Figure 8, lower panels). In both filtered and unfiltered waters the combined cobalt and succinate treatment (CoC) produced the greatest stimulation of methylation relative to unamended samples as indicated by the values of the stimulation factor normalized to unamended incubations $(0.2 \mu \mathrm{m}: 2.48 \pm 0.41$ unfiltered: $3.64 \pm 0.32$ ) (Figure 8).

In oxygen minimum waters, treatment addition stimulated methylation in filtered waters at the Equator (Figure 9, top panels). This stimulation was maintained over the 24-hour incubation period (Figure 9, top right). The addition of treatments to unfiltered waters from oxygen minimum depths did not produce clear responses and high variability was seen between replicate samples (Figure 9, bottom panels).

Waters amended with methylcobalamin showed no abiotic methylation of ${ }^{202} \mathrm{Hg}(\mathrm{II})$. In contrast, addition of methylcobalamin appeared to promote reduction of ${ }^{202} \mathrm{Hg}$ (II) as indicated by the increase in ${ }^{202} \mathrm{Hg}$ in the $\mathrm{Hg}(0)$ peaks in the chromatograms (Figure 2). However, recovery of $\mathrm{Hg}(0)$ concentrations were not quantified in our analysis, so the extent to which reduction takes place and whether ${ }^{202} \mathrm{Hg}$ (II) is reduced prior to or following methylation could not be precisely determined.

Despite the ability of many individual compound additions to stimulate methylation in waters from chlorophyll maximum depths (Figure 8), the addition of bulk organic matter from McLane pump filters did not appear to stimulate methylation for most stations. The only exception was modest stimulation in filtered waters from the chlorophyll maximum at $8^{\circ} \mathrm{S}$ (stimulation factor normalized to unamended incubations, punch: $1.65 \pm 0.20$ ). The pump filter punch additions are a complex, and uncharacterized, mixture of inorganic matter and organic matter, including cells that are smaller than the $\sim 51 \mu \mathrm{m}$. As a result, addition of pump punches to $0.2 \mu \mathrm{m}$ filtered seawater inoculates these samples with uncharacterized bacterial communities as 
well as adding both particles and organic matter. The punch treated $0.2 \mu \mathrm{m}$ filtered samples therefore represent a combination of cellular and non cellular methylation potential.

\section{Mercury Demethylation}

Measurements of $\mathrm{MM}^{198} \mathrm{Hg}$ remaining at time points indicated initial demethylation of the added $\mathrm{MM}^{198} \mathrm{Hg}$ spike prior to t0, which prevented calculations of $\mathrm{k}_{\mathrm{d}}$. The only exception to this was in unfiltered water from the oxygen minimum depth of $12^{\circ} \mathrm{S}$ (Figure 7). In these samples, $\mathrm{MM}^{198} \mathrm{Hg}$ persisted through 12 hours of incubation resulting in a calculated $\mathrm{k}_{\mathrm{d}}$ of 5.06 $\left(d^{-1}\right)$ from the slope of the line of $\ln \left(\mathrm{MM}^{198} \mathrm{Hg}\right)$ vs. incubation time.

\section{Discussion}

Correlations between methylated $\mathrm{Hg}$ concentrations and regions of net organic matter remineralization have implicated in situ methylation as a significant source of methylated $\mathrm{Hg}$ to the marine water column [Sunderland et al, 2009; Cossa et al, 2011; etc.]. Parallels between oxygen minimum zones within the marine water column and the production of MMHg by anaerobic bacteria have led to suggestions that marine bacteria methylate $\mathrm{Hg}$ in these environments [Mason and Fitzgerald, 1993]. However, previous measurements of methylation in low oxygen waters have failed to identify marine anaerobes that are capable of methylating $\mathrm{Hg}$ [Malcolm et al, 2010]. In the two previous measurements of potential methylation rates in marine waters only those in the Mediterranean distinguished between abiotic and biotic methylation [Monperrus et al, 2007]. However, the use of a 45- $\mu \mathrm{m}$ size cut off between filtered and unfiltered water and dark controls compared to diurnal incubations in that study did not account for the activity of heterotrophic bacteria, which are often small enough to pass through $45-\mu \mathrm{m}$ filters [Lalli and Parsons, 1997]. Potential methylation rates have also been measured in unfiltered water in the Canadian Arctic Archipelago and methylation observed during incubations were assumed to be due to bacterial activity [Lehnherr et al, 2011]. As a result, the current study is the first to quantify methylation potential by particulate matter including heterotrophic bacteria and to examine potential limitations of $\mathrm{Hg}$ methylation by compounds released during organic matter remineralization.

Across substantial gradients in the Pacific Ocean, we observed significant methylation potential in waters from both the chlorophyll maximum and oxygen minimum depths. In addition, methylation potential was not limited to unfiltered water. Despite pre-equilibration of enriched 
$\mathrm{Hg}$ species spikes in filtered seawater prior to addition to bottle incubation, initial methylation was measured in all waters and contributed the majority of methylation in oligotrophic waters at $12^{\circ} \mathrm{S}$. Higher temporal resolution of incubations from $12^{\circ} \mathrm{S}$ show dynamic methylation and demethylation processes take place within the time course of incubations, similar to observations of methylation in oligotrophic waters of the Sargasso Sea [Munson-this work, Chapter 3]. However, in the South Pacific, methylation over the entire 36-hour incubation period appears to be controlled by particle-induced demethylation of newly produced $\mathrm{Me}^{202} \mathrm{Hg}$ after rapid production. The $\mathrm{Me}^{202} \mathrm{Hg}$ produced in unfiltered waters from the oxygen minimum depth at $12^{\circ} \mathrm{S}$ is quickly demethylation (Figure 6, white triangles). Methylation in filtered waters is similar in magnitude to that in unfiltered waters but persists over the course of the incubation (Figure 6, black triangles).

Consistent with previous measurements from Arctic and Mediterranean waters [Lehnherr et al, 2011; Monperrus et al, 2007], values of $\mathrm{k}_{\mathrm{m}}$ measured in the water column along a transect of the Pacific are decoupled from ambient concentrations of methylated $\mathrm{Hg}$ (Figure 10). Previous work has suggested that in situ methylation within low oxygen depths of the North Pacific result in elevated methylated $\mathrm{Hg}$ concentrations [Sunderland et al, 2009]. The northernmost of our incubations, at $17^{\circ} \mathrm{N}$, took place within $750 \mathrm{~km}$ of waters sampled by Sunderland et al, 2009. At $17^{\circ} \mathrm{N}$, we observed no significant difference in potential methylation rates between the chlorophyll maximum and oxygen minimum depths despite a difference of $\sim 300 \mathrm{fM}$ between ambient methylated Hg concentrations between the two depths (Figure 4). Furthermore, the addition of bulk organic matter from McLane pump filters to bottle incubation did not enhance potential methylation in waters collected from this site. These observations suggest that delivery of $\mathrm{Hg}(\mathrm{II})$ by organic matter does not limit methylated $\mathrm{Hg}$ production in North Pacific waters.

Full $\mathrm{Hg}$ speciation measurements at Station 1 [Munson - this work, Chapter 3] reveal substantial concentrations of $\mathrm{Hg}(\mathrm{II})(\sim 1 \mathrm{pM}$, calculated as: [THg] - [Hg(0)] - [DMHg] $[\mathrm{MMHg}])$ are found in low oxygen waters at all stations where potential methylation rates were measured (Figure 11). The detection of $\mathrm{Hg}$ (II) does not provide information about its availability to processes or metabolisms involved in methylation. However, the relatively high concentrations of $\mathrm{Hg}(\mathrm{II})$ implies that methylation along the transect is not solely limited by $\mathrm{Hg}$ (II) substrate availability.

Laboratory studies have speculated that abiotic methylation of $\mathrm{Hg}$ (II) by methylcobalamin may be a possible methylation pathway in natural systems [Celo et al, 2006; 
Jimenez-Moreno, 2013]. The addition of methylcobalamin to seawater incubations resulted net reduction of $\mathrm{Hg}(\mathrm{II})$ to $\mathrm{Hg}(0)$ rather than methylation (Figure 2). As a result, we do not believe abiotic methylation by methylcobalamin is a significant source of methylated $\mathrm{Hg}$ to Equatorial Pacific waters.

Despite the lack of methylation by methylcobalamin, non cellular methylation appears to be a significant source of MMHg production and dominated total methylation measured over 24hour incubations (Figure 5). The use of $0.2 \mu \mathrm{m}$ filtered and unfiltered seawater to quantify methylation by heterotrophic bacteria is an operational distinction. Although hard to quantify, cells have been found in marine waters after filtration through $0.2 \mu \mathrm{m}$ filters in the Mediterranean and Sargasso Sea [Haller et al, 1999; Li and Dickie, 1985] under vacuum filtration. These socalled ultramicrobacteria $\left(<0.1 \mu \mathrm{m}^{3}\right.$ volume) [reviewed by Duda et al., 2012] may include cells in starvation or inactive forms, cells with flexible walls that allow them to pass through filter pores, and cells that are $<0.2 \mu \mathrm{m}$ regardless of their stage of life or nutrient status [Heller et al, 1999]. The smallest identified free-living marine cells, the SAR11 clade, have diameters of 0.12-0.20 $\mu \mathrm{m}$ [Rappé et al, 2002]. In addition, viruses, and cell materials may pass through filters. As a result, we have avoided referring to filtered water as abiotic because they likely contain materials of biological origin. However, $0.2 \mu \mathrm{m}$ filtration would potentially collect a subset any potentially intact cells such as SAR11 due to clogging of filters. In addition, if the cells that pass through filters are sessile or, like SAR11, have slow growth rates (0.40-0.58 $\left.\mathrm{d}^{-1}\right)$ [Rappé et al, 2002], filtered waters would likely have lower cell density and less diversity in the active metabolisms present compared to unfiltered waters. As a result, we have not attributed the high methylation observed in filtered waters to cellular mechanisms because such an assumption would require a number of processes, such as reactivation of sessile cells, rapid rates of cell growth, and/or preferential selection of $\mathrm{Hg}$ (II) methylating cells during filtration that cannot be determined from our experimental design. Under the assumption that filtration removed a majority of the heterotrophic bacteria relative to unfiltered waters, methylation in $0.2 \mu \mathrm{m}$ filtered Tropical Pacific waters that was equal or greater than that of unfiltered waters (Figure 5) suggests that heterotrophic bacterial methylation is not the primary source of methylated $\mathrm{Hg}$ to these waters. Instead, the presence of particles appeared to enhance demethylation of $\mathrm{Me}^{202} \mathrm{Hg}$ that can be rapidly produced in all marine waters.

Previous reports of methylation rates have differed in their considerations of available $\mathrm{Hg}$ (II) substrate. Monperrus et al, 2007 assumed a constant supply of $\mathrm{Hg}$ (II) substrate for 
methylation. In contrast, the rates presented by Lehnherr et al, 2011 were calculated from an increase in isotopically enriched MMHg relative to available $\mathrm{Hg}(\mathrm{II})$ substrate. However, in their experiments the available $\mathrm{Hg}$ (II) substrate was measured in separate bottle experiments [Lehnherr et al, 2011]. Although we were unable to calculate demethylation rates in the majority of samples, methylation potential was seen in $0.2 \mu \mathrm{m}$ filtered water, and often in excess of methylation potential in unfiltered samples, suggesting that a generalized loss of $\mathrm{Hg}$ (II) in not an accurate representation of $\mathrm{Hg}(\mathrm{II})$ availability for calculations for similar dual isotope tracer experiments.

\section{Acknowledgements}

This work was funded by the National Science Foundation in a Chemical Oceanography Program Grant (OCE-1031271) awarded to C. H. Lamborg and M. A. Saito and a Graduate Student Fellowship to K. M. Munson. The authors thank Vic Polidoro, Trevor Young, Captain Drewry, and the crew of the $R / V$ Kilo Moana.

\section{References}

Bertrand, E. M, M. A. Saito, J. M. Rose, C. R. Riesselman, M. C. Lohan, A. E. Noble, P. A. Lee, and G. R. DiTullio (2007) Vitamin B12 and iron co-limitation of phytoplankton growth in the Ross Sea. Limnol. Oceanogr., 52, 1079-1093.

Black, F. J., C. H. Conaway, and A. R. Flegal (2009) Stability of dimeethylmercury in seawater and its conversion to monomethyl mercury. Environ. Sci. Technol., 43, 4056-4062.

Blum, J. D., B. N. Popp, J. C, Drazen, C. A. Choy, and M. W. Johnson (2013) Methylmercury production below the mixed layer in the North Pacific Ocean, Nature Geosci. 6, 879-884.

Bonnet, S., E. A. Webb, C. Panzeca, D. M. Karl, D. G. Capone, and S. A. Sañudo-Wilhelmy (2010) Vitamin B12 excretion by cultures of the marine cyanobacteria Crocosphaera and Synechococcus, Limnol. Oceanogr., 55, 1959-1964.

Celo, V., D. R. S. Lean, and S. L. Scott (2006) Abiotic methylation of mercury in the aquatic environment, Sci Tot Environ., 368, 126-137.

Cossa, D., J.-M. Martin, K. Takayanagi, J. Sanjuan (1997) The distribution and cycling of mercury species in the western Mediterranean. Deep-Sea Res. II 44, 721-740.

Cossa, D., B. Averty, and N. Pirrone (2009) Origin of methylmercury in open Mediterranean waters, Limnol. Oceanogr. 54, 837-844. 
Cossa, D., L.-E. Heimbürger, D. Lannuzel, S. R. Rintoul, E. C. V. Butler, A. R. Bowie, B. Averty, R. J. Watson, and T. Remenyi (2011) Mercury in the Southern Ocean, Geochim Cosmochim Acta, 75, 4037-4052.

Droop, M. R. (2007) Vitamins, phytoplankton and bacteria: symbiosis and scavenging? J. Plankton Res., 29, 107-113.

Duda, V. I., N. E. Suzina, V. N. Polvtseva, and A. M. Boronin (2012) Ultramicrobacteria: formation of the concept and contribution of ultramicrobacteria to biology, Microbiol. 81, 379390.

Dupont, C. L., J. W. Moffett, R. R. Bidigare, and B. A. Ahner (2007) Distributions of particulate and dissolved thiols in the sub-polar North Pacific. Deep-Sea Res. I 53, 1961-1974.

Ekstrom, E. B., F. M. M. Morel, and J. M. Benoit (2003) Mercury methylation independent of the acetyl-coenzyme A pathway in sulfate-reducing bacteria, Appl. Environ. Microbiol., 69, 54145422 .

Ekstrom, E. B, and F. M. M. Morel (2008) Cobalt limitation of growth and mercury methylation in sulfate-reducing bacteria. Environ. Sci. Technol., 42, 93-99.

Filipelli, M., and F. Baldi (1993) Alkylation of ionic mercury to methylmercury and dimethylmercury by methylcobalamin: simultaneous determination by purge-and-trap GC in line wth FTIR, Appl. Organometallic Chem., 7, 487-493.

Garcia, H. E., and L. I. Gordon (1992) Oxygen solubility in seawater: better fitting equations, Limnol. Oceanogr., 37(6), 1307-1312.

Gilmour, C. C., M. Podar, A. L. Bullock, A. M. Graham, S. D. Brown, A. C. Somenahally, A. Johs, R. A. Hurt Jr., K. L. Bailey, and D. A. Elias (2013) Mercury methylation by novel microorganisms from new environments, Environ. Sci. Technol., 47, 11810-11820.

Gosnell, K., R. P. Mason, and P. H. Balcom (2013) Inorganic mercury and methylmercury concentrations in south-central Pacific phytoplankton and zooplankton, International Conference on Mercury as a Global Pollutant, Edinburgh, UK.

Graham, A. M., A. L. Bullock, A. C. Maizel, D. A. Elias, and C. C. Gilmour (2012) Detailed assessment of the kinetics of $\mathrm{Hg}$-cell association, $\mathrm{Hg}$ methylation, and methylmercury degradation in several Desulfovibrio species, Appl. Environ. Microbiol., 78, 7337-7346.

Haller, C. M., S. Rolleke, D. Vybiral, A. Witte, B. Velimirov (1999) Investigation of $0.2 \mu \mathrm{m}$ filterable bacteria from the Western Mediterranean Sea using a molecular approach: dominance of potential starvation forms. FEMS Microbiol. Ecol., 31, 153-161.

Hammerschmidt, C. R., and K. L. Bowman (2012) Vertical methylmercury distribution in the subtropical North Pacific Ocean, Mar. Chem., 132-133, 77-82. 
Hintelmann, H., and R. D. Evans (1997) Application of stable isotopes in environmental tracer studies - measurement of monomethylmercury $\left(\mathrm{CH}_{3} \mathrm{Hg}^{+}\right)$by isotope dilution ICP-MS and detection of species transformation, Fresenius J. Anal. Chem., 358, 378-385.

Hintelmann, H., and N. Ogrinc (2003) Determination of stable mercury isotopes by ICP/MS and their application in environmental studies, in Biogeochemistry of environmentally important trace elements, Eds: Cai, Y., and C. O. Braids, ACS Symp Ser Vol. 835, Washington, DC, p. 321-338.

Jiménez-Moreno, J., V. Perot, V. N. Epov, M. Monperrus, and D. Amouroux (2013) Chemical kinetic isotope fractionation of mercury during abiotic methylation of $\mathrm{Hg}$ (II) by methylcobalamin in aqueous chloride media, Chem. Geol., 336, 26-36.

Kading, T. (2013) Distribution of thiols in the northwest Atlantic Ocean. Master's thesis. MIT/WHOI Joint Program in Chemical Oceanography.

Kraepiel, A. M. L., K. Keller, H. B. Chin, E. G. Malcolm, F. M. M. Morel (2003) Sources and variations of mercury in tuna. Environ. Sci. Technol., 37, 5551-5558.

Lalli, C., and T. Parsons (1997) Biological Oceanography: An introduction. $2^{\text {nd }}$ ed. ButterworthHeinemann.

Lamborg, C., W. Fitzgerald, J. O'Donnell, and T. Torgensen (2002) A non-steady-state compartmental model of global scale mercury biogeochemistry with inter-hemispheric atmospheric gradients. Geochim. Cosmochim. Acta 66, 1105-1118.

Lamborg, C. H., C. R. Hammerschmidt, G. A. Gill, R. P. Mason, and S. Gichuki (2012) An intercomparison of procedures for the determination of total mercury in seawater and recommendations regarding mercury speciation during GEOTRACES cruises. Limnol. Oceanogr. Methods, 10, 90-100.

Lehnherr, I., V. L. St Louis, H. Hintelmann, and J. L. Kirk (2011) Metyhlation of inorganic mercury in polar marine waters, Nature Geosci., 4, 298-302.

Li, W. K. W., and P. M. Dickie (1985) Growth of bacteria in seawter filtered throu $0.2 \mu \mathrm{m}$ Nucleopore membraines: implications for dilution experiments. Mar. Ecol. Prog. Ser. 26, 245252.

Malcolm, E. G., J. K. Schaefer, E. B. Ekstrom, C. B. Tuit, A. Jayakumar, H. Park, B. B. Ward, and F. M. M. Morel (2010) Mercury methylation in oxygen deficient zones of the oceans: no evidence for the predominance of anaerobes, Mar. Chem., 122, 11-19.

Mason, R. P., and W. F. Fitzgerald (1990) Alkylmercury species in the equatorial Pacific. Nature $347,457-459$.

Mason, R. P., and W. F. Fitzgerald (1993) The distribution and cycling of mercury in the equatorial Pacific Ocean. Deep Sea Res. Part I 40, 1897-1924. 
Mason, R. P., K. A. Sullivan (1999) The distribution and speciation of mercury in the south and equatorial Atlantic. Deep Sea Res II, 46, 937-956.

Mason, R. P., K. R. Rolfhus, W. F. Fitzgerald (1998) Mercury in the North Atlantic. Mar. Chem. 61, 37-53.

Monperrus, M., E. Tessier, D. Amouroux, A. Leynaert, P. Huonnic, and O. F. X. Donard (2007) Mercury methylation, demethylation and reduction rates in coastal and marine surface waters of the Mediterranean Sea, Mar. Chem., 107, 49-63.

Monperrus, M., E. Tessier, D. Point, K. Vidimova, D. Amouroux, R. Guyoneaud, A. Leynaert, J. Grall, L. Chauvaud, G. Thouzeau, and O. F. X. Donard (2007) The biogeochemistry of mercury at the sediment-water interface in the Thau Lagoon. 2. Evaluation of mercury methylation potential in both surface sediment and the water column. Est. Coast. Shelf Sci., 72, 485-496.

Ndu, U., R. P. Mason, H. Zhang, S. Lin, and P. T. Visscher (2012) Effect of inorganic and organic ligands on the bioavailability of methylmercury as determined by using a mer-lux bioreporter. Appl. Environ. Microbiol., 78, 7276-7282.

Panzeca, C., A. J. Beck, A. Tovar-Sanchez, J. Segovia-Zavala, G. T. Taylor, C. J. Gobler, and S. A. Sanudo-Wilhelmy (2009) Distributions of dissolved vitamin B12 and Co in coastal nad openocean environments, Estuar. Coast. Shelf Sci., 85, 223-230.

Parks, J. M., A. Johs, M. Podar, R. Bridou, R. A. Hurt, S. D. Smith, S. J. Tomanicek, Y. Qian, S. D. Brown, C. C. Brandt, A. V. Palumbo, J. C. Smith, J. D. Wall, D. A. Elias, and L. Liang (2013) The genetic basis for bacterial mercury methylation, Science, 339, 1332-1335.

Rappé, M. S., S. A. Connon, K. L. Vergin, and S. J. Giovannoni (2002) Cultivation of the ubiquitous SAR11 marine bacterioplankton clade, Nature, 418, 630-633.

Sarmiento, J. L., and N. Gruber (2006) Ocean Biogeochemical Dynamics, 526pp., Princeton University Press, Princeton, New Jersery.

Schaefer, J. K., and F. M. M. Morel (2009) High methylation rates of mercury bound to cysteine by Geobacter sulfurreducens, Nature Geosci., 2, 123-126.

Schaefer, J. K., S. S. Rocks, W. Zheng, L. Liang, B. Gu, and F. M. M. Morel (2011) Active transport, substrate specificity, and methylation of $\mathrm{Hg}$ (II) in anaerobic bacteria. Proc. Natl. Acad. Sci., 108, 8714-8719.

Shanks, A. L., and M. L. Reeder (1993) Reducing microzones and sulfide production in marine snow. Mar. Ecol. Prog. Ser. 96, 43-47.

Stramma, L., Johnson, G. C., Sprintall, J., and V. Mohrholz (2008) Expanding oxygen-minimum zones in the tropical oceans, Science, 320, 655-658. 
Sunderland, E. M., D. P. Krabbenhoft, J. W. Moreau, S. A. Strode, and W. M. Landing (2009) Mercury sources, distribution, and bioavailability in the North Pacific Ocean: insights from data and models. Gobal Biogeochem. Cy., 23, GB2010.

Swarr, G., T. Kading, C. Lamborg, and C. Hammerschmidt (2013) Profiles of cysteine and glutathione from the U.S. North Atlantic GEOTRACES zonal transect. Presentation at the Aquatic Science Meeting of the Association of Limnology and Oceanography, New Orleans, LA.

Vo, A.-T. E., M. S. Bank, J. P. Shine, and S. V. Edwards (2011) Temporal increase in organic mercury in an endangered pelagic seabird assessed by century-old museum specimens. Proc. Natl. Acad. Sci. 108, 7466-7471.

Xu, L.-Q., X.-D. Liu, L.-G. Sun, Q.-Q. Chen, H. Yan, Y. Liu, Y.-H. Luo, and J. Huang (2011) A 700 -year record of mercury in avian eggshells of Guangjin Island, South China Sea. Environ.

Pollut., 159, 889-896. 
Figures and Figure Legends

Figure 1: Map of stations where mercury methylation incubations were performed in the Pacific Ocean along the Metzyme cruise track. Measurements of potential methylation were performed at $17^{\circ} \mathrm{N}, 8^{\circ} \mathrm{N}, 0^{\circ}$, and $12^{\circ} \mathrm{S}$ (circled) in the Tropical and Equatorial Pacific Ocean. The cruise track spanned a large gradient in hydrographic parameters and ambient methylated $\mathrm{Hg}$ species concentrations.

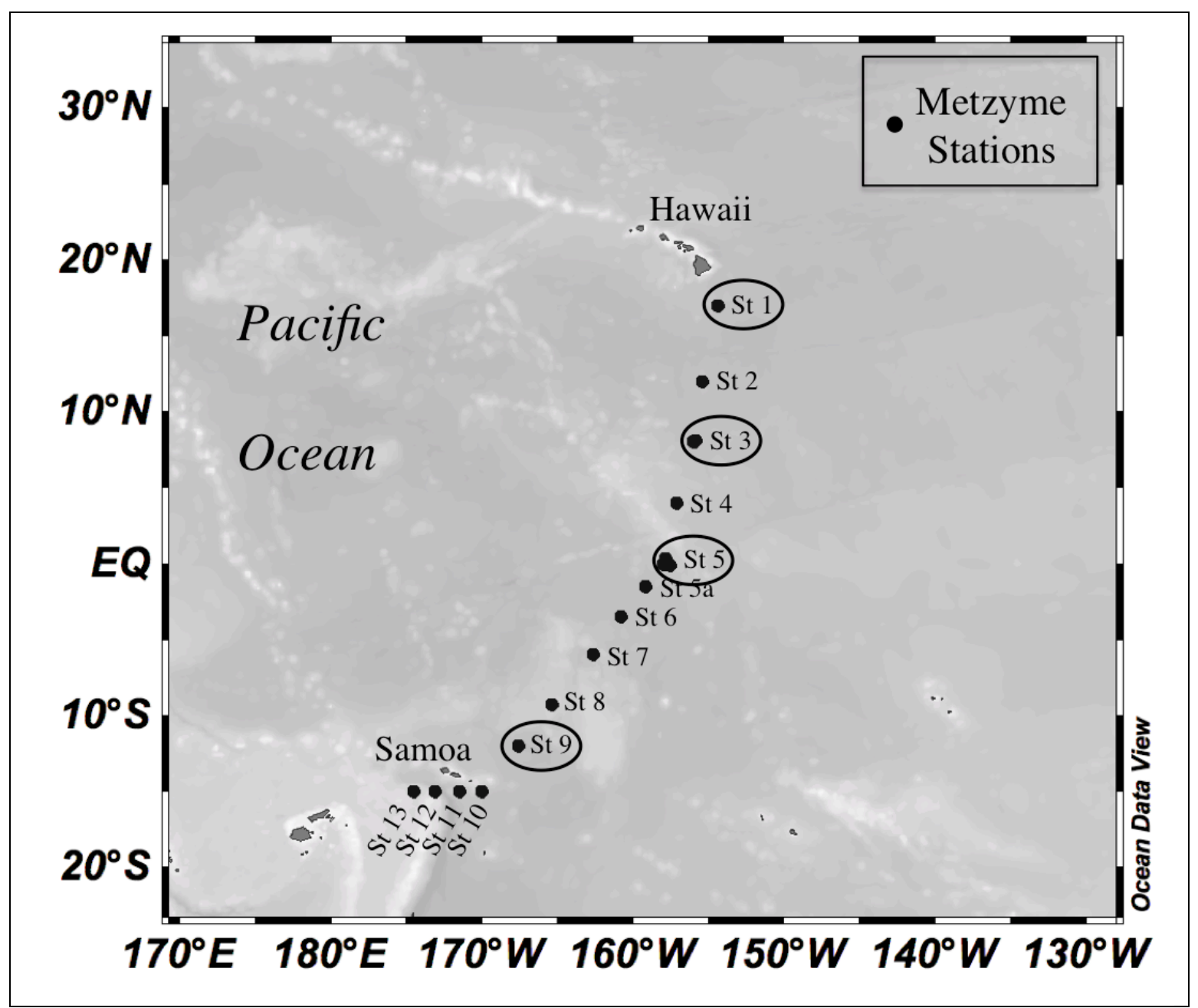


Figure 2: Reduction of mercury in incubations of marine waters amended with

methylcobalamin. Chromatograms of ICPMS intensity for $\mathrm{Hg}$ isotopes monitored to trace methylation and demethylation, ${ }^{198} \mathrm{Hg}$ (black), ${ }^{200} \mathrm{Hg}$ (grey), ${ }^{202} \mathrm{Hg}$ (dotted) from two replicate bottles of $t 0$ unfiltered water from the North Pacific $\left(17^{\circ} \mathrm{N}\right)$. In one replicate $(\mathrm{A}), \mathrm{Hg}^{\circ}(1), \mathrm{MMHg}$ (2,), and $\mathrm{Hg}$ (II) (3) peaks are quantifiable. In the second replicate (B) a substantial amount of ${ }^{202} \mathrm{Hg}$ (II) is lost to reduction and is apparent in the increase of the $\mathrm{Hg}(0)$ peak. None of the isotope traces in the resulting $\mathrm{MMHg}$ peak (2) are measurable relative to the baseline.




Figure 3: Concentrations of dissolved oxygen and and calculated values of apparent oxygen utilization at incubation stations. Dissolved oxygen concentrations (top panel) in intermediate waters are lowest in the North Pacific, increase in the Equatorial Pacific, and are highest in the South Pacific. Values of AOU (bottom panel) match closely with oxygen throughout cruise transect. At $12^{\circ} \mathrm{S}$ (Station 9), an unusual dissolved $\mathrm{O}_{2}$ depth profile showed two low dissolved $\mathrm{O}_{2}$ depths $(175 \mathrm{~m}$ and $400 \mathrm{~m})$, both of which were used for incubation experiments.

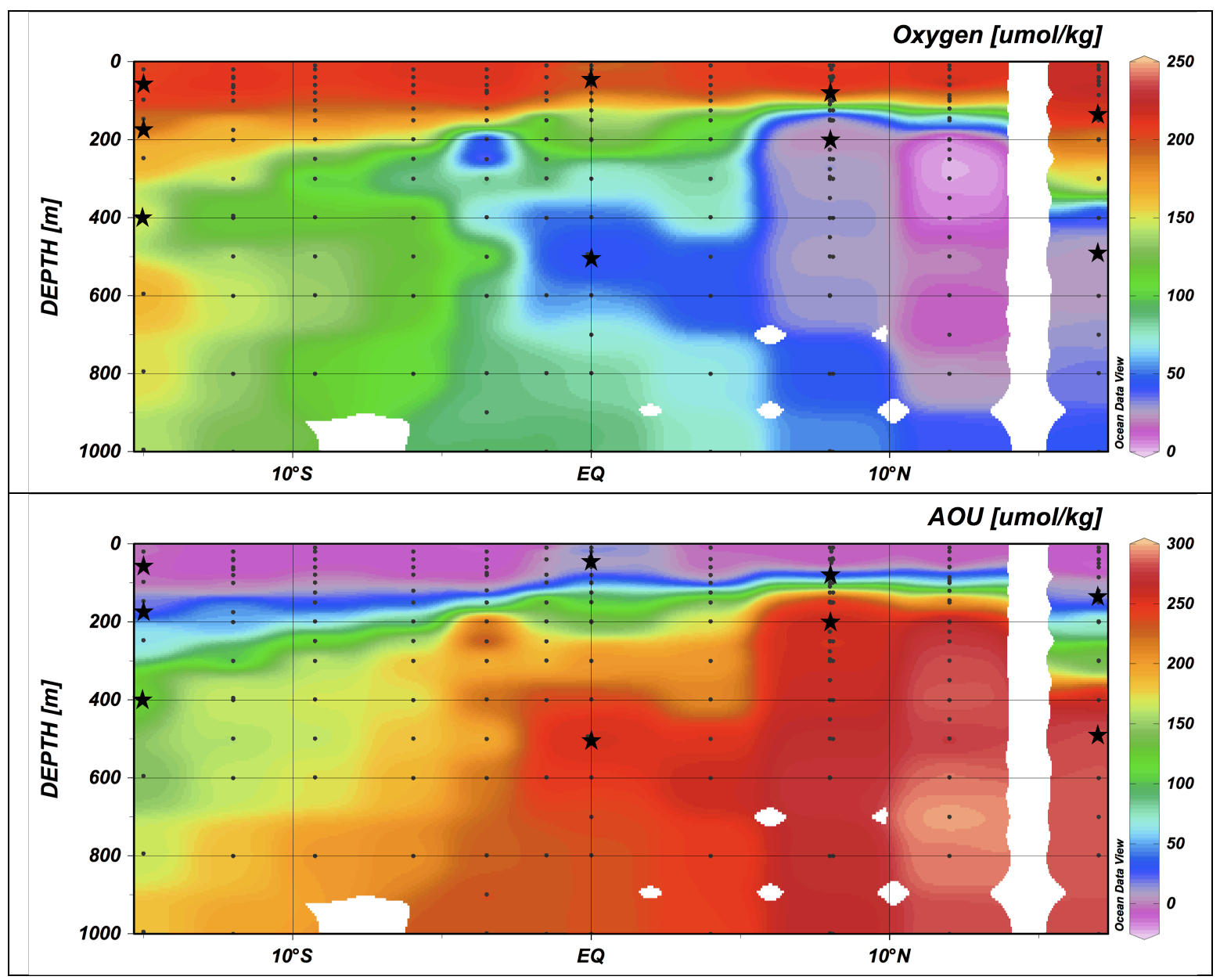


Figure 4: Concentrations of dissolved total and methylated mercury at incubation stations. Methylated $\mathrm{Hg}$ (measured as [DMHg] and [MMHg]) concentrations are shown along cruise transect with incubation locations and depths indicated by stars. Incubations were performed at depths of the chlorophyll-a maximum and minimum dissolved $\mathrm{O}_{2}$ concentration from CTD data at each station. At $17^{\circ} \mathrm{N}$ (Station 1), MMHg concentrations were estimated from concentrations in incubations bottles.

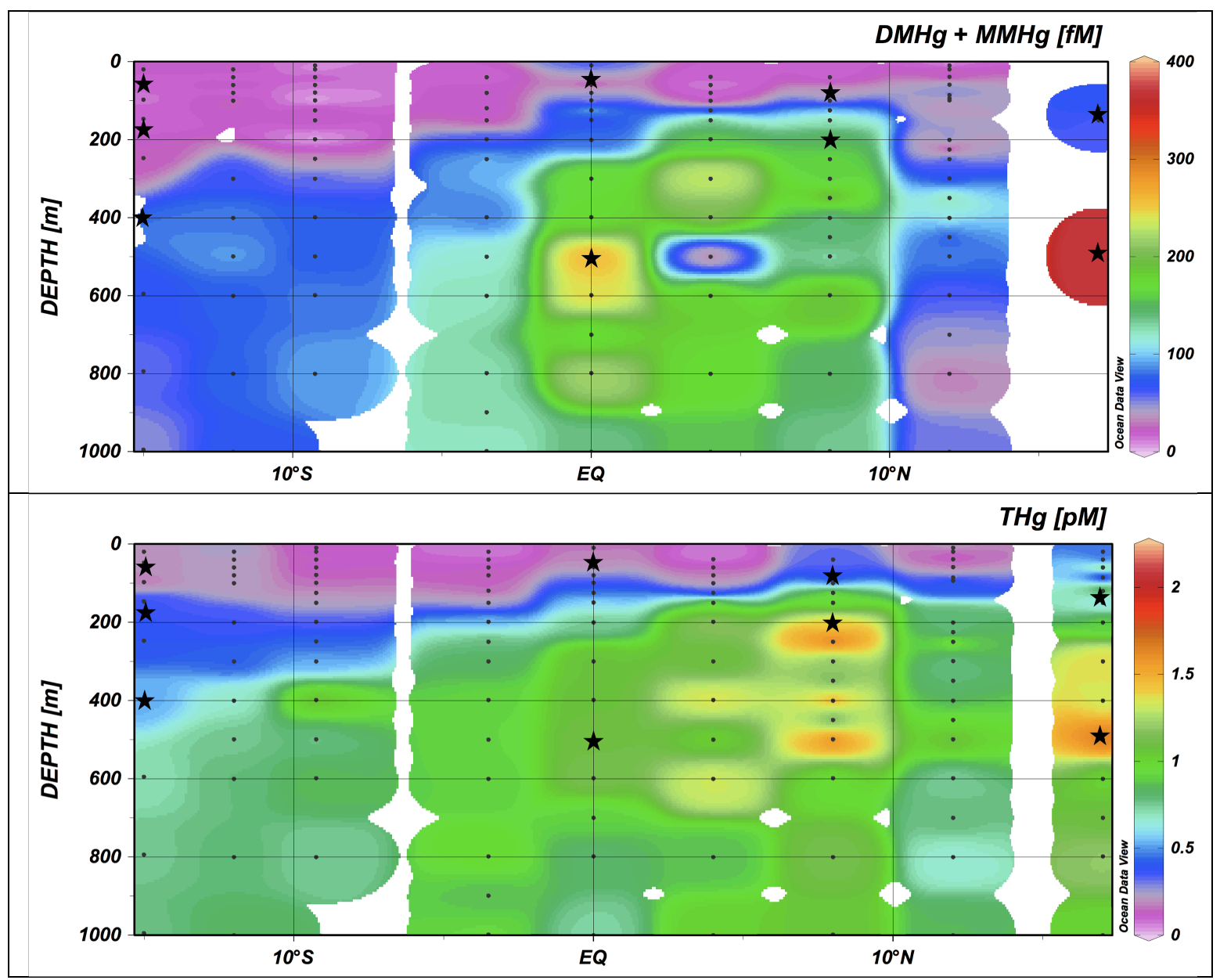


Figure 5: Initial and total methylation of $\mathrm{Hg}$ (II) in Tropical Pacific waters. Methylation, calculated as the percentage of $\mathrm{Me}^{202} \mathrm{Hg}$ produced from available ${ }^{202} \mathrm{Hg}$ (II) substrate from isotope spike additions, is shown for four stations along the Metzyme cruise track from the North to South Pacific. Methylation was measured in $0.2 \mu \mathrm{m}$ filtered $(0.2 \mu \mathrm{m})$ and unfiltered (un) from the chlorophyll maximum (CMX) and oxygen minimum (OMZ) at each station. At all stations, initial methylation (black bars) was measureable in t0 bottles relative and could account for the total methylation observed over 24-hour incubations (grey bars).
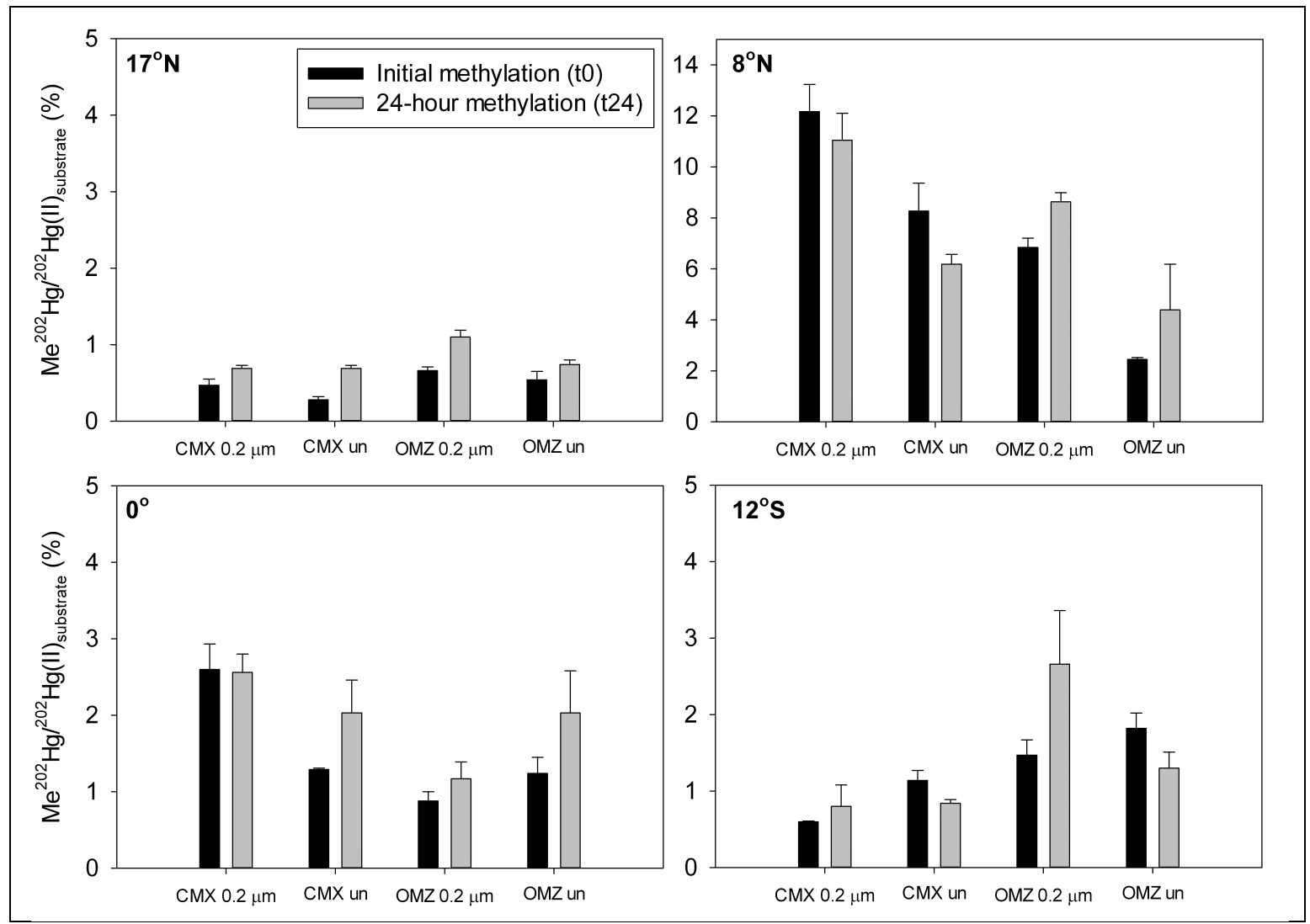
Figure 6: Methylated mercury production over a 36-hour time course in South Pacific waters. Methylation, calculated as the percentage of $\mathrm{Me}^{202} \mathrm{Hg}$ produced from available ${ }^{202} \mathrm{Hg}$ (II) substrate from isotope spike additions, is shown for 6 time points over a 36-hour incubation time course at $12^{\circ} \mathrm{S}$. Methylation was measured in $0.2 \mu \mathrm{m}$ filtered $(0.2 \mu \mathrm{m}$, black symbols $)$ and unfiltered (un, white symbols) seawater from the chlorophyll maximum (CMX, circles) and oxygen minimum (OMZ, triangles) depths at this station. Higher resolution sampling reveals dynamic cycling between methylation and demethylation compared to net changes over 24-hour incubation periods (Figure 5). Demethylation of newly formed methylated $\mathrm{Hg}$ occurs after 6 hours in unfiltered water from the oxygen minimum depth (white triangles) and is enhanced by the presence of particulate matter compared to $0.2 \mu \mathrm{m}$ filtered water (black triangles) in which produced $\mathrm{Me}^{202} \mathrm{Hg}$ persists throughout the full incubation period.

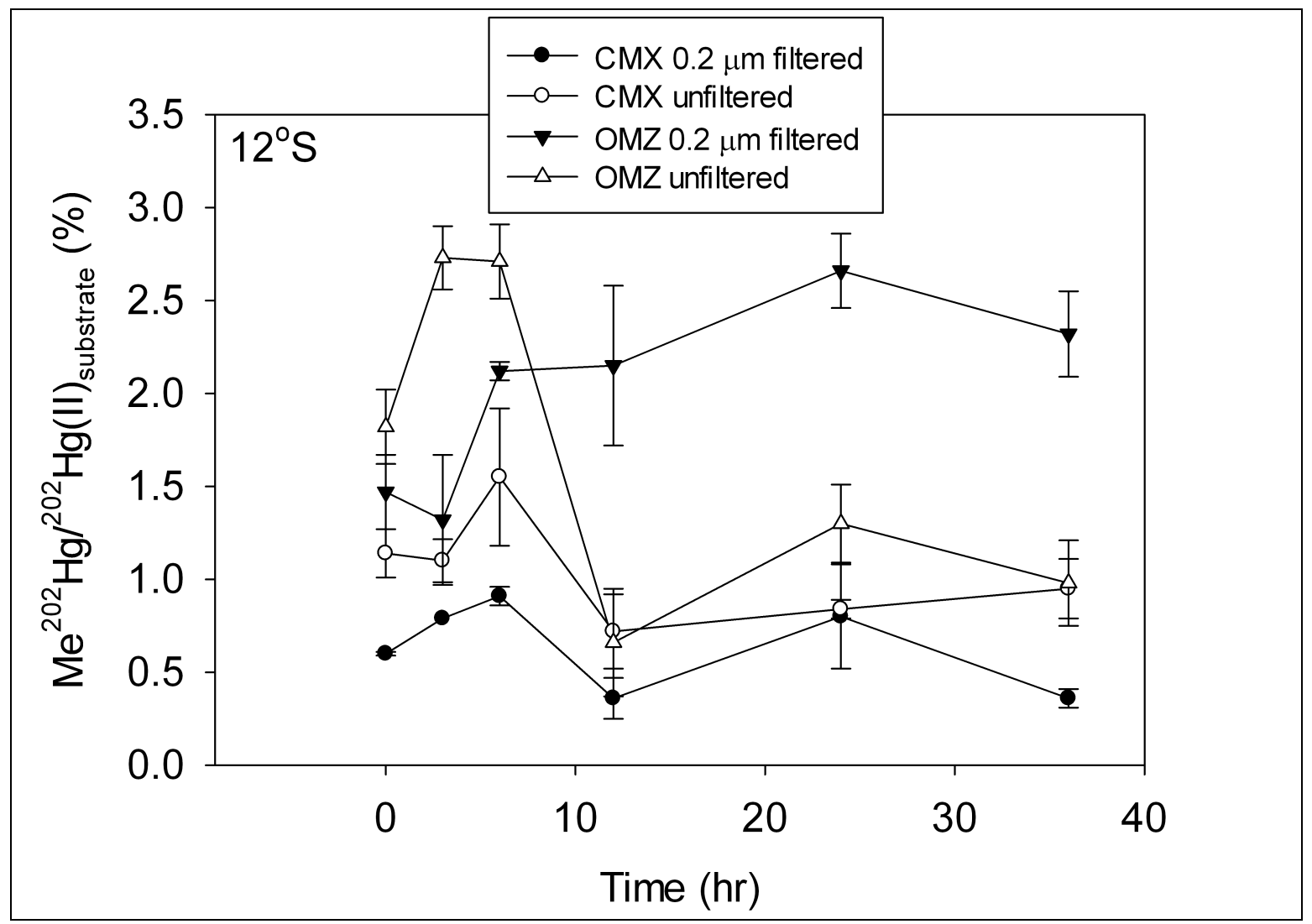


Figure 7: Demethylation of monomethylmercury over a 36-hour time course incubation in South Pacific waters. Demethylation is measured as the loss of added $\mathrm{MM}^{198} \mathrm{Hg}$ over from 0.2 $\mu \mathrm{m}$ filtered $(0.2 \mu \mathrm{m}$, black symbols) and unfilterd (un, white symbols) waters from the chlorophyll maximum (CMX) and oxygen minimum (OMZ) depths at $12^{\circ} \mathrm{S}$. Rapid demethylation of $\sim 300 \mathrm{fM}$ added $\mathrm{MM}^{198} \mathrm{Hg}$ spikes pre-equilibrated with natural ligands in filtered seawater was implied by the loss of added spike prior to fixation of t0 sample bottles for chlorophyll maximum waters (circles) and filtered oxygen minimum waters (black triangles). Quantitative demethylation was limited to unfilterd waters from the oxygen minimum depth (white triangles) at $12^{\circ} \mathrm{S}$.

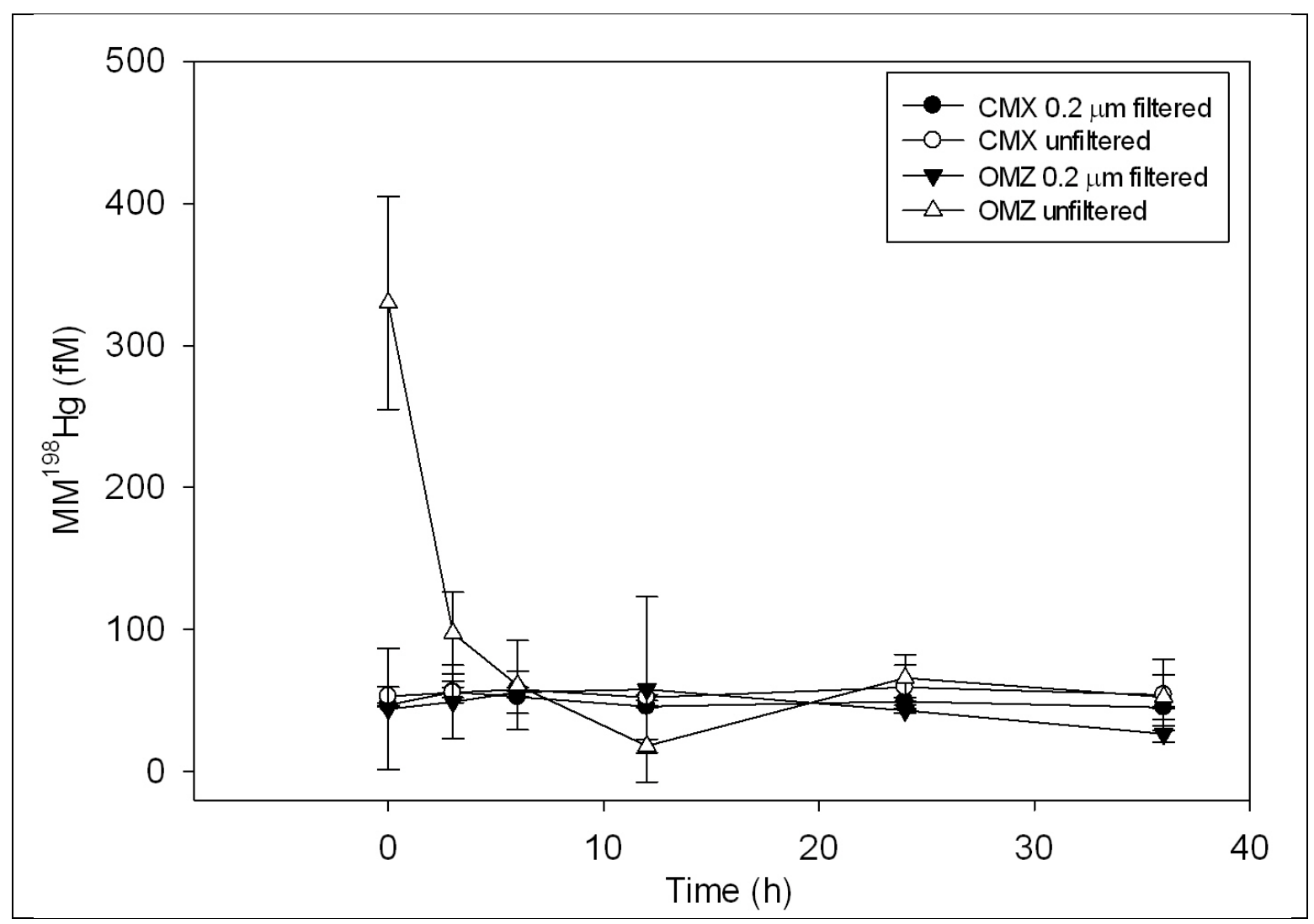


Figure 8 (following page): Methylation of mercury in treatment-amended incubations of water from chlorophyll maximum waters in the Tropical Pacific. Methylation, calculated as the percentage of $\mathrm{Me}^{202} \mathrm{Hg}$ produced from available ${ }^{202} \mathrm{Hg}$ (II) substrate from isotope spike additions, for waters amended with additions of compounds thought to be involved with $\mathrm{Hg}$ (II) uptake and methylation normalized to unamended (un) samples. Treatments are abbreviated as follows: succinate $(\mathrm{C})$, cobalt (Co), succinate and cobalt (CoC), McLane pump sections (punch), cobalt and cysteine (CoCys), cysteine (Cys), glutathione (GSH), methylcobalamin (B12), and cysteine and succinate (CysC). Grey bars in upper panel indicate incubation treatments that were not performed for filtered water. Only unfiltered waters (lower panel) from $12^{\circ} \mathrm{S}$ (yellow) were amended with treatments. The error bars represent one standard deviation from triplicate incubation bottles. 


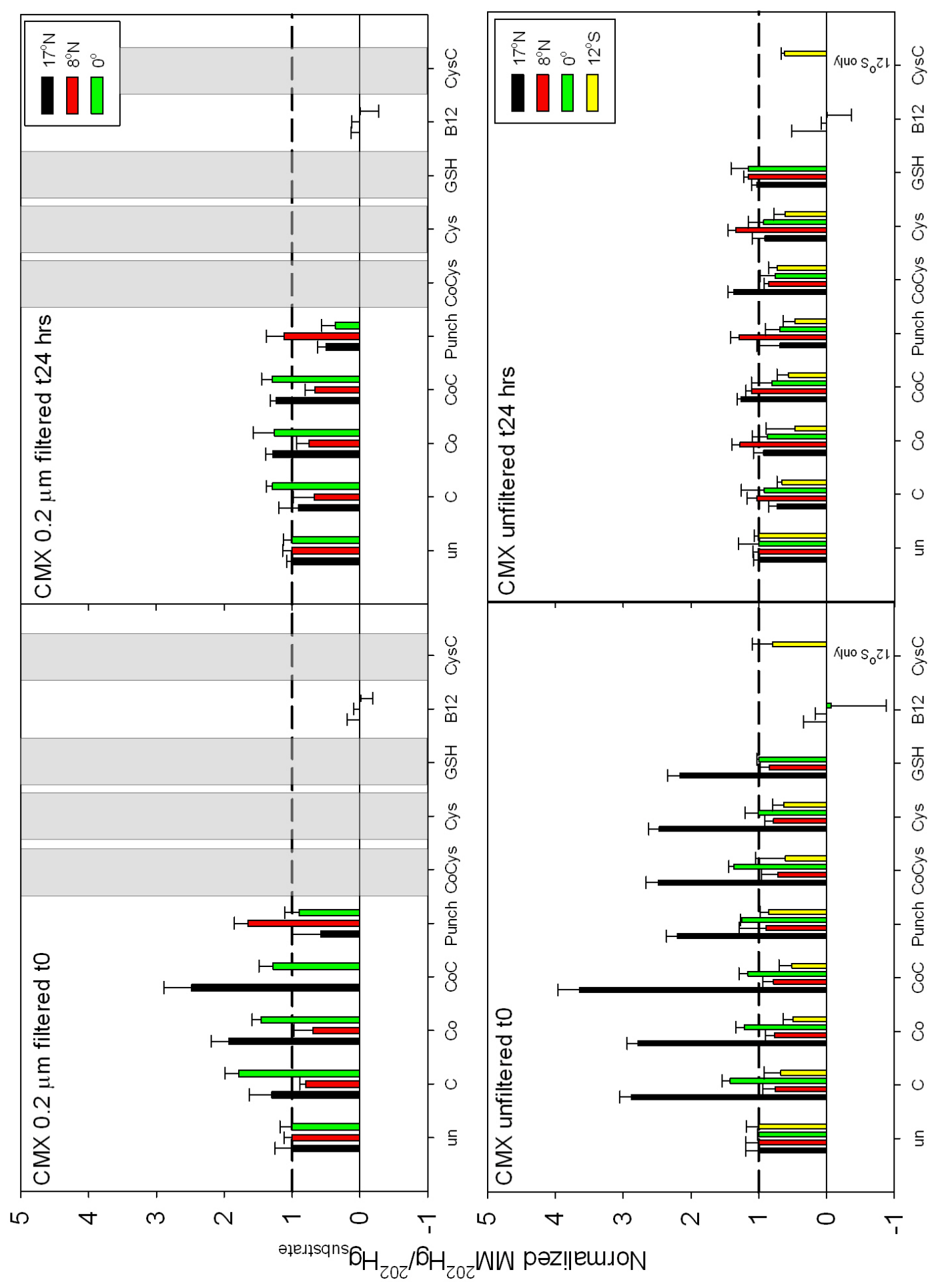


Figure 9 (following page): Methylation of mercury in treatment-amended incubations of water from oxygen minimum waters in the Tropical Pacific. Methylation, calculated as the percentage of $\mathrm{Me}^{202} \mathrm{Hg}$ produced from available ${ }^{202} \mathrm{Hg}$ (II) substrate from isotope spike additions, for waters amended with additions of compounds thought to be involved with $\mathrm{Hg}$ (II) uptake and methylation normalized to unamended (un) samples. Treatments are abbreviated as follows: succinate $(\mathrm{C})$, cobalt $(\mathrm{Co})$, succinate and cobalt (CoC), McLane pump sections (punch), cobalt and cysteine (CoCys), cysteine (Cys), glutathione (GSH), methylcobalamin (B12), and cysteine and succinate $(\mathrm{CysC})$. Grey bars in upper panel indicate incubation treatments that were not performed for filtered water. Only unfiltered waters (lower panel) from $12^{\circ} \mathrm{S}$ (yellow) were amended with treatments. The error bars represent one standard deviation from triplicate incubation bottles. 





Figure 10: Relationships between methylation and measured MeHg and THg

concentrations in Tropical Pacific waters. Initial methylation (black symbols) and 24-hour incubation methylation (grey symbols) from unfiltered waters from the chlorophyll maximum (CMX, left panels) and oxygen minimum (OMZ, right panels) depths in Tropical Pacific waters versus measured concentrations of total mercury ( $\mathrm{THg}$, top panels) and methylated mercury $([\mathrm{DMHg}]+[\mathrm{MMHg}])$. No clear relationship was observed between methylation and mercury species concentrations.

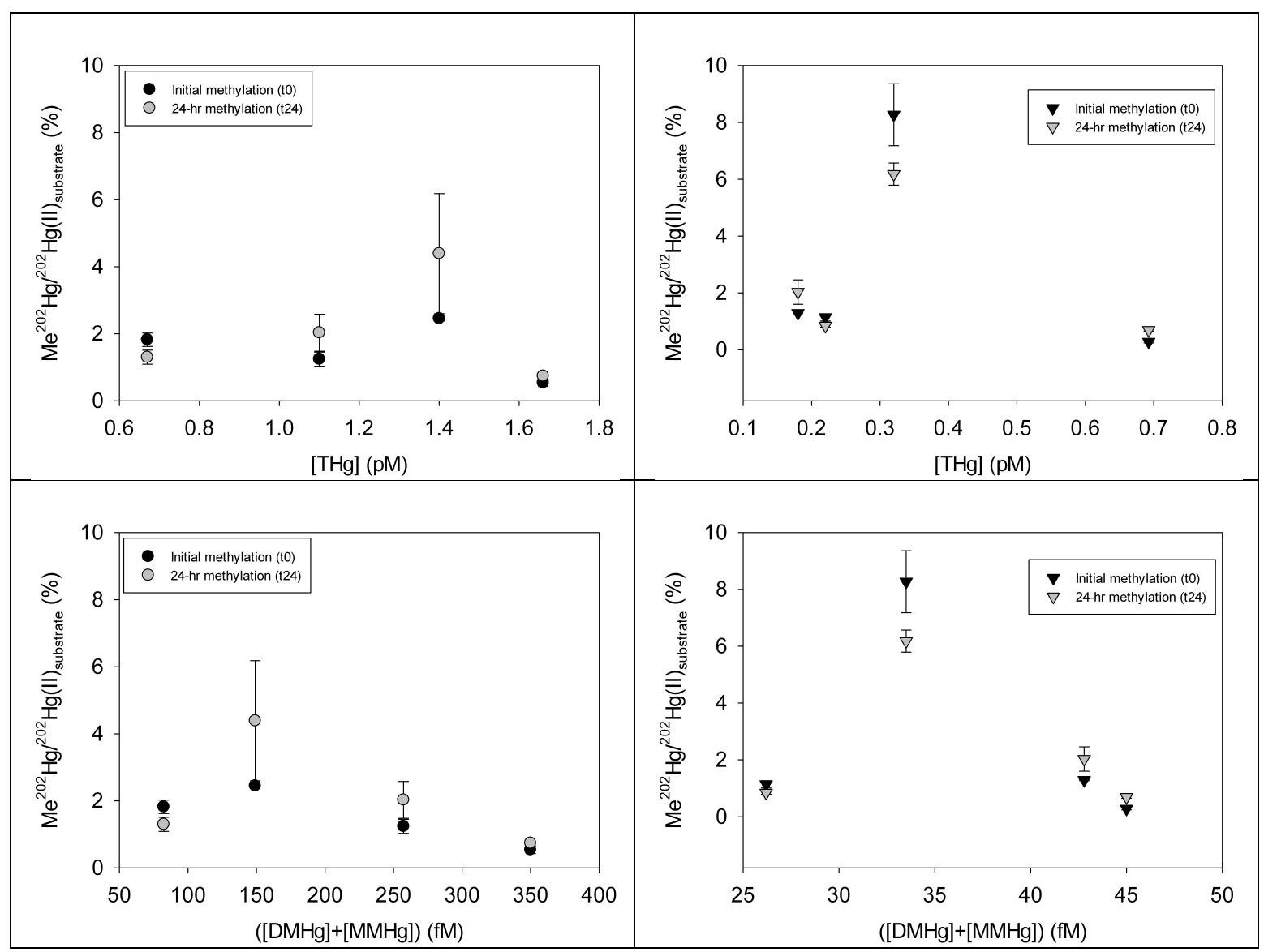


Figure 11: Calculated dissolved Hg(II) in the Tropical Pacific. Dissolved $\mathrm{Hg}(\mathrm{II})(\mathrm{pM})$ was calculated as the difference between THg and the sum of $\mathrm{Hg}(0), \mathrm{DMHg}$, and MMHg measured as distinct chemical species along Metzyme cruise track. In regions of high methylated $\mathrm{Hg}(500 \mathrm{~m}$ at St 5,500m at St 1), The close relationship observed in the North Pacific between methylated $\mathrm{Hg}$ concentrations and organic carbon remineralization rates implies methylation is limited by $\mathrm{Hg}$ (II) substrate delivery to depths of organic matter remineralization [Sunderland et al, 2009]. The persistence of dissolved $\mathrm{Hg}$ (II) in concentrations between 1-1.25 pM, suggests that methylation may not be limited by dissolved $\mathrm{Hg}$ (II) concentrations at these depths and is limited by additional factors such as $\mathrm{Hg}(\mathrm{II})$ availability or methyl donors.

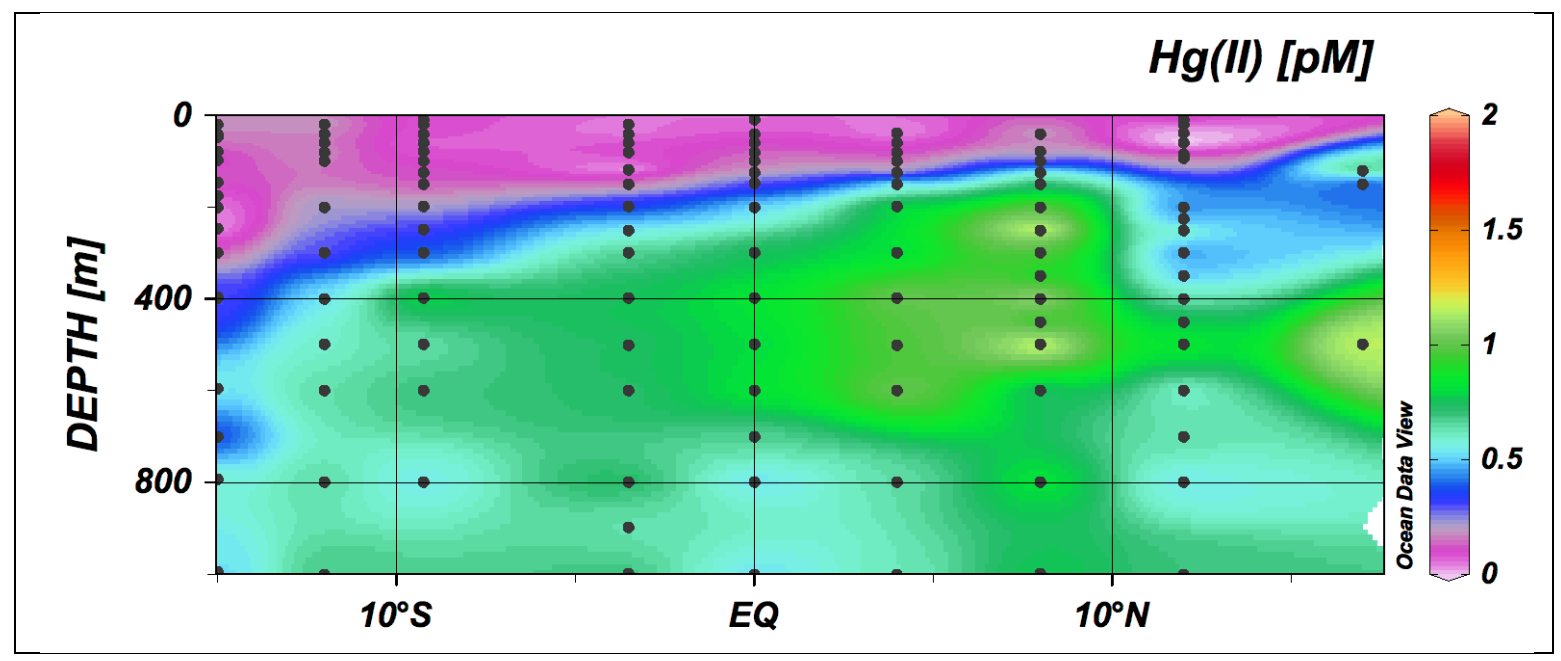


Tables and Table Legends

Table 1: Water column characteristics for Pacific Ocean waters from which potential mercury methylation rates were measured.

\begin{tabular}{|l|l|l|l|l|l|l|l|l|}
\hline Sta & $\begin{array}{l}\text { Depth } \\
(\mathrm{m})\end{array}$ & $\begin{array}{l}\text { Temp } \\
\left({ }^{\circ} \mathrm{C}\right)\end{array}$ & $\begin{array}{l}\mathrm{Temp}_{\text {inc }} \\
\left({ }^{\circ} \mathrm{C}\right)^{1}\end{array}$ & $\begin{array}{l}\mathrm{O}_{2 \text { diss }} \\
(\mu \mathrm{mol} / \mathrm{kg})\end{array}$ & $\begin{array}{l}\text { AOU* } \\
(\mu \mathrm{mol} / \mathrm{kg})\end{array}$ & $\begin{array}{l}\text { THg } \\
(\mathrm{pM})\end{array}$ & $\begin{array}{l}\text { DMHg } \\
(\mathrm{fM})\end{array}$ & $\begin{array}{l}\text { MMHg } \\
(\mathrm{fM})\end{array}$ \\
\hline $17^{\circ} \mathrm{N}$ & $\begin{array}{l}1: 3 \mathrm{mix} \\
20: 150\end{array}$ & 22 & $19-26$ & $214: 205$ & - & $1: 0.59$ & $40: 30$ & $10^{3}$ \\
\hline $17^{\circ} \mathrm{N}$ & 500 & 7 & 13 & 20 & 282.9 & 1.66 & 40 & $310^{3}$ \\
\hline $8^{\circ} \mathrm{N}$ & $75-80$ & 21 & 23 & 218 & - & 0.32 & 30 & 3.5 \\
\hline $8^{\circ} \mathrm{N}$ & 200 & 11 & 13 & 15 & 264.1 & 1.4 & 100 & 49.1 \\
\hline $0^{\circ}$ & 50 & 26 & 23 & 202 & - & 0.18 & 20 & 22.8 \\
\hline $0^{\circ}$ & 500 & 8 & 14 & 43 & 252 & 1.1 & 110 & 147.3 \\
\hline $12^{\circ} \mathrm{S}$ & 60 & 28 & $13-16$ & 207 & - & 0.22 & 0 & 26.2 \\
\hline $12^{\circ} \mathrm{S}$ & 175 & 25 & $13-16$ & 162 & 47.0 & 0.35 & 20 & 0 \\
\hline $12^{\circ} \mathrm{S}$ & 400 & 11 & $13-16$ & 116 & 163 & 0.67 & 40 & 42.4 \\
\hline
\end{tabular}

${ }^{1}$ Ranges represent monitored variations in temperature observed over incubation period. Values without ranges were constant for duration of incubation.

${ }^{2}$ Water was mixed for CMX at Station 1 due to water budget limitations.

${ }^{3} \mathrm{MMHg}$ concentrations calculated from ambient $200 \mathrm{Hg}$ in $\mathrm{t} 0$ incubation bottles after subtraction of contribution from added MMHg spike.

${ }^{4}$ Because station 9 displayed an unusual $\mathrm{O}_{2}$ depth profile, an additional low $\mathrm{O}_{2}$ depth was selected for non-amended incubations.

*Note that values of AOU cannot be accurately determined in the upper water column due to the influence of gas exchange and mixing. Values for AOU in waters above $100 \mathrm{~m}$ are therefore not shown. 
Table 2: Amendments tested for enhancement of mercury methylation. McLane punches were collected from matching stations as those used for incubation water collection and contain particles $>51 \mu \mathrm{m}$ including organic matter, cells, and inorganic material.

\begin{tabular}{|l|l|}
\hline Treatment & Final concentration \\
\hline McLane punches & $1 / 2$ of 2-cm punch \\
\hline Inorganic Co & $500 \mathrm{pM}$ \\
\hline C (as succinate) & $1 \mathrm{mM}$ \\
\hline Cysteine & $10 \mathrm{nM}$ \\
\hline Glutathione & $10 \mathrm{nM}$ \\
\hline Methylcobalamin & $100 \mathrm{pM}$ \\
\hline CoC & $500 \mathrm{pM}, 1 \mathrm{mM}$ \\
\hline CoCys & $500 \mathrm{pM}, 10 \mathrm{nM}$ \\
\hline CysC & $10 \mathrm{nM}, 1 \mathrm{mM}$ \\
\hline
\end{tabular}


Table 3: Potential methylation rates from Tropical Pacific waters. Total potential methylation rates (M) calculated from t-1 to $24 \mathrm{hr}$ corrected for ${ }^{202} \mathrm{Hg}$ (II) from diethylHg peak. Potential methylation rate constants $\left(\mathrm{k}_{\mathrm{m}}\right)$ for production of methylated $\mathrm{Hg}([\mathrm{DMHg}]+[\mathrm{MMHg}])$ relative to isotopically enriched $\mathrm{Hg}$ (II) substrate in $0.2 \mu \mathrm{m}$ filtered and unfiltered seawater from the Pacific Ocean. The errors given represent one standard deviation of triplicate bottle incubations.

\begin{tabular}{|l|l|l|l|}
\hline Station & Depth & $\begin{array}{l}\text { M-0.2 } \mu \mathrm{m} \text { filt } \\
\left(\mathrm{x} 10^{-2} \mathrm{~d}^{-1}\right)\end{array}$ & $\begin{array}{l}\text { M-unfilt } \\
\left(\mathrm{x} 10^{-2} \mathrm{~d}^{-1}\right)\end{array}$ \\
\hline $17^{\circ} \mathrm{N}$ & CMX & $0.39 \pm 0.11$ & $0.43 \pm 0.02$ \\
\hline & OMZ & $0.95 \pm 0.08$ & $0.64 \pm 0.05$ \\
\hline $8^{\circ} \mathrm{N}$ & $\mathrm{CMX}$ & $10.19 \pm 0.98$ & $5.71 \pm 0.36$ \\
\hline & OMZ & $7.40 \pm 0.31$ & $3.77 \pm 1.54$ \\
\hline $0^{\circ}$ & CMX & $2.19 \pm 0.20$ & $1.74 \pm 0.37$ \\
\hline & OMZ & $1.00 \pm 0.19$ & $1.74 \pm 0.47$ \\
\hline $12^{\circ} \mathrm{S}$ & CMX & $0.69 \pm 0.28$ & $0.72 \pm 0.02$ \\
\hline & OMZ & $0.20 \pm 0.04$ & $0.49 \pm 0.08$ \\
\hline & OMZ & $2.28 \pm 0.70$ & $1.12 \pm 0.21$ \\
\hline
\end{tabular}

${ }^{2}$ Because station $12^{\circ} \mathrm{S}$ displayed an unusual $\mathrm{O}_{2}$ depth profile, an additional low $\mathrm{O}_{2}$ depth was selected for non-amended incubations. 


\section{Chapter 6 \\ Conclusions}

Despite longstanding debate over the importance of monomethylmercury ( $\mathrm{MMHg}$ ) production in the marine water column relative to transport from coastal sediments, few direct measurements have been performed to quantify these processes in open ocean locations. Measurements of potential methylation and demethylation rates provide quantitative constraints on the magnitude of in situ MMHg production. However, we present only the third report of these measurements in marine systems. In addition, we are the first to incorporate experiments that probe potential mechanisms for environmental conditions that lead to MMHg production in open ocean waters.

Our experimental design incorporated pre-equilibration of concentrated spikes of isotopically enriched $\mathrm{Hg}$ and $\mathrm{MMHg}$. Previous measurements have relied on additions of $\mathrm{MMHg}$ and, especially, $\mathrm{Hg}$ well in excess of ambient concentrations [Lehnherr et al, 2011] that are added bound to chloride ligands [Lehnherr et al, 2011; Monperrus et al, 2007]. Because isotope tracer experiments require additions of exogenous $\mathrm{Hg}$, we aimed to add low concentrations of spikes that more closely mimic the $\mathrm{Hg}$ species that a parcel of ocean water would encounter in situ. Even low concentrations of pre-equilibrated spike underwent methylation and demethylation within minutes of introduction, suggesting that methylation in marine waters is widespread and dynamic, regardless of the ambient concentrations of methylated $\mathrm{Hg}$ species.

We measured potential methylation rates from $\mathrm{Hg}(\mathrm{II})$ in waters across large gradients of oxygen utilization, primary productivity, and ambient $\mathrm{Hg}$ (II) and $\mathrm{MMHg}$ concentrations. Notably, in oligotrophic waters in both the South Pacific and the Sargasso Sea, we observed significant methylation potential in filtered waters. In addition, the only methylation attributed to cellular processes was observed in oxygen minimum waters of the Sargasso Sea. These findings are inconsistent with known mechanisms of MMHg production in anoxic sediments, which occurs primarily by cellular processes in anaerobic bacteria [Gilmour et al, 2013]. We also did not see significant abiotic methylation after addition of methylcobalamin, despite its ability to methylate $\mathrm{Hg}$ in buffered pH 5 solutions [Jiminez-Martinez, 2013]. Combined, these results suggest that $\mathrm{Hg}$ methylation in marine waters is controlled by factors specific to these environments. Time course experiments in both oligotrophic regions suggest that rapidly produced MMHg is short lived, especially in the presence of particulate matter. This is contrary to observed bioaccumulation factors in marine particulate matter, $>10^{4}$ [Hammerschmidt et al, 2013], relative 
to dissolved $\mathrm{Hg}$ concentrations. How particles can both promote demethylation and serve as the first step of $\mathrm{Hg}$ bioaccumulation, the step that results in the highest bioaccumulation factor, is an important question that should be addressed in future open ocean studies of $\mathrm{Hg}$ speciation.

Both our Hg speciation data in the Tropical Pacific as well as our methylation rate measurements suggest that a simple model of marine $\mathrm{Hg}$ methylation is not comprehensive enough to account for differences among ocean basins. Although methylation is likely ultimately limited by $\mathrm{Hg}(\mathrm{II})$ substrate, the strong relationship between methylated $\mathrm{Hg}$ concentrations and organic carbon remineralization rates observed in the North Pacific [Sunderland et al, 2009] does not extend into the Equatorial Pacific (Figure 1). Instead, factors that influence the availability of $\mathrm{Hg}(\mathrm{II})$ to methylation appear to limit DMHg and MMHg production even in low oxygen waters. We have identified denitrification as a likely control on THg availability for methylation (Figure 2). Although some sulfate-reducing bacteria appear to methylate $\operatorname{Hg}(0)$ directly in culture studies [Hu et al, 2013], this does not appear to occur in the low oxygen regions of the marine water column as a region of strong denitrification observed in the Tropical Pacific suggested that reduction inhibited MMHg and DMHg production [Munson — this work, Chapter 4]. In addition, the reduction induced by methylcobalamin additions to filtered and unfiltered seawater prohibited methylation [Munson - this work, Chapter 5], making $\mathrm{Hg}(0)$ an unlikely substrate for marine $\mathrm{Hg}$ methylation.

In our amended methylation rate measurement experiments, we aimed to test whether individual compounds limit $\mathrm{Hg}$ methylation, especially in high productivity waters where cells compete for limited dissolved nutrients. Compound addition appeared to induce methylation in both filtered and unfiltered water, which might implicate methyl transfer to $\mathrm{Hg}$ (II) facilitated by ligand binding, or another unidentified process. Whatever the mechanism of this rapid methylation, it appears to be distinct from cellular methylation, as indicated by the steady production of $\mathrm{MeHg}$ over 24-hour incubations in unfiltered low oxygen waters from the Sargasso Sea [Munson-this work, Chapter 3].

The relative importance of rapid methylation, which occurs in the absence of cells in our filtered water incubations, and cellular methylation, that was measured only in the Sargasso Sea, for bioaccumulation is beyond the scope of our current study. However, future work should address to what extent these seemingly distinct processes impact MMHg uptake and transfer in marine biota. 
Despite the low concentrations of Hg species measured in Tropical Pacific waters, we observed active methylation in these waters. If the resulting $\mathrm{MMHg}$ is incorporated into biomass, increases in $\mathrm{Hg}$ emissions since the Industrial Revolution will ultimately be transferred from marine waters to marine food webs and pose increasing threats to human health.

\section{References}

Gilmour, C. C., M. Podar, A. L. Bullock, A. M. Graham, S. D. Brown, A. C. Somenahally, A. Johs, R. A. Hurt Jr., K. L. Bailey, and D. A. Elias (2013) Mercury methylation by novel microorganisms from new environments, Environ. Sci. Technol., 47, 11810-11820.

Hammerschmidt, C. R., M. B. Finiguerra, R. L. Weller, and W. F. Fitzgerald (2013) Methylmercury accumulation in plankton on the continental margin of the Northwest Atlantic Ocean, Environ. Sci. Technol., 47, 3671-3677.

Hu, H., H. Lin, W. Zheng, S. J. Tomanicek, A. Johs, X. Feng, D. A. Elias, L. Liang, and B. Gu (2013) Oxidation and methylation of dissolved elemental mercury by anaerobic bacteria. Nat. Geosci., 6, 751-754.

Jiménez-Moreno, J., V. Perot, V. N. Epov, M. Monperrus, and D. Amouroux (2013) Chemical kinetic isotope fractionation of mercury during abiotic methylation of $\mathrm{Hg}$ (II) by methylcobalamin in aqueous chloride media, Chem. Geol., 336, 26-36.

Lehnherr, I., V. L. St. Louis, H. Hintelmann, and J. Kirk (2011) Methylation of inorganic mercury in polar waters. Nat. Geosci., 4, 298-302.

Monperrus, M., E. Tessier, D. Amouroux, A. Leynaert, P. Huonnic, and O. F. X. Donard (2007) Mercury methylation, demethylation and reduction rates in coastal and marine surface waters of the Mediterranean Sea. Mar. Chem. 107, 49-63.

Sunderland, E. M., D. P. Krabbenhoft, J. W. Moreau, S. A. Strode, and W. M. Landing (2009) Mercury sources, distribution, and bioavailability in the North Pacific Ocean: Insights from data and models. Global Biogeochem. Cy. 23:GB2010. 
Figure 1: Methylated mercury concentrations in marine intermediate waters $(100-1000 \mathrm{~m})$ versus organic carbon remineralization rates. The correlation between metylated $\mathrm{Hg}$ and OCRR, first observed in North Pacific Intermediate Waters by Sunderland et al, 2009 (blue) does not appear to exist in all ocean basins. Concentrations of methylated $\mathrm{Hg}$ measured at two offshore stations of in the North Atlantic (red, Bowman et al, 2013) appear to increase with ORCC, coastal stations have low methylated Hg concentrations across the full OCRR range. Methylated $\mathrm{Hg}$ concentrations and OCRR are low in Indian waters (purple, Sunderland et al, 2011). Intermediate concentrations of methylated $\mathrm{Hg}$ measured in waters from the Tropical Pacific (white, Metzyme, Munson - this work, chapter 3) are found at intermediate OCRR values.

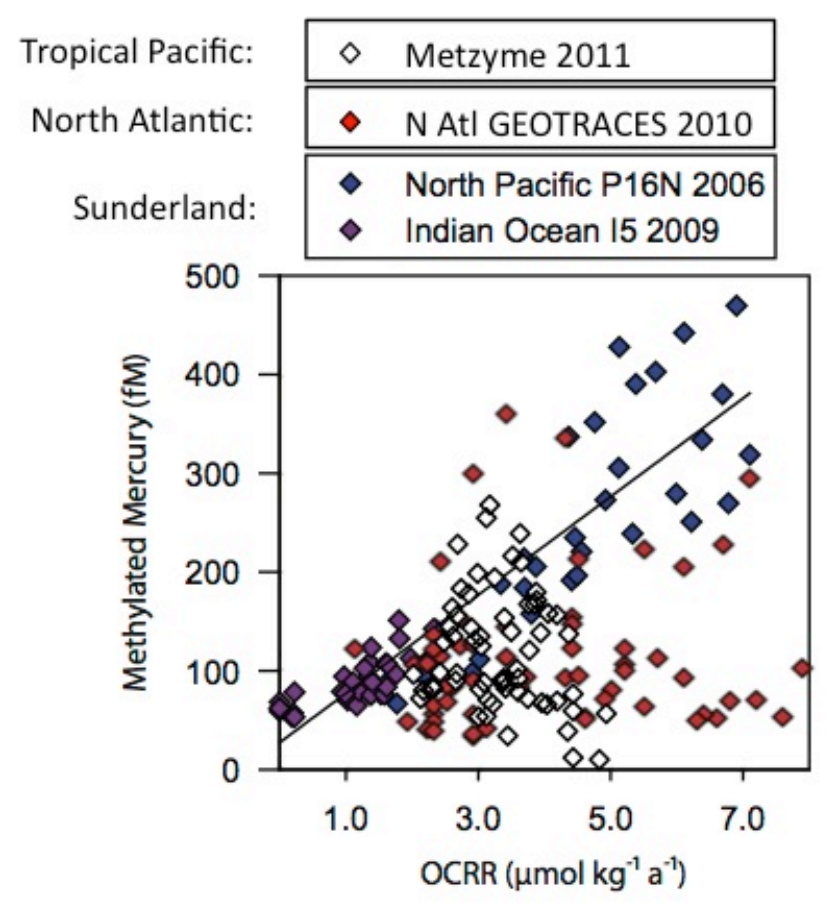




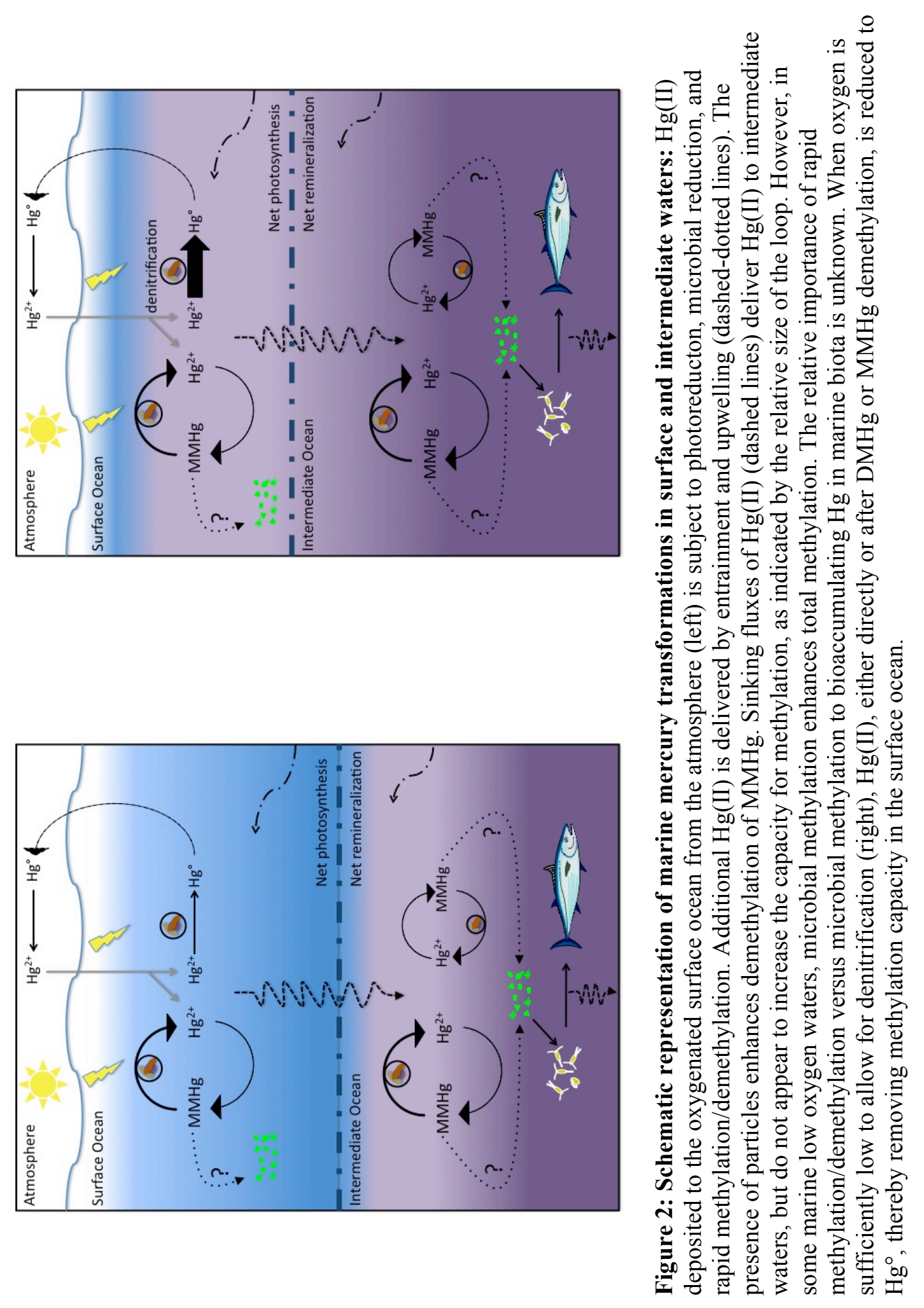




\section{Appendix I \\ Methylation and Demethylation Rate Measurements}

Adapted from: Hintelmann and Evans, 1997 and Hintelmann and Ogrinc, 2003.

The 7 stable isotopes of $\mathrm{Hg}$ allow for simultaneous detection of multiple tracers of $\mathrm{Hg}$ species transformations. In the experiments described in Chapters 4 and 5, we used isotopically enriched $\mathrm{Hg}$ species to trace methylation and demethylation in water samples. By adding $\mathrm{Hg}$ (II) and $\mathrm{MMHg}$, each enriched in different isotopes, we were able to simultaneously track methylation and demethylation within the same bottle over the incubation period.

Using ${ }^{202} \mathrm{Hg}(\mathrm{II})$, we measured the following methylation reaction:

$$
{ }^{202} \mathrm{Hg}^{2+}+\mathrm{CH}_{3}^{2-} \rightarrow \mathrm{CH}_{3}{ }^{202} \mathrm{Hg}^{+}
$$

Using $\mathrm{CH}_{3}{ }^{198} \mathrm{Hg}^{+}$, we measured the following demethylation reaction:

$$
\mathrm{CH}_{3}{ }^{198} \mathrm{Hg}^{+} \rightarrow{ }^{198} \mathrm{Hg}^{2+}+\mathrm{CH}_{3}^{2-}
$$

These two reactions were monitored by quantifying the isotopic composition of the $\mathrm{CH}_{3} \mathrm{Hg}^{+}$peak using a linked CVAFS-ICPMS protocol modeled after descriptions by Hintelmann and Evans (1997) and the USGS Wisconsin District Mercury Laboratory, Madison, Wisconsin [as used by DeWild et al, 2002].

\section{Analytical Setup:}

The hardware of the linked system is easily set up. The outlet of the 2700 Tekran Automated Methylmercury Analyzer can be attached to a y-junction or the side arm of a t-junction to join the ICPMS sample gas flow, typically $\sim 1 \mathrm{~L} / \mathrm{min}$. The two Thermo Element 2 instruments in the WHOI Plasma Facility were used in these experiments. The Tekran 2700 was transported and set up on a trolley. The Tekran instrument was controlled by the Lamborg Lab MMHg computer and run off of a separate Ar gas cylinder. Troubleshooting the linked set-up typically requires careful attention to the backpressure from the ICPMS system, which may result due to the flow differential between the CVAFS and ICPMS systems.

When connected to the $\mathrm{CO}_{3}{ }^{2-}$ Thermo Element 2, the ICPMS data collection could be triggered by an electrical signal from the Tekran 2700 prior to heating of the Tenax trap. A command was added to the ETF of the Tekran 2700. In the Sequence Editor of the ICPMS software, the external signal was added to the sample template and the sequence was set to continue automatically.

In order to tune the instrument, a glass $U$ was inserted between the tubing from the Tekran 2700 cell outlet and the y-junction into the ICPMS sample gas flow. The glass U contained a drop of $\mathrm{Hg}$ contained in a small capped plastic cylinder. The volatile $\mathrm{Hg}(0)$ carried through the $U$ by the Tekran 2700 provided sufficient signal for instrument tuning. Because of the high $\mathrm{Hg}$ signal of the standard relative to sample concentrations, the ICPMS signal was allowed to re-establish a baseline for $>30$ minutes prior to analyzing standards or samples. 
Although not used for these experiments, the tubing (type?) between the CVAFS and the ICPMS can be heated by means of a heated strip to avoid loss of $\mathrm{Hg}$ signal to the walls of the tubing.

Sample and standard $\mathrm{CH}_{3} \mathrm{Hg}^{+}$derivitization was performed in the Watson Building clean room and bottles were transported to the ICPMS lab for analysis. Between 8-10 samples were prepared at a time.

\section{Data Analysis:}

During analysis, the Thermo ICPMS software yields a chromatogram of individual Hg isotopes. The method was written to maximize the number of data points collected within a period of time that corresponded to the chromatogram produced by the Tekran 2700. A .txt file of the counts per second (cps) of each of the 4-7 Hg isotopes measured at each time point was produced for each sample. The software allows users to manually integrate specific peak windows. However, for ease of data analysis in the presented analyses, MATLAB files (written by C. H. Lamborg) were used to extract peak integrations from .txt files of the chromatographs of the peak intensity produced by the ICPMS. These MATLAB files consisted of:

chromcrunch.m

chromint.m

These operations yielded integrations of the separated $\mathrm{Hg}$ species $\mathrm{Hg}(0)$, methylethyl $\mathrm{Hg}$, and diethylHg that correspond to 4-7 isotopes of $\mathrm{Hg}(0), \mathrm{CH}_{3} \mathrm{Hg}^{+}$, and $\mathrm{Hg}^{2+}$. Four isotopes $(198,199$, 200, and 202) were monitored for most measurements (Chapter 4, excluding +B12 treatments), while all $7 \mathrm{Hg}$ isotopes were monitored for later measurements (Chapter 5).

The output of the Matlab files were .txt files containing sample peak integrations that were adapted into .xlsx spreadsheets for calculations. Peak areas for each isotope were corrected for reagent contributions from daily reagent blanks. For methylation rate measurements, the blank corrected $\mathrm{Hg}$ isotope abundances from the separated $\mathrm{CH}_{3} \mathrm{Hg}^{+}$peak were used to measure changes in $\mathrm{MMHg}$ from demethylation and methylation. The integrated ${ }^{202} \mathrm{Hg}$ in the $\mathrm{Hg}^{2+}$ peak was monitored to determine changes in $\mathrm{Hg}^{2+}$ substrate availability over the course of the incubation (see below).

Once peak integrations were determined, we input the following mathematical calculations into the integrations spreadsheets to yield transformation rates:

According to Hintelmann and Evans, 1997, the total concentration of a specified isotope is the sum of that isotope in ambient solutions plus concentrations of that isotope in tracer solutions.

$$
\begin{aligned}
& \Sigma^{1} \mathrm{I}={ }^{1} \mathrm{a}+{ }^{1} \mathrm{~b} \ldots+{ }^{1} \mathrm{n} \\
& \Sigma^{2} \mathrm{I}={ }^{2} \mathrm{a}+{ }^{2} \mathrm{~b} \ldots+{ }^{2} \mathrm{n} \\
& \Sigma^{\mathrm{i}} \mathrm{I}={ }^{\mathrm{i}} \mathrm{a}+{ }^{\mathrm{i}} \mathrm{b} \ldots+{ }^{\mathrm{i}} \mathrm{n}
\end{aligned}
$$

where a-n denote different solutions and 1-i represent different isotopes. Thus for our experiments, the sum of all contributions of ${ }^{202} \mathrm{CH}_{3} \mathrm{Hg}^{+}$to our bulk measurement: 


$$
\Sigma^{202} \mathrm{I}={ }^{202} \mathrm{SW}+{ }^{202} \text { meth }+{ }^{292} \text { inorg }
$$

where

$$
{ }^{202} \Sigma \mathrm{I} \text { is the sum of }{ }^{202} \mathrm{Hg}
$$

$\mathrm{sw}$ is the ambient seawater in each incubation bottle to which isotope solutions are added meth is the solution of enriched $\mathrm{CH}_{3}{ }^{198} \mathrm{Hg}^{+}$from which the $\mathrm{CH}_{3}{ }^{198} \mathrm{Hg}^{+}$spike is added inorg is the solution of enriched ${ }^{202} \mathrm{Hg}^{2+}$ from which the ${ }^{202} \mathrm{Hg}^{2+}$ spike is added

This allows for full consideration of any contribution of rare isotopes in enriched solutions (such as the small \% of ${ }^{202} \mathrm{CH}_{3} \mathrm{Hg}^{+}$in the enriched ${ }^{198} \mathrm{CH}_{3} \mathrm{Hg}^{+}$solution).

The relative contribution of each isotope is expressed as relative abundance in each source (sw, meth, inorg) to the most abundant isotope:

$$
\begin{aligned}
& { }^{200}{ }_{\mathrm{SW}} /{ }^{200} \mathrm{SW}=\mathrm{R}_{11}=1 \\
& { }_{\mathrm{SW}} /{ }^{200} \mathrm{SW}=\mathrm{R}_{21} \\
& { }^{202}{ }_{\mathrm{SW}} /{ }^{200} \mathrm{SW}=\mathrm{R}_{31}
\end{aligned}
$$$$
{ }^{200} \text { meth } /{ }^{198} \text { meth }=\mathrm{R}_{21}
$$$$
{ }^{200} \text { inorg } /{ }^{202} \text { inorg }=\mathrm{R}_{13}
$$$$
{ }^{198} \text { meth } /{ }^{198} \text { meth }=\mathrm{R}_{22}=1
$$$$
{ }^{198} \text { inorg }{ }^{202} \text { inorg }=\mathrm{R}_{23}
$$$$
{ }^{202} \text { meth } /{ }^{198} \text { meth }=\mathrm{R}_{32}
$$$$
{ }^{202} \text { inorg }{ }^{202} \text { inorg }=\mathrm{R}_{33}=1
$$

As a result, equation $\mathrm{X}$ can be rewritten after substitution with the ratio notation:

$$
\Sigma^{1} \mathrm{I}={ }^{1} \mathrm{a}+\mathrm{R}_{12}{ }^{2} \mathrm{~b}+\mathrm{R}_{1 \mathrm{i}}{ }^{\mathrm{i}} \mathrm{n}
$$

Or for our example in equation $\mathrm{X}$ :

$$
\Sigma^{202} \mathrm{I}=\mathrm{R}_{31}{ }^{200} \mathrm{SW}+\mathrm{R}_{32}{ }^{198} \text { meth }+{ }^{292} \text { inorg }
$$

As a result, by knowing the well-defined $\mathrm{Hg}$ isotope ratios of ambient seawater solution (sw: assumed natural abundance of $\mathrm{Hg}$ isotopes) and of the $\mathrm{CH}_{3} \mathrm{Hg}^{+}$spike solution (meth; defined by the enriched isotopes in the starting enriched $\mathrm{HgO}$ species and altered by any changes due to preequilibration), we can calculate the ${ }^{202} \mathrm{CH}_{3} \mathrm{Hg}^{+}$produced from the $\mathrm{Hg}$ (II) spike solution (inorg) by measuring the total ${ }^{202} \mathrm{Hg}\left(\Sigma^{202} \mathrm{I}\right)$ present in the separated $\mathrm{CH}_{3} \mathrm{Hg}^{+}$peak determined by CVAFSICPMS.

Hintelmann and Evans (1997) and Hintelmann and Ogrinc (2003) use certified values of enriched $\mathrm{HgO}$ to determine the isotope ratios of spike solutions. In our experiments, both spike solutions, ${ }^{198} \mathrm{CH}_{3} \mathrm{Hg}^{+}$(meth) and ${ }^{202} \mathrm{Hg}$ (II) (inorg) were incubated in filtered seawater for 24-hours prior to addition to experimental bottle incubations in order to complex the $\mathrm{Hg}$ species to naturally occurring ligands in the seawater matrix. As a result, the isotope ratios of $\mathrm{HgO}$ certified by the manufacturer could not be used in our calculations. Instead, values for spike ratios were measured directly from the equilibrated spike solutions during sample analysis and used for calculations. IUPAC values were used for natural abundance ratios assumed for ambient seawater. 
The matrix inversion approach [Hintelmann and Ogrinc, 2007] presents the contributions of isotope tracers using the following representation of the equations outlined above [Hintelmann and Evans, 1997]:

\section{$\mathrm{AX}=\mathrm{B}$}

With

$$
A=\left[\begin{array}{llr}
1 & \mathrm{R}_{12} & \mathrm{R}_{13} \\
\mathrm{R}_{21} & 1 & \mathrm{R}_{23} \\
\mathrm{R}_{31} & \mathrm{R}_{32} & 1
\end{array}\right] \quad \mathrm{X}=\left[\begin{array}{l}
1_{\text {sw }} \\
2_{\text {meth }} \\
3_{\text {inorg }}
\end{array}\right] \quad \mathrm{B}=\left[\begin{array}{l}
\Sigma^{1} \mathrm{I} \\
\Sigma^{2} \mathrm{I} \\
\Sigma^{3} \mathrm{I}
\end{array}\right]
$$

Where the unknown contributions of the isotopes from various sources (sw, meth, inorg) that contribute to the total isotopic signal, I, of each isotope observed in the $\mathrm{CH}_{3} \mathrm{Hg}^{+}$peak (ex: $\left.\Sigma^{198} \mathrm{I}\right)$ can be solved for in the vector X using the inverse of A, as represented by the following:

$$
\mathrm{X}=\mathrm{A}^{-1} \mathrm{~B}
$$

The matrix calculation was entered into the spreadsheet to calculate resulting contributions of ${ }^{200} \mathrm{Hg},{ }^{198} \mathrm{Hg}$, and ${ }^{202} \mathrm{Hg}$ from the solutions sw, meth, and inorg into the bulk $\mathrm{CH}_{3} \mathrm{Hg}^{+}$pool.

Within the spreadsheet, the raw cps intensity values for ${ }^{200} \mathrm{Hg},{ }^{198} \mathrm{Hg},{ }^{202} \mathrm{Hg}$ from the $\mathrm{CH}_{3} \mathrm{Hg}^{+}$peaks (and ${ }^{199} \mathrm{Hg}$ when used as a isotope dilution standard) were first corrected for contributions from reagent blanks measured daily. Blank corrected signals were then input as the vector $\mathrm{B}$ in equation $\mathrm{X}$. After solving, the results of vector $\mathrm{X}$ were converted to concentrations of $\mathrm{CH}_{3} \mathrm{Hg}^{+}$from standard curves of $\mathrm{CH}_{3} \mathrm{Hg}^{+}$analyzed daily. These values represent the $\mathrm{CH}_{3}{ }^{202} \mathrm{Hg}^{+}$ formed from methylation and the $\mathrm{CH}_{3}{ }^{198} \mathrm{Hg}^{+}$remaining after demethyaltion for each time point.

Potential methylation and demethylation rate constants were calculated using a variety of models of ${ }^{202} \mathrm{Hg}$ (II) substrate availability.

Initially, $202 \mathrm{Hg}$ (II) substrate availability was assumed to be constant over the course of the incubation, as was done by Monerrus et al, 2007. As a result, values for produced $\mathrm{MM}^{202} \mathrm{Hg}$ were calculated and shown in units of (\% d-1) referring to the percent of total $202 \mathrm{Hg}$ (II) spike added that was methylated over the course of the 24-hour incubation.

However, Lehnherrr et al, 2011 dispute the assumption that $\mathrm{Hg}(\mathrm{II})$ substrate concentrations are constant, despite the fact that he used significantly higher initial concentrations of $\mathrm{Hg}$ (II) substrate relative to ambient conditions. They therefore performed some experiments to determine how $\mathrm{Hg}$ (II) substrate availability changed over the course of their incubations. They found a decrease in $\mathrm{Hg}(\mathrm{II})$ added to filtered seawater over time in a series of separate experiments from their rate measurements. The values they present and use to calculate their potential rates correspond to their isotopically enriched $\mathrm{MMHg}$ relative to available enriched $\mathrm{Hg}$ (II). In order to calculate $\mathrm{km}$ values, they fit the $\mathrm{Hg}$ (II) substrate decay to a best fit line and also account for the "instantaneous" methylation observed in their t0 bottles. However, they do not indicate whether the source of the filtered water for their $\mathrm{Hg}$ (II) substrate availability determination was any of the stations where they measured potental rates nor do they indicate when these additional experiments were performed. 
Because we have the simultaneous ability to measure $\mathrm{MMHg}$ and $\mathrm{Hg}$ (II) as methylethylHg and diethylHg, we wanted to improve on the calculations of Lehnherr et al, 2011 by calculating $\mathrm{MM}^{202} \mathrm{Hg}$ as a percentage of the ${ }^{202} \mathrm{Hg}(\mathrm{II})$ substrate. First, I attempted to do this by dividing the matrix transformed $\mathrm{MM}^{202} \mathrm{Hg}$ signal by the bulk ${ }^{202} \mathrm{Hg}$ (II) signal in the diethylHg peak for each bottle. However, the bulk ${ }^{202} \mathrm{Hg}$ (II) value includes any ambient ${ }^{202} \mathrm{Hg}$ (II) in those waters. Therefore, I took the integrations of the diethylHg peaks and used the same setup for the linear matrix calculations outlined above for $\mathrm{MMHg}$ and calculated the $\mathrm{MM}^{202} \mathrm{Hg}$ as a percent of the ${ }^{202} \mathrm{Hg}(\mathrm{II})$ spike substrate. For most stations, $18 \mathrm{~N}, 0,12 \mathrm{~S}$, and BATS site, this resulted $\sim 25 \%$ increases in values of $\mathrm{MM}^{202} \mathrm{Hg} / \mathrm{Hg}(\mathrm{II})$ substrate (\%) but did little to change the trends observed when the calculation included all ${ }^{202} \mathrm{Hg}$ (II) including ambient. However, for the $8 \mathrm{~N}$ station, where the highest concentrations of ambient $\mathrm{Hg}$ (II) were measured, the values for $\mathrm{km}$ went from being below detection to being the highest measured along the entire cruise track. This makes sense. With more $\mathrm{Hg}(\mathrm{II})$ available, the denominator of $\mathrm{MM}^{202} \mathrm{Hg} / \mathrm{Hg}(\mathrm{II})$ substrate (\%) when it included all available ${ }^{202} \mathrm{Hg}(\mathrm{II})$ was quite large, and overwhelmed any signal specific to the added isotope spikes. After using the linear matrix transformation to differentiate between the ${ }^{202} \mathrm{Hg}$ (II) contributed by the spike and that from ambient $\mathrm{Hg}$ (II) in seawater, the value of $\mathrm{MM} 202 \mathrm{Hg} / \mathrm{Hg}$ (II) substrate (\%) decreased correspondingly.

In all cases, the calculation of $\mathrm{k}_{\mathrm{d}}$, the potential demethylation rate constant, was much simpler. For this calculation, we used a similar assumption as that made by Lehnherr et al, 2011 and approximate demethylation as a first-order reaction.

\section{References}

DeWild, J., M. Olson, and S. Olund (2002) Determination of methylmercury by aqueous phase ethylation, followed by gas chromatographic separation with cold vapor atomic fluorescence detection, U. S. Geol. Surv. Open File Rep. 01-445, 19 pp.

Hintelmann, H., and R. D. Evans (1997) Application of stable isotopes in environmental tracer studies - measurement of monomethylmercury $(\mathrm{CH} 3 \mathrm{Hg}+)$ by isotope dilution ICP-MS and detection of species transformation. Fresnius J. Anal. Chem., 358, 378-385.

Hintelmann and Orgrinc (2003) Determination of stable mercury isotopes by ICP/MS and their application in environmental studies. In Biogeochemistry of Environmentally Important Trace Elements (eds Cai, Y. and C. O. Braids) Ch 21 (ACS, 2003).

Lehnherr, I., V. L. St. Louis, H. Hintelmann, and J. Kirk (2011) Methylation of inorganic mercury in polar waters. Nat. Geosci., 4, 298-302.

Monperrus, M., E. Tessier, D. Amouroux, A. Leynaert, P. Huonnic, and O. F. X. Donard (2007) Mercury methylation, demethylation and reduction rates in coastal and marine surface waters of the Mediterranean Sea. Mar. Chem. 107, 49-63. 
chromcrunch.m

¿function chromerunch

othis version meant for use with an ICP method that looks for Hg$198,-199$,

\% -200 and -202 .

\% chl july 2012

olaunch user interface to get the file names for data to process. \%downloaded from matlab exchange 12/2011

filelist=uigetfile_n_dir;

\% get ready to write file later

filename $=$ 'icpresults.txt';

fid $=$ fopen (filename, ' $\mathrm{w}$ ');

\%loop to process each of the selected files

for $w=1$ : length (filelist)

oimport the data from an icp txt file. creates a structure with the first 5

oheader lines stored in field "textdata" and the counts for each isotope in

othe field "data".

ofilename

$A=$ importdata(filelist $\{w\}, ' \backslash t$ ', 5$)$;

ostart writing the output file line-by-line

ofirst with the filename and isotope...does it 4 times for each of the 4

\%isotopes.

othen, extracts the isotopes from the "data" field and prints them to the

\%file, isotope by isotope in the transposed direction (from left to right,

\%instead of top to bottom.

for $i=1: 4$

fprintf(fid, 'os', filelist $\{w\})$;

if $i==1$

fprintf(fid, '\tod', 198);

elseif $i==2$

fprintf(fid, '\t\%d', 199);

elseif $i==3$

fprintf(fid, '\t\%d', 200);

else

end

fprintf(fid, '\tod', 202 );

$x=i+1$;

fprintf(fid, '\tod', A.data $(:, x)$ ') ; 


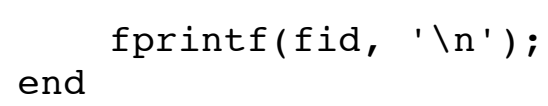

end

owhen done, closes the file. fclose (fid); 
chromint.m

\%chromint

\%chl july 2012

clear all;

\%set the start and endpoints for integration here srtpts $=\left[\begin{array}{lll}28 & 47 & 62\end{array}\right]$;

endpts $=\left[\begin{array}{lll}45 & 61 & 90\end{array}\right]$;

\%determine peak widths

wdth=endpts-srtpts +1 ;

\%import the combined results file

filename=uigetfile ('*.txt');

$A=$ importdata(filename);

\% get ready to write file later

filename $=$ 'icpintegrations.txt';

fid = fopen (filename, ' $\left.\mathrm{w}^{\prime}\right)$;

fprintf(fid, 'Sample \t Isotope \t Hg(0) Area \t MMHg Area \t Hg(II) Area $\left.\backslash t \backslash n^{\prime}\right)$;

\%smooth the data before integration

Asmooth $=[$ ] ;

windowSize $=5$;

for $j=1$ : length (A.textdata)

Asmooth $(j,:)=$ filter (ones $(1$, windowSize)/windowSize, $1, A$.data $(j, 2:$ en

d) ) ;

end

for $i=1:$ length (A.textdata)

fprintf(fid, '\%s', A.textdata $\{i\})$;

fprintf(fid, '\tod', A.data $(i, 1))$;

hgoarea $=\operatorname{sum}(A \operatorname{smooth}(i, \operatorname{srtpts}(1): \operatorname{endpts}(1)))-$

mean ([Asmooth(i, srtpts(1)) Asmooth(i,endpts(1))])*wdth(1); mmhgarea $=\operatorname{sum}(A \operatorname{smooth}(i, \operatorname{srtpts}(2)$ :endpts (2))) -

mean ([Asmooth (i, srtpts (2)) Asmooth(i,endpts (2))])*wdth(2); hg2 area $=\operatorname{sum}(A \operatorname{smooth}(i, \operatorname{srtpts}(3): \operatorname{endpts}(3)))-$

mean ([Asmooth(i, srtpts (3)) Asmooth(i,endpts (3)) ]) *wdth (3);

fprintf(fid, '\tod', hgoarea);

fprintf(fid, '\tod', mmhgarea);

fprintf(fid, '\tod', hg2area); 
fprintf(fid, '\n');

end 